\title{
Determinants of patient satisfaction after cataract surgery
}

Citation for published version (APA):

Nijkamp, M. D. (2003). Determinants of patient satisfaction after cataract surgery. [Doctoral Thesis, Maastricht University]. Universiteit Maastricht. https://doi.org/10.26481/dis.20030522mn

Document status and date:

Published: 01/01/2003

DOI:

10.26481/dis.20030522mn

Document Version:

Publisher's PDF, also known as Version of record

\section{Please check the document version of this publication:}

- A submitted manuscript is the version of the article upon submission and before peer-review. There can be important differences between the submitted version and the official published version of record.

People interested in the research are advised to contact the author for the final version of the publication, or visit the DOI to the publisher's website.

- The final author version and the galley proof are versions of the publication after peer review.

- The final published version features the final layout of the paper including the volume, issue and page numbers.

Link to publication

\footnotetext{
General rights rights.

- You may freely distribute the URL identifying the publication in the public portal. please follow below link for the End User Agreement:

www.umlib.nl/taverne-license

Take down policy

If you believe that this document breaches copyright please contact us at:

repository@maastrichtuniversity.nl

providing details and we will investigate your claim.
}

Copyright and moral rights for the publications made accessible in the public portal are retained by the authors and/or other copyright owners and it is a condition of accessing publications that users recognise and abide by the legal requirements associated with these

- Users may download and print one copy of any publication from the public portal for the purpose of private study or research.

- You may not further distribute the material or use it for any profit-making activity or commercial gain

If the publication is distributed under the terms of Article $25 \mathrm{fa}$ of the Dutch Copyright Act, indicated by the "Taverne" license above, 
Determinants of patient satisfaction after cataract surgery

Marjan Daniëlle Nijkamp 



\section{Determinants of patient satisfaction after cataract surgery}

\section{PROEFSCHRIFT}

ter verkrijging van de graad van doctor aan

de Universiteit Maastricht, op gezag van de Rector Magnificus

Prof dr. A.C. Nieuwenhuijzen Kruseman, volgens het besluit van het College van Decanen, in het openbaar te verdedigen

op donderdag 22 mei 2003 om 14:00 uur

door

Marjan Daniëlle Nijkamp

geboren te Heerenveen op 27 mei 1975 
Promotores:

Prof.dr. F. Hendrikse

Prof.dr. H.W. van den Borne

Co-promotor:

Dr. R.M.M.A. Nuijts

Beoordelingscommissie:

Prof.dr. N.K. de Vries (voorzitter)

Prof.dr. J.Th.M. van Eijk

Prof.dr. E. Griez

Prof.dr. P.D. Mullen (University of Texas, USA)

Prof.dr. G. van Rij (Erasmus Medisch Centrum, Rotterdam)

Marjan Daniëlle Nijkamp

Determinants of patient satisfaction after cataract surgery

C Copyright 2003 ERIM Publications

All rigths reserved. No part of this book may be translated or reproduced in any form by print, photo print, microfilm, or any other means without prior written permission of the publisher.

ISBN: 90-5681-163-0

Printed by: Unigraphic Maastricht

Cover design and lay-out by: Gaston Jamin

Illustration cataract surgery by: Ron Slagter

The study presented in this thesis was financially supported by the Eye Research Institute Maastricht (ERIM), and performed at the ERIM and the Care and Public Health Research Institute (CAPHRI), which participates in the Netherlands School of Primary Care Research (CaRe), acknowledged in 1995 by the Royal Dutch Academy of Sciences (KNAW). 


\section{Contents}

Introduction Aim and outline of the thesis 7

$\begin{array}{lll}\text { Chapter } 1 & \text { Theoretical background } & 11\end{array}$

Definition and measurement of patient satisfaction

Chapter $2 \quad$ Determinants of patient satisfaction 39

after cataract surgery in 3 settings

Chapter 3a Quality of care from the perspective of the cataract patient:

the QUOTE-Cataract questionnaire

Chapter 3b Quality of care from the perspective of the cataract patient:

the reliability and validity of the QUOTE-cataract

Chapter $4 \mathrm{a} \quad$ Factors related to fear in patients undergoing cataract surgery

A qualitative study focusing on factors associated with fear and reassurance among patients who need to undergo cataract surgery

Chapter 4b Determinants of surgery related anxiety in cataract patients

Chapter 5 Effectiveness of multifocal intraocular lenses to correct

presbyopia after cataract surgery: a randomised controlled trial

Epilogue Determinants of patient satisfaction after cataract surgery:

Most important findings, practical implications,

and recommendations for future research

Summary/Samenvatting

Dankwoord en Curriculum Vitae 



\section{Introduction}

Aim and outline of the thesis 


\section{Aim and outline of the thesis}

Clinical impressions of patient satisfaction may differ from actual patient satisfaction, e.g. a dissatisfied patient may not harmonise with a successful medical outcome. On the one hand this apparent paradox may be explained by an incongruence in the multidimensional evaluation of patient satisfaction. For example, the patient is very satisfied about the medical outcome but extremely dissatisfied about the doctor's counselling. On the other hand this contradiction may reflect the difference between the patient's and the doctor's perspective, who are supposed to have their own standards and perceptions of quality of care. ${ }^{1,2}$

In Chapter $\mathbf{1}$ a historical overview of developments in satisfaction theories and models is represented. A selection of satisfaction models is described and criticized. This chapter results in the theoretical model underlying the studies described in this thesis. Furthermore, satisfaction studies among cataract patients are reviewed in the last paragraph of this chapter with special attention for an innovative multifocal intraocular lens.

Chapter 2 describes the determinants of patient satisfaction after cataract surgery in three clinical settings. This study analysed the determinants of satisfaction and postoperative functioning in patients who had cataract surgery using monofocal intraocular lenses. The study was conducted to get an impression of the patient satisfaction levels in three fundamentally different settings: an academic hospital, a general hospital and a 'private' hospital.

Based on the findings of chapter 2 a new questionnaire (QUOTE-cataract) was developed that measures the quality of process and structure related quality of care from the patient's perspective. Chapter 3a reports the clinical usefulness and outcomes of this questionnaire in a multi-centre study together with the potential of the QUOTE-cataract questionnaire in quality assurance and improvement programs (i.e. feasibility of the QUOTE-cataract). Besides being useful and applicable to clinical practice, scientific requirements should be met by this measurement instrument. Therefore Chapter $\mathbf{3 b}$ deals with the reliability and validity of the QUOTE-cataract questionnaire.

Following on the previous chapter, it is important to know how patients perceive the pre-, per-, and postoperative stages in cataract surgery to be able to improve the quality of care. Chapter $4 \mathbf{a}$ describes a qualitative study on factors related to fear in patients undergoing cataract surgery. The relative importance of these factors were studied by quantitative analyses and are reported in Chapter $\mathbf{4 b}$.

Surgical methods for cataract extraction have changed significantly since the introduction of microsurgical techniques and intraocular lens implantation. It is of utmost importance that technical innovations that are claimed to be superior to existing products undergo a randomised study to define the advantages and disadvantages of the new product. 
Chapter 5 describes a randomised controlled trial, and shows the success of an innovative multifocal intraocular lens with respect to clinical results and patient satisfaction. 


\section{References}

1. Campen van C, Sixma HJM, Friele RD et al. Quality of care and patient satisfaction: A review of measuring instruments. Medical Care Research and Review, 1995; 52: 109-133

2. Adams $\mathbf{P}$ and Mylander M. Gesundheit!: Bringing good health to you, the medical system, and society through physician service, complementary therapies, humor, and joy. Rochester (Canada): Healing Arts Press, 1998 
Chapter 1

\section{Theoretical background}

Definition and measurement of patient satisfaction 


\subsection{Definition of patient satisfaction}

According to the English dictionary "to satisfy" means "to supply fully with what is desired, expected or needed". ${ }^{1}$ Scientists had difficulties with the translation of this rather wide definition into objectively observable units of measurement, which is indicated by the numerous amount of and variability in the conceptualisation of satisfaction. Over 3,000 articles were published about satisfaction within the health care setting only, and dozens of measurement instruments regarding patient satisfaction were developed during the past decade. $^{2}$ One of the difficulties is that satisfaction may be considered as both a multidimensional construct and an overall summary construct. ${ }^{3,4}$ On the one hand the multidimensional approach distinguishes the functional quality of care (i.e., the way in which the care is provided) and the technical quality of care (i.e., the technical accuracy of the diagnosis and treatment). ${ }^{4-7}$ On the other hand the summary construct can be considered as both a generic attitude $e^{8}$ and an overall fulfilment of expectations. ${ }^{9}$

Strasser argued that any model of patient satisfaction should account for both a multidimensional construct and a summary construct since it is well documented that patients form both types of judgement. ${ }^{3}$ Furthermore, a distinction was made between objective satisfaction reports and subjective satisfaction ratings. ${ }^{10}$ The latter attempt to capture a personal evaluation of care that cannot be known by observing care directly. These ratings include personal preferences of the patient, of personal expectations, and of the actual care. In this way a satisfaction rating is both a measure of care and a reflection of the respondent. Many researchers have tried to develop theories and models of satisfaction, a selection of these models is described in paragraph 1.2.

Because different satisfaction studies are conducted in very specific contexts, it is understandable that any standard classification never seems entirely appropriate. ${ }^{7}$ The original motivation of studying satisfaction within the health care setting was to introduce the concept of consumerism in health care settings, and to introduce an indicator of the quality of care. This relationship between quality of health care and patient satisfaction is the focus of paragraph 1.3.

Because of the lack of consistency in defining the concept of satisfaction, reliability and validity of the measurement instruments is ambivalent, which is described in paragraph 1.4.

Paragraph 1.5 gives an overview of satisfaction studies among cataract patients. Subparagraph 1.5.3 describes satisfaction after implantation of multifocal intraocular lenses specifically. 


\subsection{Models of Patient Satisfaction}

In reaction to the lack of statistical support for the definition of satisfaction as an attitude ${ }^{8}$ the importance of direct experiences was emphasized. ${ }^{4}$ As a consequence the definition of patient satisfaction was changed into "a health care recipient's reaction to salient aspects of the context, process, and results of their service experience". ${ }^{4}$ This evaluation concerns a comparison of salient aspects of the quality of care to a subjective standard that consists of an ideal, a sense of what one deserves, past experience or a minimally accepted level. Parasuraman, Zeithalm, and Berry were the first who combined these evaluations of the actual care experience and expectations in their satisfaction measurement. ${ }^{11}$ They developed the SERVQUAL-model (Figure 1.1), which measures satisfaction as a comparison of expectations and perceptions on various dimensions.

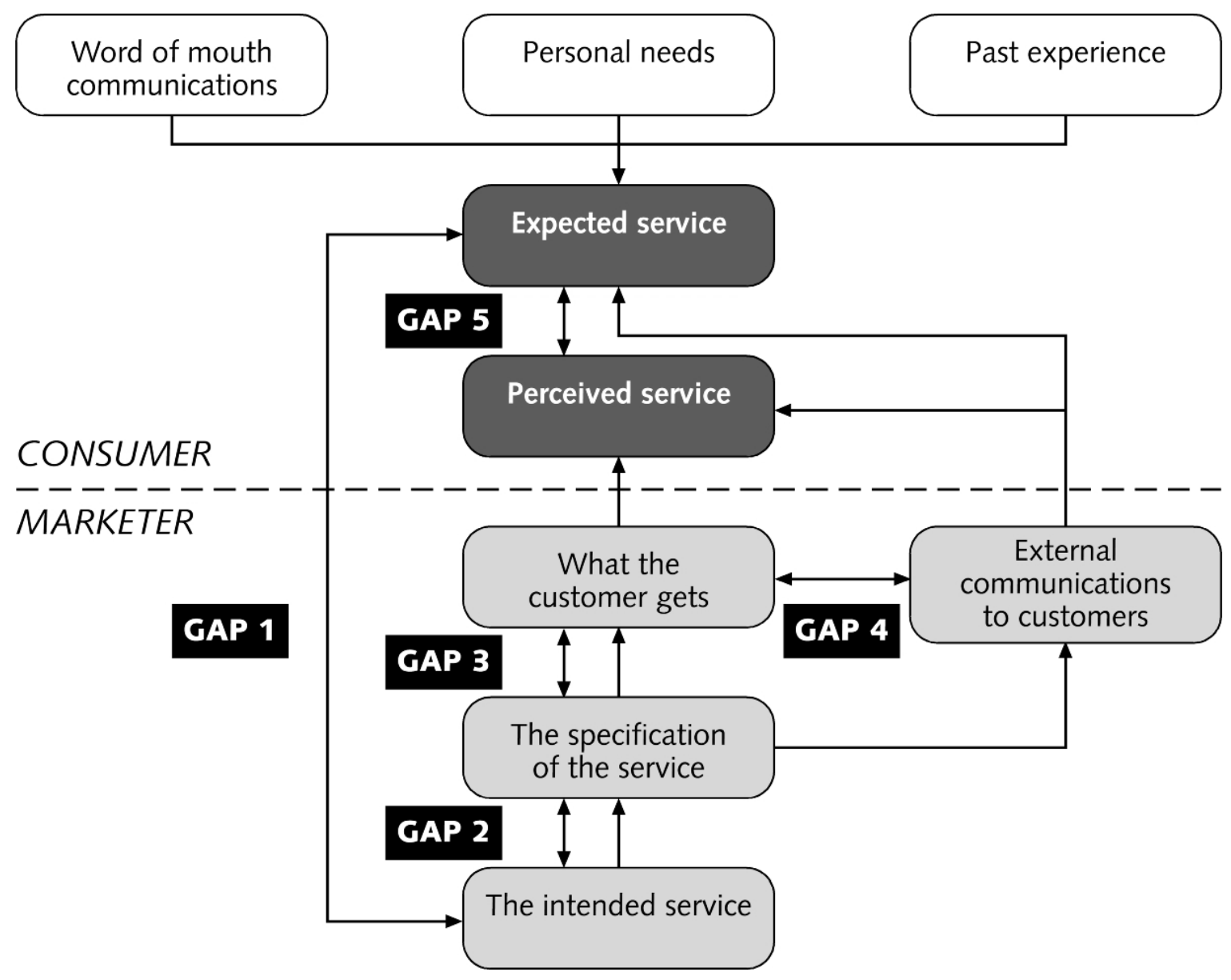

Figure 1.1: Servqual-model

Service quality (SQ) is defined as the discrepancy between customer's expectations (E) and their perceptions $(\mathrm{P}): \mathrm{SQ}=\mathrm{P}-\mathrm{E} \cdot{ }^{12,13}$ The resulting $\mathrm{SQ}$ scores are referred to as the service-quality gap scores. 
The SERVQUAL tool was easily adapted to the health care services by changing the concept consumer into patient, and companies were substituted by hospitals. ${ }^{14}$ Five different gaps can be distinguished within the model, e.g. 'Manager's/hospital's policy does not fit the expectations of customers/patients' (Gap 1) and 'Discrepancy between customer's expectations and perceptions of the delivered service' (Gap 5).

These gaps that describe cognitive incongruities were replaced by 'expectancy disconfirmations' by Cadotte et al. ${ }^{9}$ By developing the 'Model of disconfirmation-ofexpectations process' (Figure 1.2), an affective component was added to the relationship between expectations and actual performance.

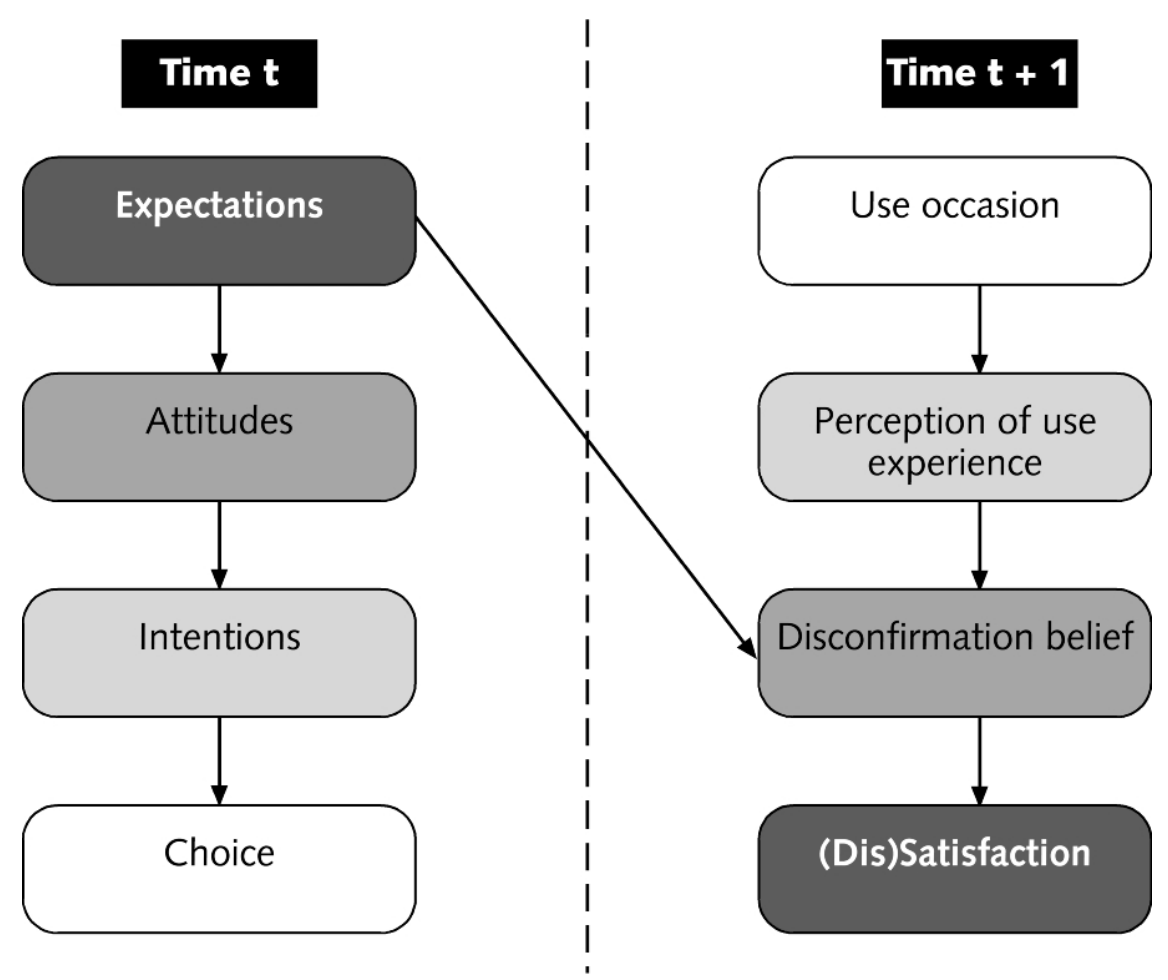

Figure 1.2: Model of disconfirmation-of-expectations process

This affective component is represented by the concept of 'disconfirmation belief', which triggers a positive, neutral or negative emotion. Furthermore, the concept satisfaction is explicitly described within the model. As represented in Figure 1.2, a choice of product or service is made at time $\mathrm{t}$ based upon expectations, attitudes and intentions (the standard). At a subsequent time $(t+1)$ a consumer or patient uses a product or service, which triggers a perception of the performance. Confirmation occurs when performance matches the standard, leading to a neutral feeling. If perceived performance exceeds the standard, positive disconfirmation results, which leads to satisfaction. If performance is evaluated as worse than the standard, negative disconfirmation results in dissatisfaction. The personal standards with which the actual performances are compared to are operationalised as expectations in most studies. 
When expectations are low, they will be easily met, and a high level of satisfaction will be realised. However, if the expectations are high, it is harder to meet the expectations, and the likelihood of satisfied patients is lowered.

To increase the practical value of satisfaction models in the measurement of hospital performance, a distinction should be made in relatively more and less important aspects of health care. Therefore, another model was developed by Zastowny et al. that links patient expectations, perceived performance and relative importance of care aspects. ${ }^{5}$ This conceptual model of event-driven patient satisfaction was developed within the framework of the Patient Experience Survey (PES), and is therefore normally referred to as the PESmodel (Figure 1.3). According to this model, satisfaction can be improved by maintaining or increasing the frequency of positive events and decreasing the frequency of negative events. Performance represents the frequency of events. The importance is defined as the degree to which performance is empirically related to satisfaction using independent regression analyses for each aspect of care. The impact (on satisfaction) is determined by the combination of performance and importance by converting the regression coefficient and problem incidence to a score ranging from 0 to 100. The larger the regression coefficient (higher importance score) and the greater the problem incidence (high 'negative' performance score), the larger the impact score for a given quality of care aspect.

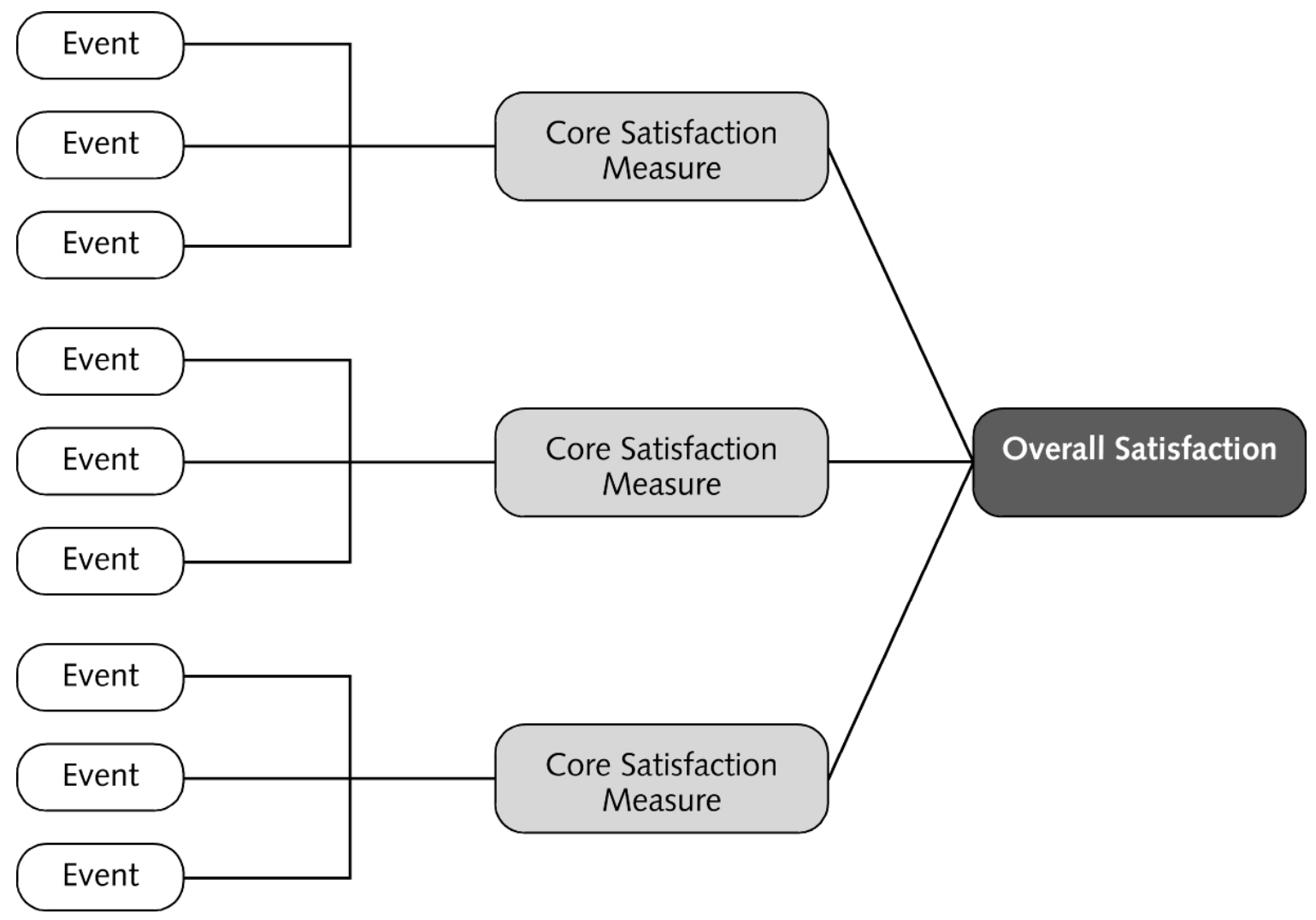

Figure 1.3: Conceptual model of event-driven patient satisfaction (PES-model) 
Although patient satisfaction may be based on a general theoretical framework including expectations, evaluations, and relative importance, individual patient characteristics (e.g. personality characteristics, personal preferences or previous experiences) may also influence patient satisfaction. ${ }^{3-5,7}$ Furthermore, the described models fail to identify the interdependency of quality of care aspects.

\subsection{Quality of care from the patient's perspective}

Nowadays patient satisfaction is considered as a key measure of quality of care. ${ }^{5,15}$ However, it was suggested that patient satisfaction is merely an indicator of the quality of care as perceived by patients. ${ }^{2,7}$ Satisfaction can be conceptualised as a global indicator of patient's total response to care or as an important personal response to the last episode of care. The International Organisation of Standardisation (ISO) defined quality as "the totality of features and characteristics of a product or service that bear on its ability to satisfy stated or implied needs". ${ }^{16}$

Donabedian has developed a model to identify three dimensions within quality of health care: structure, process, and outcome. ${ }^{17}$ Structure related quality aspects concern characteristics of the health care system, e.g. the hospital's policy on the consulting time. The process aspects address the encounter between the doctor or other health care professionals and the patient. Donabedian interrelated outcome with both structure and process by defining outcome as a change in a patient's current and future health status that can be attributed to the antecedent care. Although all three dimensions contribute to the perceived quality of care, it was indicated that consumers of care (patients) are more concerned with the process quality of health care than with the outcome of care or technical competencies of health care personnel. ${ }^{18}$ One explanation for this may be that patients are incapable of evaluating technical quality of care due to a lack of medical knowledge, and are more critically aware of the manner of providing care. Another explanation may be that patients are reserved in expressing critical comments with respect to the abilities of doctors. ${ }^{19,20}$

Existing instruments to measure the quality of care are mainly developed from the perspective of health professionals, researchers or policy makers. Nevertheless, each perspective is supposed to have it's own standards and perceptions of the quality of care. Quality of care from the patient's perspective is defined as "a set of individual, expectationrelated judgements of aspects of health services regarded as important by the patient". Quality judgement (QJ) was operationalised in the same way as Service Quality according to the following equation: $\mathrm{QJ}=$ Perception (P) - Expectation (E). Patient satisfaction can be considered as a QJ concerning the general valuation of health services by a patient on all three dimensions of care. Patient satisfaction represents the perceived quality of structure, process and outcome related care, which is influenced by individual patient characteristics (Figure 1.4). 


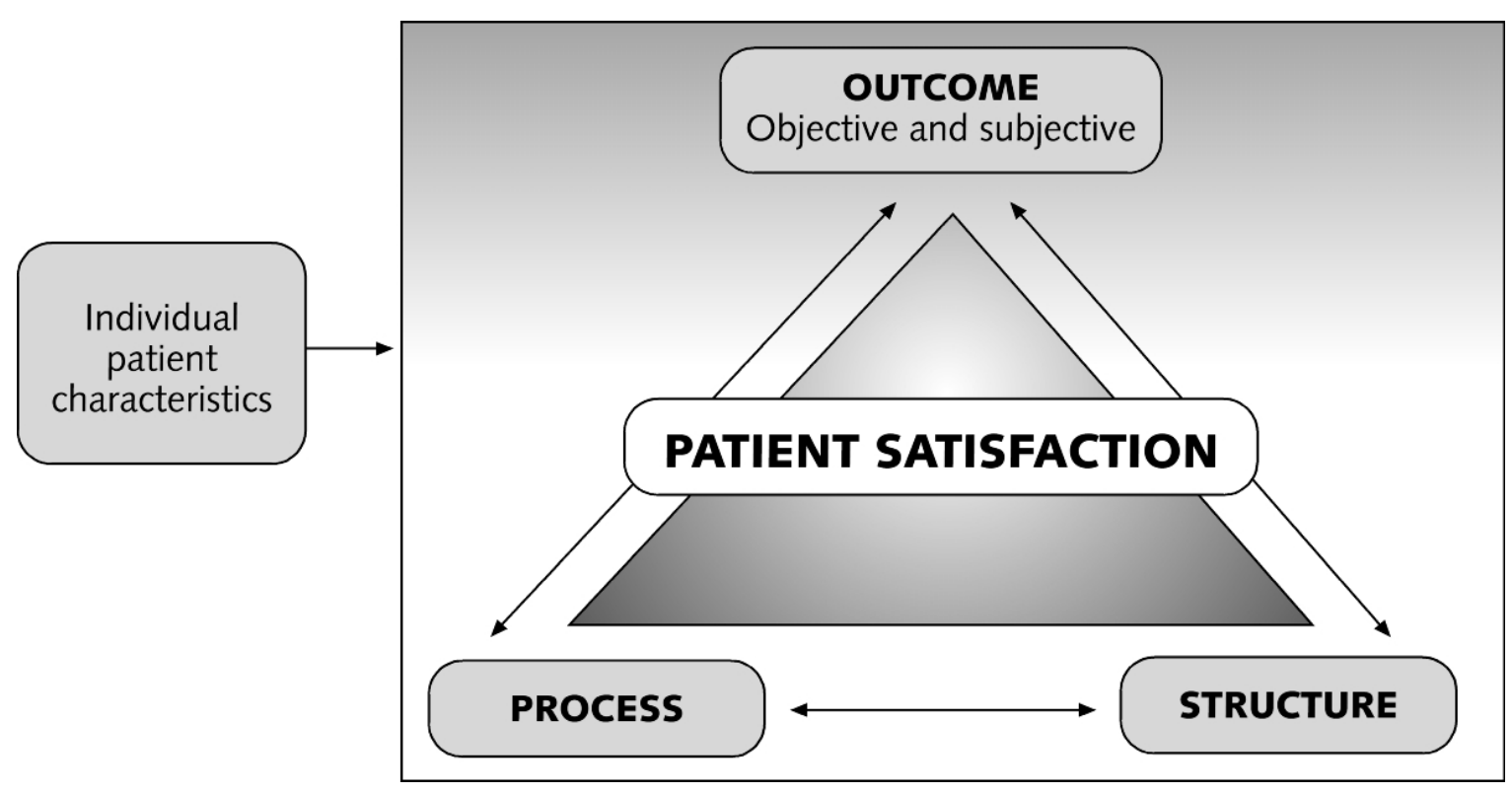

Figure 1.4: A three-dimensional model of patient satisfaction

It was argued that patients, as expert witnesses of health care, should be involved in the selection of aspects for the quality of health care measurement. ${ }^{7}$ Therefore, a new series of disease-specific questionnaires was developed to prevent the methodological problems, which were faced with previous satisfaction and quality of care instruments: The QUOTEquestionnaires. The acronym QUOTE stands for QUality Of care Through the patient's Eyes. QUOTE-questionnaires were developed to produce specific data on health care services, which are related to individual's needs and expectations and contain aspects formulated in collaboration with patients. ${ }^{21}$

\subsection{Satisfaction Measurement}

As a result of the differences in defining satisfaction, studies differ with regard to the directness, specificity, type of care, and dimensionality of their satisfaction measurements. A measurement is direct if patients are asked directly about their satisfaction level, e.g. "How satisfied were you with the information you got from your doctor?". This type of question is usually accompanied by response options varying from 'not satisfied at all' to 'very satisfied'. Indirect questions describe or evaluate the care, e.g. "My doctor informed me well", which may be answered by a scale varying from 'totally disagree' to 'totally agree'. An agreeing response in the latter example is considered to indicate (high) satisfaction. Specificity of satisfaction measurement refers to a continuum from a specific event to an evaluation of the quality of care in general. ${ }^{22}$ It has been suggested that more general measures may yield more global impressions of the care, and hence may not accurately reflect those aspects that are most closely and specifically related to actual quality of care and outcome. ${ }^{5}$ Type of care considers the kind of care or service being evaluated (e.g. in- or outpatient). 
Dimensionality is represented by the number and content of the different quality of care aspects. Outcomes of satisfaction studies are subordinate to the measurement method (indirect vs. direct, general vs. specific) used. ${ }^{23}$ Specifically, the outcomes of different types of measures of satisfaction may be incomparable. ${ }^{10,19,22}$

A simple causal relationship does not exist between quality of care and patient satisfaction. A number of psychosocial factors influence that relationship. These moderators have implications for the interpretation of satisfaction ratings and for the methodological strategies. One problem might be that overall satisfaction scores cannot reveal aspects that are responsible for the relative dissatisfaction. ${ }^{4,24-26}$ Furthermore, the transition from dissatisfied to satisfied might be indistinct. Although satisfaction is considered to be a continuous measure in general, satisfaction research often categorises/dichotomises the construct. This introduces an artificial distinction of satisfied and dissatisfied, which leads to a non-responsive measure with low reliability. 4,26

With respect to response bias, a lot of respondents tend to give a confirmative answer, irrespective of the content of the question. ${ }^{27}$ These asquiescent respondents induce a lowered reliability of the questionnaire. ${ }^{23}$ Ware showed that 40 to $60 \%$ of the respondents agreed with the statement on whatever question. ${ }^{28}$ Furthermore, some respondents tend to choose the most neutral response category, which leads to less variability. ${ }^{4,27}$ Respondents may also react to perceived norms and expectations, i.e., social desirability and fear for repercussions. Patients worry that if they express dissatisfaction, they will receive a bad quality of care, incomplete treatment or despise from care givers. This phenomenon was referred to as 'ingratiating response bias' by Sitzia and Wood. ${ }^{7}$ In a study by Visser et al. one third of the patients agreed with the comment "Because you never know the consequences of your statements, it is better not to express your complaints about treatment and care". ${ }^{6}$ Additionally, satisfaction studies may be biased by the Hawthorne effect. By taking part in a research project patients automatically get more attention from the researcher. The appreciation of this extra attention may be expressed by a more positive evaluation of the treatment. ${ }^{29}$

\subsection{Satisfaction studies among cataract patients}

\subsubsection{Cataract and cataract surgery}

Senile cataract is an eye disease characterized by opacification and discolouring of the crystalline lens. Patients with cataract usually complain about decreased visual acuity, double or distorted vision, bother from glare and halo's, and changed colour perception. ${ }^{30}$ Possible risk factors for cataract that are studied by epidemiologists concern demographic (e.g. age and ethnicity), heredity (twin studies), systemic (e.g. diabetes and medication), and environmental (e.g. UV-radiation and cigarette smoking) factors. ${ }^{31}$ Furthermore, researchers have been investigating the protective effect of diets (vitamin supplements) on the development of cataracts. ${ }^{32}$ 
Although researchers are learning more and more about cataracts, for the time being the cause of this eye disease remains unclear and is therefore generally attributed to a normal ageing process. Nearly everyone who lives long enough will develop cataract to some extent. On the long run cataract will lead to irreversible blindness. As yet there is no way to prevent the development of a cataract. The only possible treatment is cataract surgery, in which the opacificated lens is extracted from the eye and replaced by an artificial intraocular lens (IOL). The earliest written reference to cataract surgery is found in ancient Hindu medicine dating from the $5^{\text {th }}$ century $\mathrm{BC}$. This first type of cataract surgery is known as couching or reclination, in which the cataractous lens was displaced away from the pupil into the vitreous body. ${ }^{33}$ Although the dislocated lens enabled the patient to see better, vision of the aphakic eye remained out of focus because of the lack of a corrective lens. In the course of time the use of spectacles with high refractive power (e.g. +20D) restored the blurred vision after lens extraction. It wasn't until Harold Ridley introduced the intraocular lens in the 1950s that good uncorrected visual acuity was a realistic outcome of cataract surgery. At present the most common procedure of cataract surgery is phacoemulsification with implantation of an artificial lens. The cloudy lens is removed by using ultrasound energy to break the lens up into small pieces, which are then aspirated out of the eye (Figure 1.5a-1.5e). 


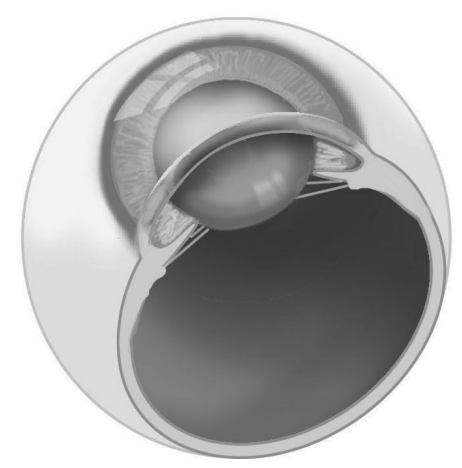

Figure 1.5a: Preoperative eye with crystalline lens

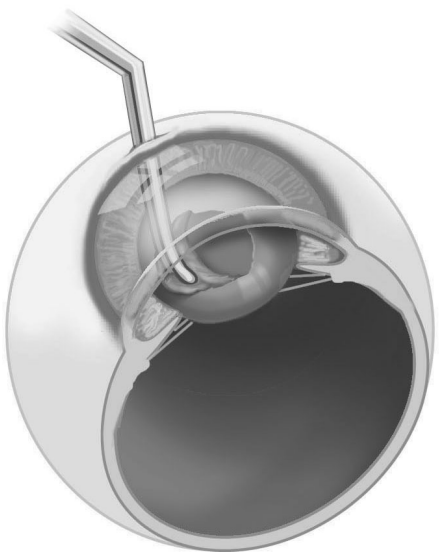

Figure 1.5b: Capsulorrhexis

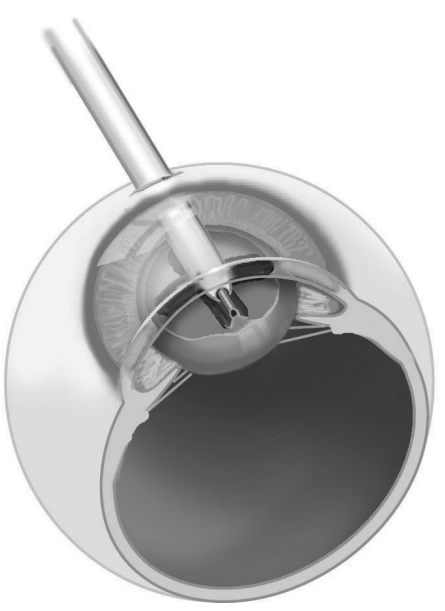

Figure 1.5c: Extraction of the crystalline lens ('divide and conquer' technique)

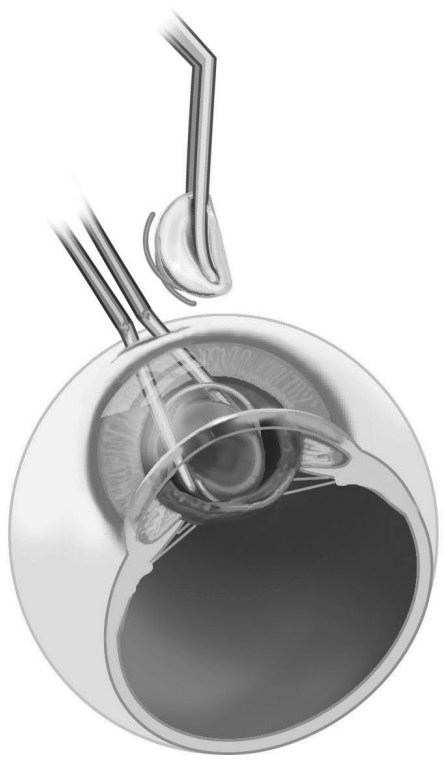

Figure 1.5d: Implantation of an artificial IOL

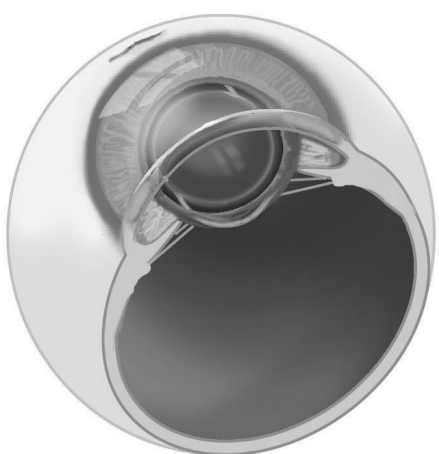

Figure 1.5e: Postoperative eye with an artificial IOL 
There is no definite ophthalmological test to determine severity thresholds for the indication of surgery. The Agency for Health Care Policy and Research (AHCPR) have set up a guideline, which states that cataract extraction is indicated if the cataract causes functional impairment regardless of the visual acuity. ${ }^{34}$ Accordingly, low visual acuity alone is not considered to be an indication for surgery. Naturally, cataract surgery is only indicated in cooperation with the patient. The New Zealand criteria for prioritising cataract surgery combine objective ophthalmic parameters of visual disability (low visual acuity, glare disability and ocular comorbidity) with these subjective indications (ability to work, impairment in visual function, and other substantial disability). ${ }^{35}$ The main reason for this combined indication for surgery instead of an objective visual acuity measure alone are the safe surgical techniques with a low complication rate of less than five per cent, ${ }^{36}$ and altered life-style demands for good vision. ${ }^{37}$

\subsubsection{Patient satisfaction after cataract surgery}

From a societal perspective, cataract is especially considered to be a medical and economic problem. Because of the high prevalence, age-related cataract constitutes the main surgical workload of ophthalmic services and the greater part of ophthalmic surgical waiting lists in the Netherlands.[http://www.nvz-ziekenhuizen.nl] With the global ageing of populations and the post second world war 'baby-boom', which turned out to a cohort of people who are now at risk for developing cataract, the demand for cataract surgery is expanding rapidly. These medical and economic problems caused by cataract are reflected by the numerous clinical and cost-effectiveness studies, which mainly describe the benefits of cataract surgery. However, it is important to also examine the psychosocial aspects of cataract to reinspect surgical indications and to educate and counsel patients properly. Especially, when modern indications for cataract surgery are based on daily interference of visual function of the patient. ${ }^{38}$

Although cataract surgery is routine surgery, one should never forget the uniqueness of the surgical experience for the patient. The eye is an important organ, both from a physiological and a psychological point of view. Accordingly, eye surgery may induce fear, which subsequently might have a negative influence on the evaluation of patients regarding the quality of care. Psychological studies showed that fear can be reduced by appropriate information and counselling, tailored to the needs of the individual patient. ${ }^{39,40}$ Furthermore, confidence in the surgeon and reassurance from acquaintances who already had cataract surgery may relieve anxiety. ${ }^{41}$

With respect to an outcome-related quality of care, point of view is that cataract surgery has proximal and distal goals: to improve vision, which results in better vision related functioning that will subsequently enhance the generic quality of life (Figure 1.6). ${ }^{42}$ 


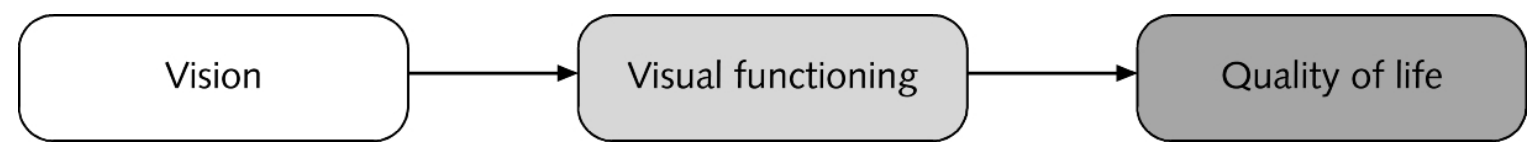

Figure 1.6: Proximal and distal goals of cataract surgery

Visual functioning and quality of life have been recognised as important measures of treatment effectiveness in addition to the more traditional outcome parameter visual acuity. ${ }^{30,43,44}$ The difference between the more traditional definition of success of cataract surgery from the doctor's perspective and the patient's defined success is demonstrated by the following quotations. Citing an ophthalmologist: "My patient has 20/20 Snellen vision and reads Jaeger 1". A patient may translate this medical outcome into "Subtitles on the television are not blurred anymore, and I have taken up my needlework". Although satisfaction levels are clearly related to clinical outcome, they do not refer directly to medical outcome. ${ }^{5}$ Former studies indicated that satisfaction is particularly correlated to the process-related quality of care. ${ }^{5,21,45}$ In addition, the differential perspectives may also play an important role in perceived structure and process related care, which is reflected by the following anecdotal reports.

"I got to the hospital on time, but couldn't find the department of ophthalmology at first. ... g gave my name to the receptionist, and she couldn't find my appointment...

I waited in the waiting room for one and a half hours,

saw the doctor for five minutes, and I still have no answer to all my questions...

I had to pay 5 euros for parking my car...

You want me to tell about satisfaction?"

(Anonymous patient who participated in the study)

"I got 7 and a half minutes per patient, ...

I see 50 patients a day...

Waiting lists induce impatient patients...

I do not get rewarded in line with the hard work...

You want me to tell about quality of care?"

(Anonymous ophthalmologist)

Quality of care from the patient's perspective is based on a framework of patient's expectations and actual experiences. ${ }^{7}$ Good quality of care fits the cognitive and affective needs of patients. The ophthalmologist Pankow referred to the relevance of understanding the patient's perspective after he had to undergo cataract surgery himself: "My cataract surgery has reminded me that there is an art to practicing optometry and educating patients as well as a set of technical skills...May we all think about 'seeing' our diagnosis and treatments trough the patient's eyes". ${ }^{6}$ 
Despite this emphasized importance of both technical and functional quality of care, satisfaction studies among cataract patients are still specially limited to the (objective and subjective) outcome related quality of care.

Recently Margolis et al. ${ }^{47}$ and Massof and Rubin ${ }^{48}$ reviewed all published questionnaires that measure vision related functioning on their validity and reliability. Massof and Rubin distinguished patient-based assessments that record patients' subjective judgements about their own functional state and performance-based assessments, which are considered to be objective measurements of the patient's functional status. Subjective refers to a latent measurement (i.e., a private experienced state that is inferred from judgements), whereas objective is defined as a manifest variable (i.e., a publicly observable and quantifiable attribute or behaviour) ${ }^{48}$ Margolis et al analysed specifically whether a visionspecific instrument to measure health related quality of life was developed from a patient's or a clinician's perspective. ${ }^{47}$ Table 1.1 represents all visual functioning questionnaires that were developed for cataract patients specifically or were tested on it's feasibility, validity and reliability for this specific patient group. Studies that describe only several questions related to vision related functioning and review articles were not included in this overview. In total 20 different questionnaires were developed to measure visual functioning among cataract patients from 1981 to 1999 . The various subscales or domains of these questionnaires, which are listed in the fourth column of this Table, illustrate that 'visual functioning' can be operationalised as visual impairments (e.g. visual acuity and glare disability), an inability to perform certain activities (e.g. reading and driving), participating in activities (e.g. work and hobbies), degree of independence (e.g. mobility), and one's social, psychological and general well-being. The scope of each visual function assessment tool can be categorized as follows: cataract symptom severity (VAQ, MIOLS VF, CSS), visual impairment in daily functioning (VFI, cataract TyPE specification, Lowe's visual function questionnaire, VPQ, ADVS, VF-14, Catquest, NEI-VFQ, VDA, ASCRS-ACDCF), visual impact on general wellbeing (SIPV, IVI), and vision-related quality of life (VF-QOL, VCM1, MIOLS HR-QOL, QoL-VFQ). 


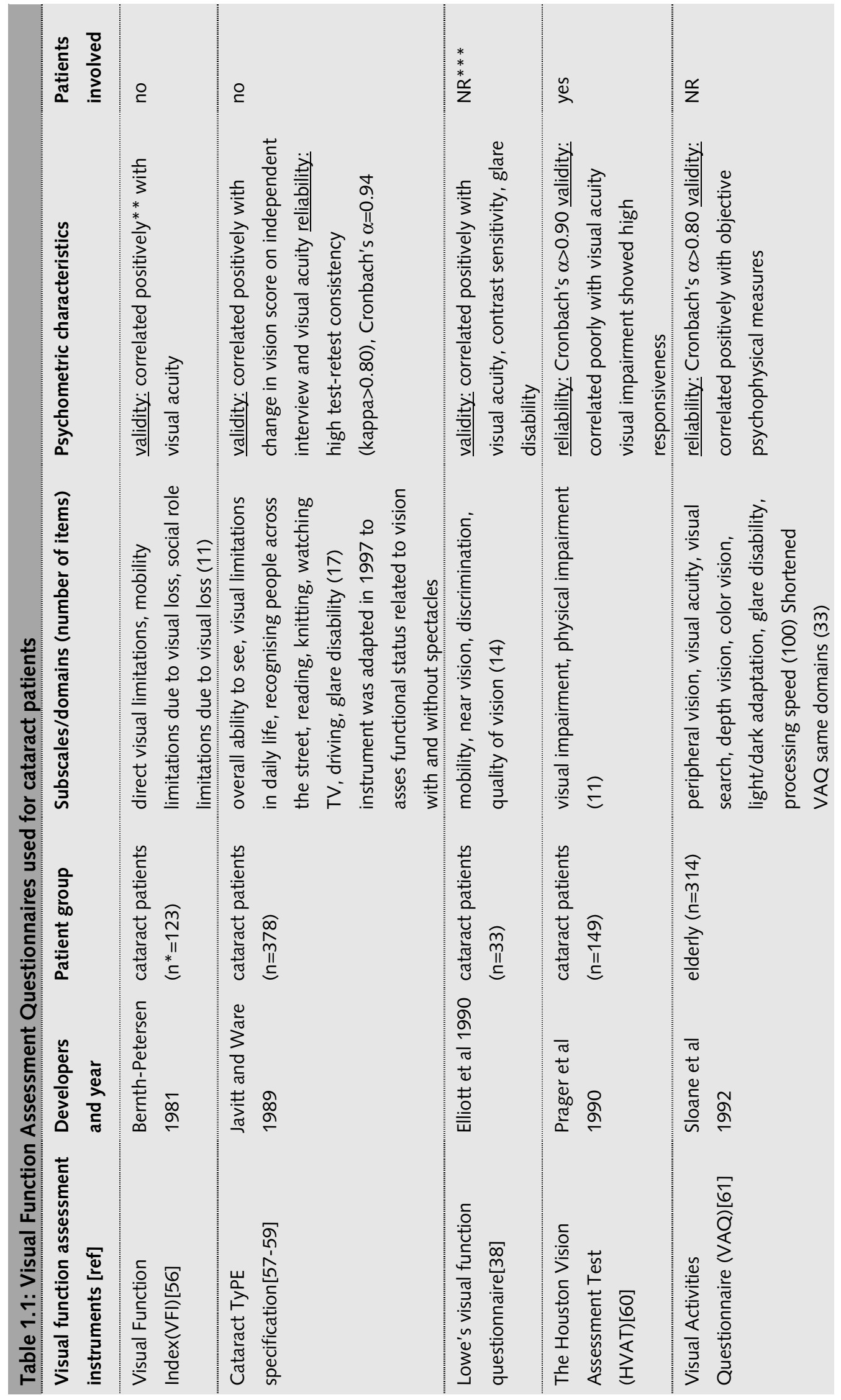




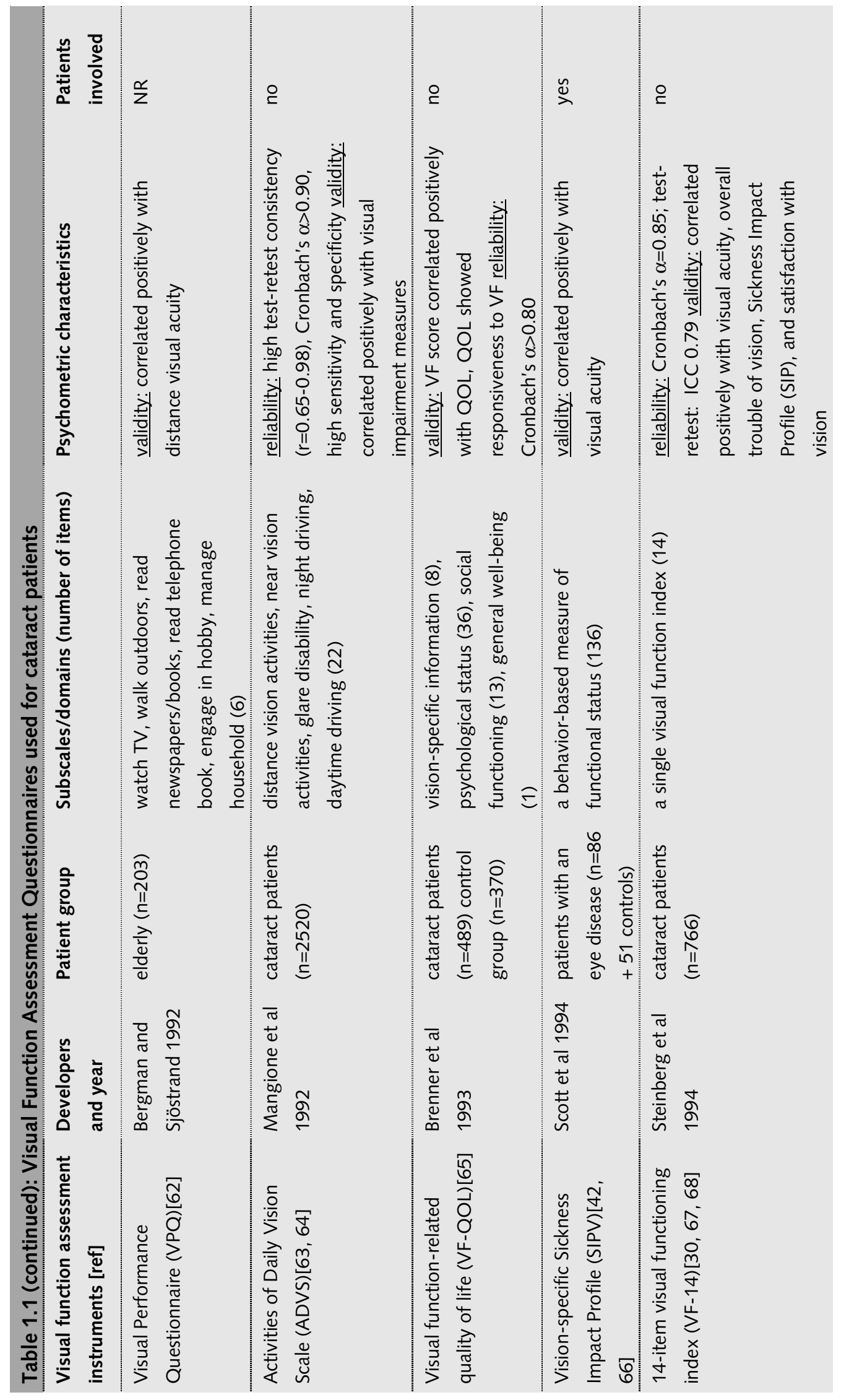




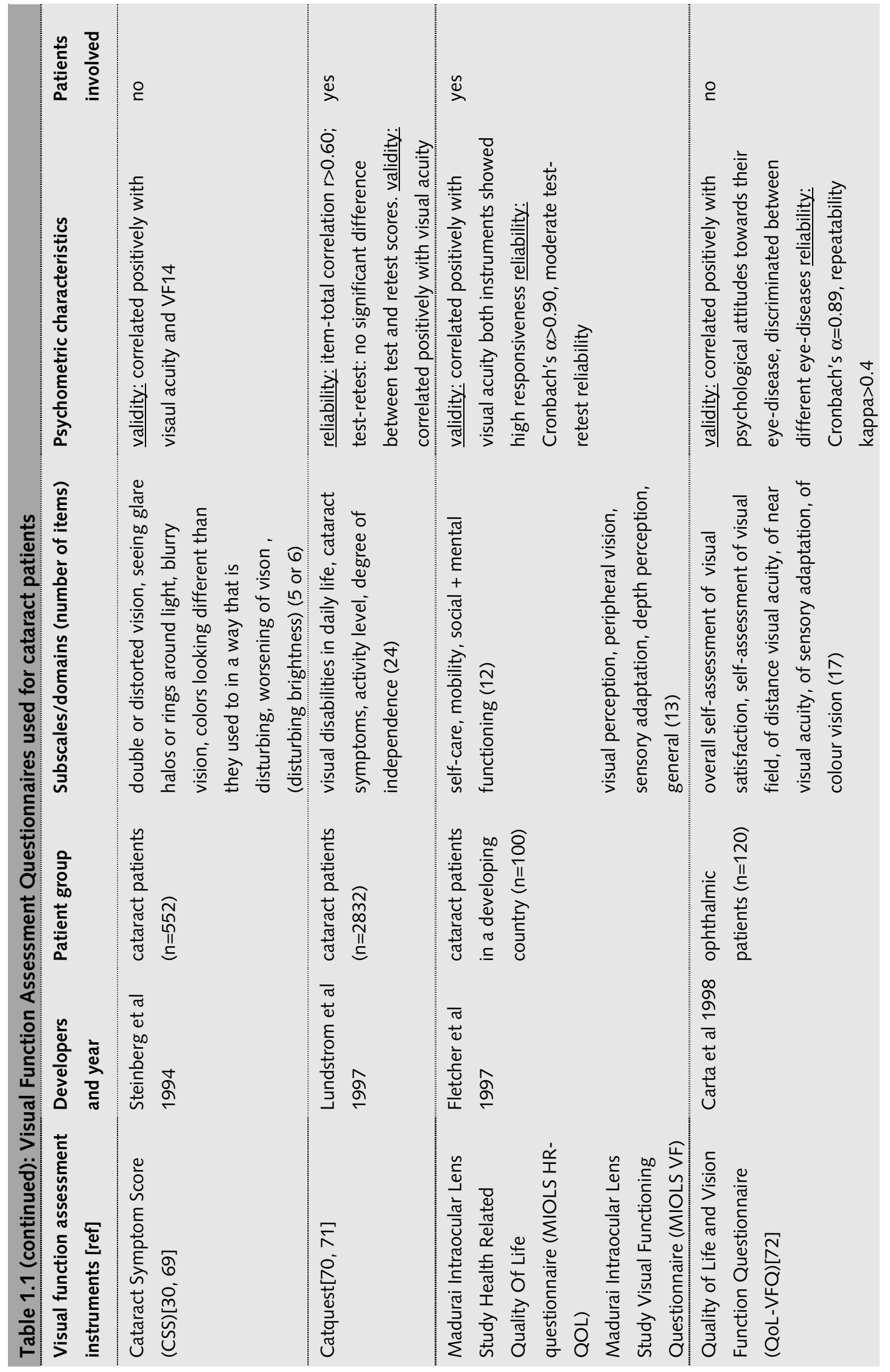




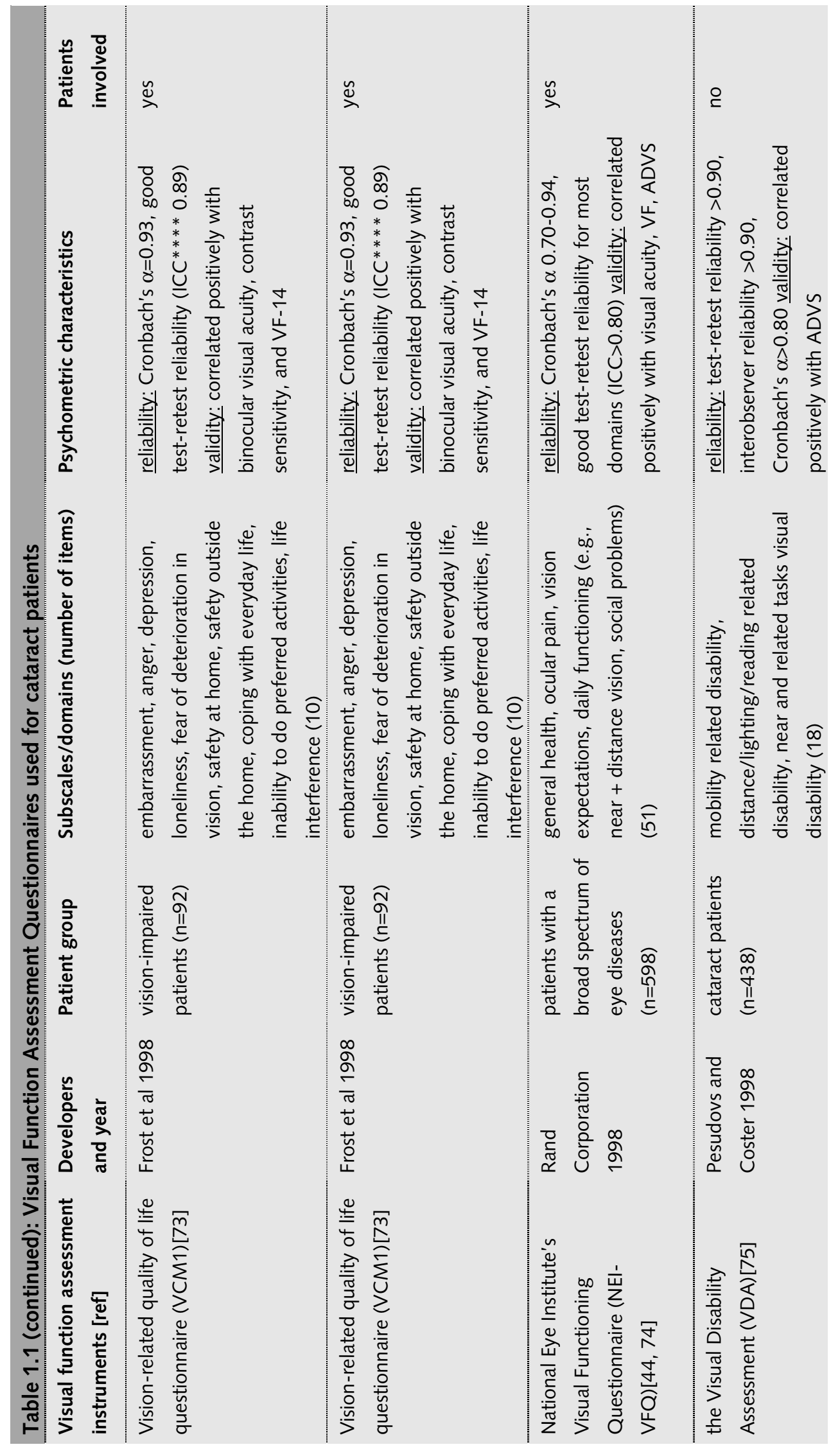




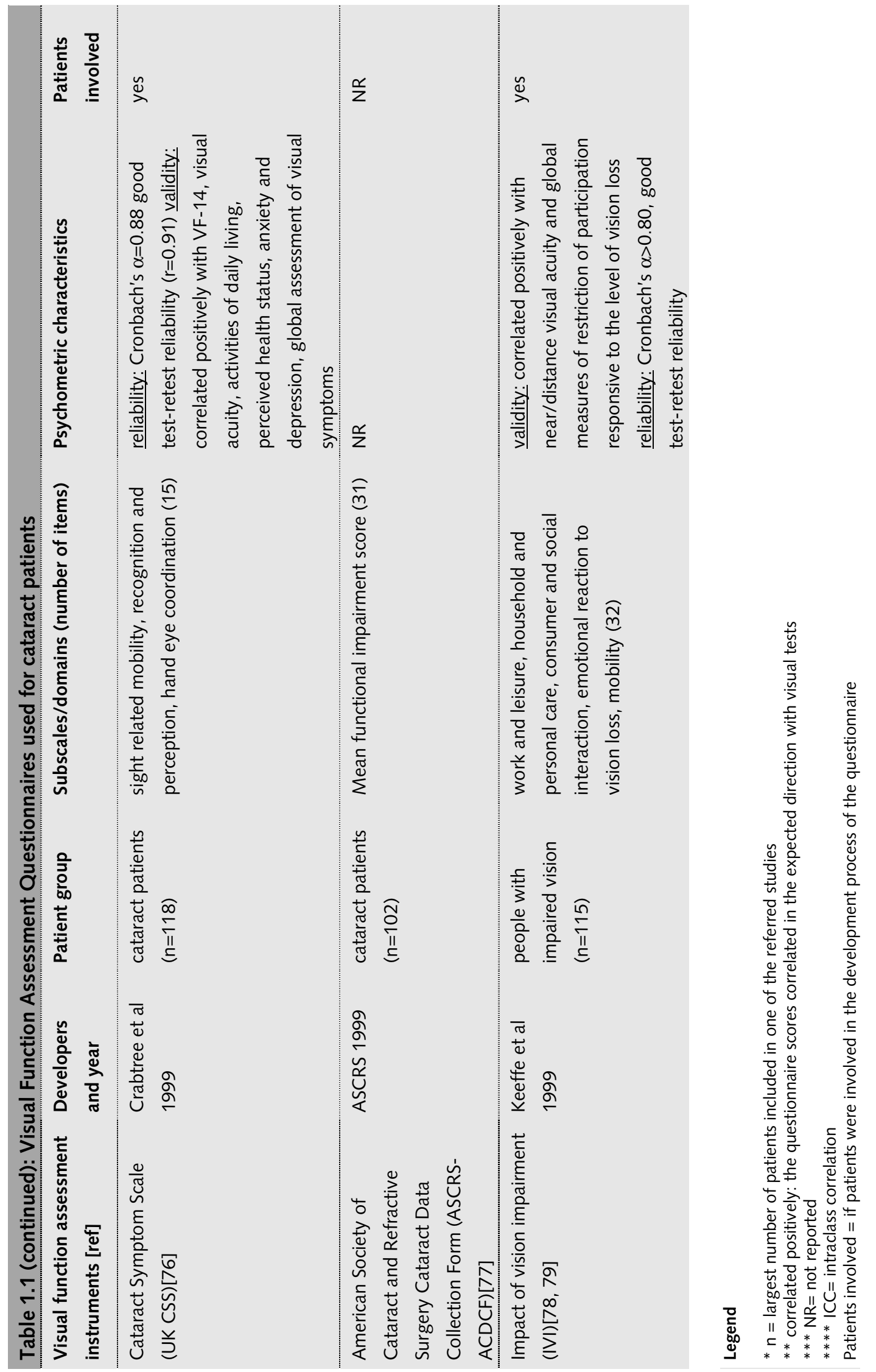




\subsubsection{Patient satisfaction with monofocal and multifocal intraocular lenses}

When cataract surgery is performed, the usual artificial implant lens is a monofocal intraocular lens. In general the intraocular lens power is chosen to achieve emmetropia, i.e., sharp vision at distance without refractive correction. However, due to the loss of accommodative power the patient is made presbyopic. Presbyopia refers to a normal agerelated ocular condition that reduces the accommodative power of the crystalline lens. The traditional remedy for presbyopia has been to fit the patient with reading or bifocal spectacles. In bifocal glasses the upper segment of the spectacle optic is used for far vision and the lower segment with plus add for near vision. An ideal intraocular lens, however, would simulate the original function of the non aged crystalline lens both at near and distance. ${ }^{49,50}$ Recent developments of multifocal intraocular lenses (IOLs) may offer a reasonable option to treat not only the cataract patient's lens opacity, but also prevent the subsequent presbyopia. From a technical point of view an IOL changes the path of light rays coming from an object through the cornea and focuses them to the retina. The amount of bending (change of the path) is dependent on incident angle to the surface and refractive indexes of the optical material. A plane surface of an IOL directs the emerging rays to a single point (single-focus imaging). By dividing the surface into areas of different curvatures, a multifocal optic can be formed. ${ }^{51}$ Because of the ridgy front surface of a multifocal intraocular lens, it allows you to see clearly at near, intermediate and far distance. The optical design of a multifocal IOL is of utmost importance for the quality of vision. The design of one specific type of multifocal IOL, which is called the Allergan Medical Optics (AMO) Array intraocular lens (AMO Array ${ }^{\circledR}$ ), is zonal progressive (Figure 1.7).

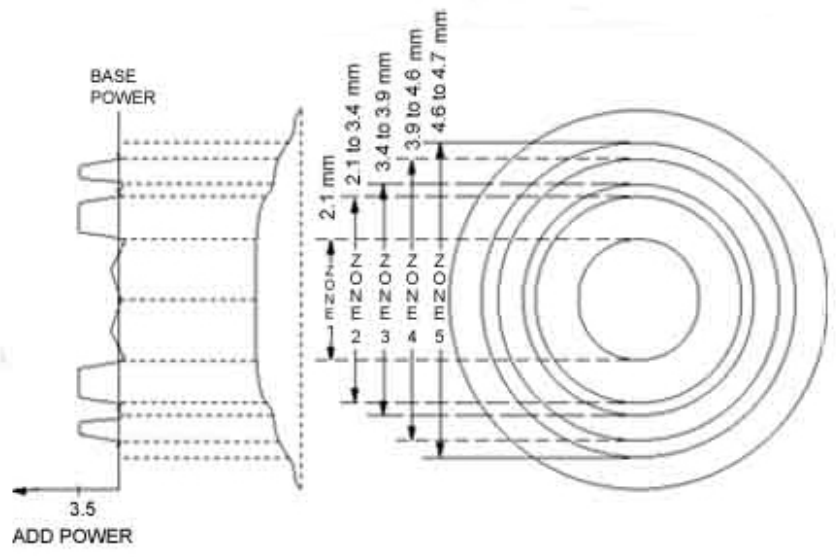

Figure 1.7: the multifocal intraocular lens AMO Array ${ }^{\circledR}$ SA 4ON

This design was developed to minimize the dependence on pupillary diameter, to reduce problems related to decentration and lens tilt, to limit consequences of inappropriate power calculation, and to avoid light scattering and diffraction. The increased range of vision from near to far may result in reduced dependence on glasses. Specifically, implantation of a multifocal IOL may serve as a triple therapy for cataract patients: extraction of the opacificated lens, provide a remedy for refractive error, and prevent or restore presbyopia. 
However, the multifocal IOL may also have some trade-offs. When light passes through the optic of a multifocal IOL, it is partitioned into more than one image. As a consequence the intensity of the image that is in focus is diluted. This may lead to a decreased contrast sensitivity. Furthermore, the transition of the different refractive zones may be associated with the perception of halos or glare around sources of light. These various components of eyesight should be taken into account when evaluating the quality of vision with multifocal IOLs. Therefore, postoperative ophthalmic testing should not be restricted to visual acuity alone. While in daily environments visual targets vary in spatial frequency, contrast, temporal frequency, spatial location, colour, luminance, and presence of glare and fog, visual acuity assesses visual performance under optimal conditions, i.e., high contrast and high luminance. ${ }^{52}$ To optimise the visual performance of the multifocal IOL and to minimize the decrease in contrast sensitivity specifically, ${ }^{53}$ the preoperative cylinder should be smaller than 1.75 Diopters (D). ${ }^{54}$ Furthermore, since emmetropia or small amounts of hyperopia have been shown to provide optimal visual outcome with this lens design, IOL power calculations should be made very accurately. ${ }^{55}$ Additionally, axial lengths should not exceed $26 \mathrm{~mm}$ to maximize the accuracy of the lens power calculations. ${ }^{54}$

Table 1.2 summarizes reference studies (published from 2000 to 2002) on medical outcome (a), spectacle dependence, and patient satisfaction (b) using the foldable multifocal IOL AMO Array ${ }^{\circledR}$ type SA 40N (AMO, Irvine, CA). ${ }^{49,50,80}$ Case studies and review articles were not included in this overview. Most studies evaluating the effectiveness of multifocal IOLs report only objective clinical outcome measures. Other studies that used the AMO Array ${ }^{\circledR}$ type SA $40 \mathrm{~N}$ focussed on specific characteristics of the lens (e.g. depth of focus and stereopsis) that were not reported in any other study, which make comparisons impossible. ${ }^{81-88}$ However, the studies in Table 1.2 included a visual function questionnaire or satisfaction measure. Uncorrected near visual acuity (UCNVA) showed an advantage for multifocal compared to monofocal IOLs in Javitt's studies. Accordingly, these studies represent a reduced spectacle dependence in the multifocal IOL group and a higher satisfaction rate with respect to vision without spectacles for overall and near distances. Leyland did not find a significant difference in UCNVA nor in satisfaction scores. All three studies reported disadvantages of multifocal IOLs concerning the perception of halos and glare. 


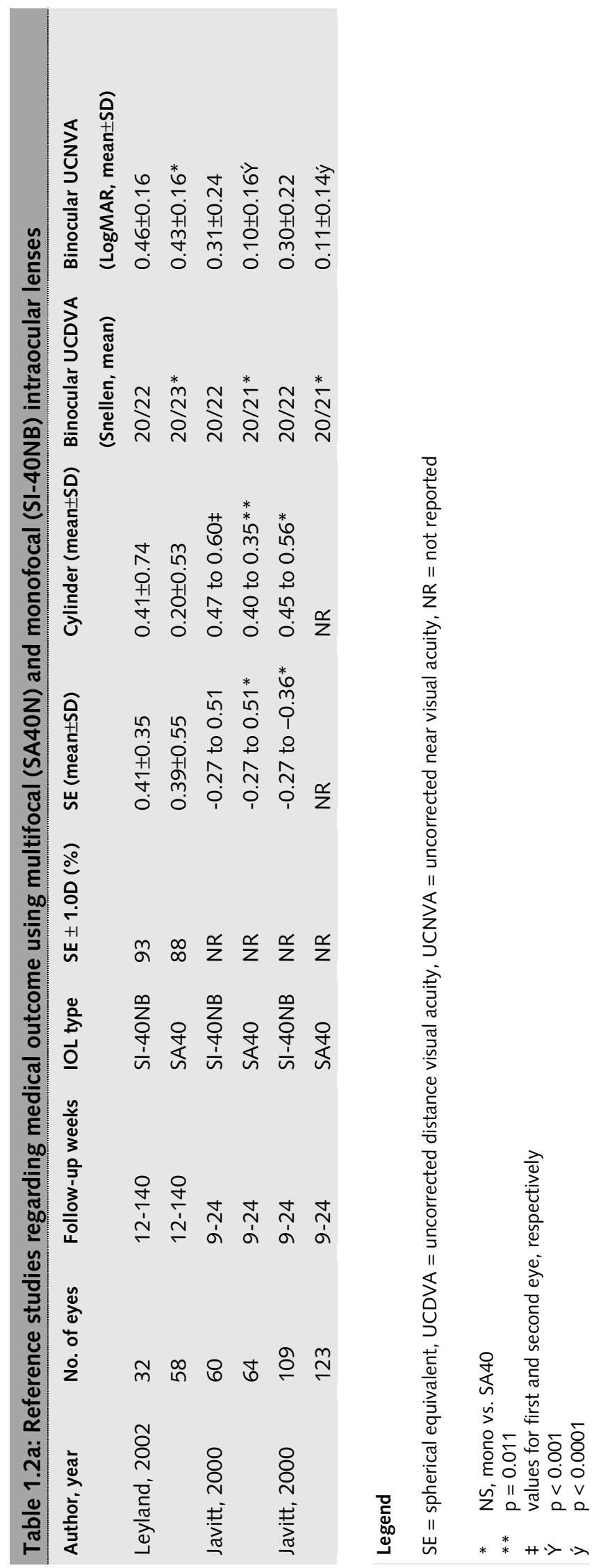




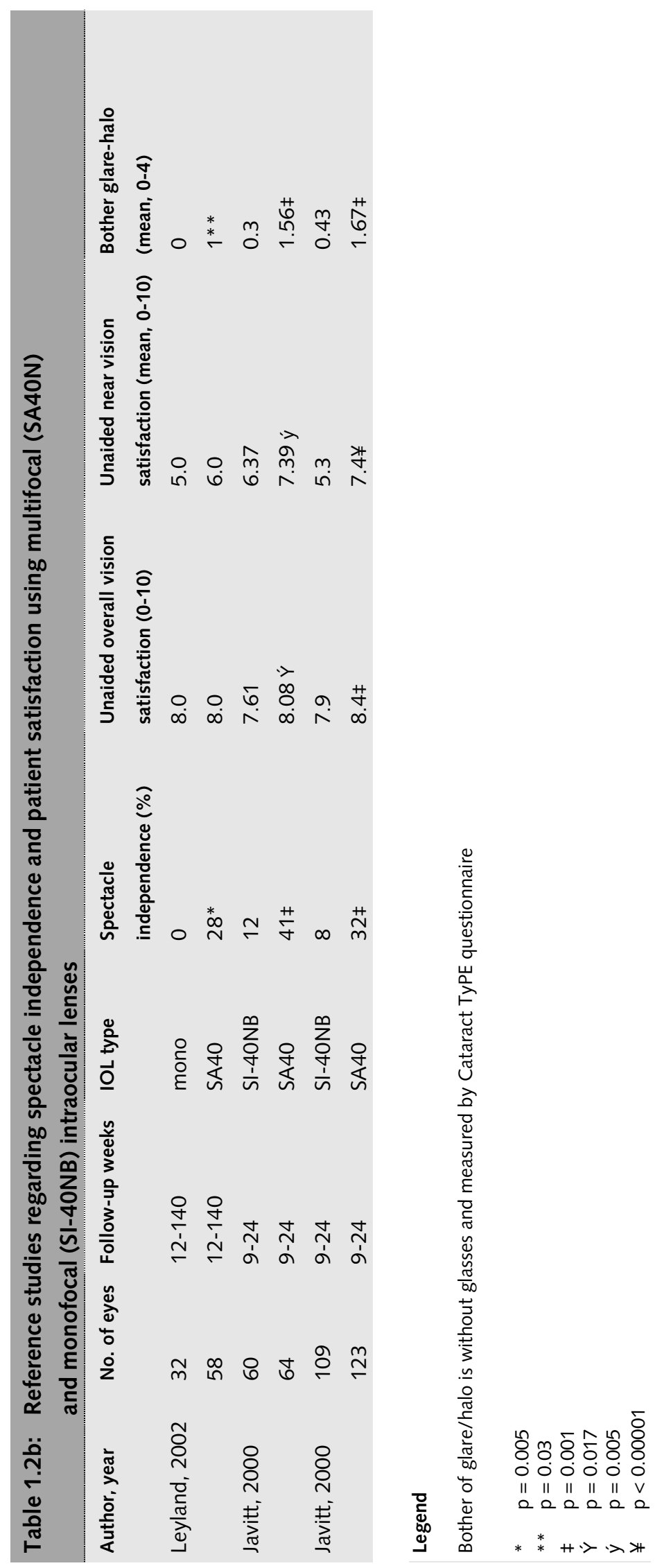




\section{References}

1. The new international Webster's pocket dictionary of the English language. 1997, Trident Press International: USA

2. Campen van $\mathrm{C}$, Sixma $H$, Friele RD et al. Quality of care and patient satisfaction: A review of measuring instruments. Med Care Res Rev, 1995;52:109-133

3. Strasser S, Aharony L, Greenberger D. The patient satisfaction process: moving toward a comprehensive model. Med Care Rev, 1993;50:219-248

4. Pascoe GC. Patient satisfaction in primary health care: A literature review and analysis. Evaluation and Program Planning, 1983;6:185-210

5. Zastowny TR, Stratmann WC, Adams EH et al. Patient satisfaction and experience with health services and quality of care. Qual Manag Health Care, 1995;3: 50-61

6. Visser AP. Patiënt in het ziekenhuis - Voorlichting en begeleiding. 1986, Assen: Van Gorcum

7. Sitzia J, Wood N. Patient satisfaction: a review of issues and concepts. Soc Sci Med, 1997;45:1829-1843

8. Linder-Pelz SU. Toward a theory of patient satisfaction. Soc Sci Med, 1982;16:577-582

9. Cadotte ER, Woodruff RB, Jenkins R. Expectations and norms in models of consumer satisfaction. J Marketing Res, 1987;24:305-314

10. Ware JE, Hays RD. Methods for measuring patient satisfaction with specific medical encounters. Med Care, 1988;26:393-402

11. Parasuraman A, Zeithaml VA, Berry LL. A conceptual model of service quality and its implications for future research. Journal of Marketing, 1985;49:41-50

12. Zeithalm VA, Parasuraman A, Berry L. Delivering Quality Service. 1990, New York: MacMillan

13. Kunst PJ, Lemmink J, Prins R. Meten en verbeteren van kwaliteit in dienstverlening - Handboek Integrale Kwaliteitszorg, beleid-methodiek-toepassing. 1995

14. Scardina SA. SERVQUAL: a tool for evaluating patient satisfaction with nursing care. J Nurs Care Qual, 1994;8:38-46

15. Baron-Epel $O$, Dushenat $M$, Friedman $N$. Evaluation of the consumer model: relationship between patiens' expectations, perception and satisfaction with care. Int J Qual Health Care, 2001;13: 317-323

16. International Organization for Standardization. Quality management and quality system elements, Part 2: Guidelines for services. 1990, ISO: Genève

17. Donabedian A. The definition of quality and approaches to its assessment. Explorations in Quality assessment and monitoring. 1980

18. Kelman $\mathrm{H}$. Evaluation of health care quality by consumers. International Journal of health services, 1976;6:431-441

19. Hall J, Dornan $M$. What patients like about their medical care and how often they are asked: a meta-analysis of the satisfaction literature. Soc Sci Med, 1988;27:935-939

20. Fitzpatrick R, Hopkins A. Problems in the conceptual framework of patient satisfaction research: an empirical exploration. Soc Health Illness, 1983;5:297-311

21. Sixma $H$, Campen van $C$, Kerssens JJ et al. Quality of care from the perspective of elderly people: the QUOTE-Elderly instrument. Age Ageing, 2000;29:173-178

22. Hall J, Dornan M. Meta-analysis of satisfaction with medical care: description of research domain and analysis of overall satisfaction levels. Soc Sci Med, 1988;27: 637-644 
23. Ross C, Steward C, Sinacore J. A comparative study of seven measures of patient satisfaction. Med Care, 1995;33:392-406

24. Bowling A. Assessing health needs and measuring patient satisfaction. Nurs Times, 1992;88:3134

25. Harteloh PPM, Casparie AF. Kwaliteit van zorg - van een zorginhoudelijke benadering naar een bedrijfskundige aanpak. 3rd ed. 1994, Utrecht: De Tijdstroom.

26. Pascoe GC, Attkisson CC. The evaluation ranking scale: A new methodology for assessing satisfaction. Evaluation and Program Planning, 1983;6:335-347

27. Swanborn PG. Methoden van sociaal-wetenschappelijk onderzoek. 1993, Meppel: Boom.

28. Ware JE, Snyder MK, Wright WR et al. Defining and measuring patient satisfaction with medical care. Evaluation and Program Planning, 1983;6:247-263

29. LeVois M, Nguyen TD, Attkinson CC. Artefact in client satisfaction assessment - experience in community mental health settings. Evaluation and Program Planning, 1981;4:139-150

30. Steinberg EP, Tielsch $J M, S c h e i n$ OD et al. The VF-14. An index of functional impairment in patients with cataract. Arch Ophthalmol, 1994;112:630-638

31. Johnson G. Limitations of epidemiology in understanding pathogenesis of cataracts. Lancet, 1998;351:925

32. Javitt J, Wang F. Blindness due to cataract: epidemiology and prevention. Annu Rev Public Health, 1996;17:159-177

33. Duke-Elder S. Diseases of the lens and vitreous, glaucoma and hypotony. System of Ophthalmology, ed. Duke-Elder. Vol. 11. 1969, London: Henry Kimpton Publishers.

34. O'Day D. Management of cataract in adults. Quick reference guide for clinicians. The Cataract Management Guideline Panel of the Agency of Health Care Policy and Research. Arch Ophthalmol, 1993;111:453-459

35. Hadorn D, Holmes A. The New Zealand priority criteria project: Part 1: Overview. BMJ, 1997;314:131-134

36. Powe NR, Schein OD, Gieser SC et al. Synthesis of the literature on visual acuity and complications following cataract extraction with intraocular lens implantation. Cataract Patient Outcome Research Team. Arch Ophthalmol, 1994;112:239-252

37. Bellucci R, Pucci V, Morselli $S$ et al. Cataract surgery in eyes with early cataracts. J Cataract Refract Surg, 1995;21:522-527

38. Elliott $D B$, Hurst $M A$, Weatherill J. Comparing clinical tests of visual function in cataract with the patient's perceived visual disability. Eye, 1990;4:712-717

39. Breemhaar B, Borne van den HW, Mullen PD. Inadequacies of surgical patient education. Patient Educ Couns, 1996;28:31-44

40. Fagerstrom R. Fear of a cataract operation in aged persons. Psychol Rep, 1993;72: 1339-1346

41. O'Malley T, Newmark TS, Rothman MI et al. Emotional aspects of cataract surgery. Int J Psychiatry Med, 1989;19:85-89

42. Desai $P$, Reidy $A$, Minassian DC et al. Gains from cataract surgery: visual function and quality of life. Br J Ophthalmol, 1996;80:868-873

43. Steinberg EP, Tielsch JM, Schein OD et al. National study of cataract surgery outcomes. Variation in 4-month postoperative outcomes as reflected in multiple outcome measures. Ophthalmology, 1994;101:1131-1140 
44. Mangione CM, Berry S, Spritzer $\mathrm{K}$ et al. Identifying the content area for the 51-item National Eye Institute Visual Function Questionnaire: Results from focus groups with visually impaired persons. Arch Ophthalmol, 1998;116:227-233

45. Nijkamp MD, Nuijts RMMA, Borne van den HW et al. Determinants of patient satisfaction after cataract surgery in 3 settings. J Cataract Refract Surg, 2000;26: 1379-1388

46. Pankow L. Seeing through the patient's eyes. J Am Optom Assoc, 1992;63:678-679

47. Margolis M, Coyne K, Kennedy-Martin T et al. Vision-specific instruments for the assessment of health-related quality of life and visual functioning: A literature review. Pharmacoeconomics, 2002;20:791-812

48. Massof R, Rubin G. Visual Function Assessment Questionnaires. Survey of Ophthalmology, 2001;45:531-548

49. Javitt J, Brauweiler HP, Jacobi KW et al., Cataract extraction with multifocal intraocular lens implantation: clinical, functional, and quality-of-life outcomes. Multicenter clinical trial in Germany and Austria. J Cataract Refract Surg, 2000;26: 1356-1366

50. Javitt JC, Steinert RF. Cataract extraction with multifocal intraocular lens implantation: a multinational clinical trial evaluating clinical, functional, and quality-of-life outcomes. Ophthalmology, 2000;107:2040-2048

51. American Academy of Ophthalmology. Optics, Refraction, and Contact Lenses. 1997-1998

52. Haegerstrom, Portnoy G, Scheck ME et al. Seeing into old age: Vision function beyond acuity. Optometry and Vision Science, 1999;76:141-158

53. Ravalico GF, Parentin F, Baccara F. Effect of astigmatism on multifocal intraocular lenses. J Cataract Refract Surg, 1999;25:804-807

54. Brydon KW, Tokarewicz AC, Nichols BD. AMO array multifocal lens versus monofocal correction in cataract surgery. J Cataract Refract Surg, 2000;26:96-100

55. Wallace III RB. Multifocal vision after cataract surgery. Current Opinion in Ophthalmology, 1998;9:66-70

56. Bernth-Petersen P. Visual functioning in cataract patients. Methods of measuring and results. Acta Ophthalmol Copenh, 1981;59:198-205

57. Javitt J, Ware J. User's manual: Cataract TyPE specification. 1989, Wothen Center for Eye Care Research, Georgetown University: Washington.

58. Lawrence DJ, Brogan C, Benjamin L et al. Measuring the effectiveness of cataract surgery: the reliability and validity of a visual function outcomes instrument. Br J Ophthalmol, 1999;83:66-70

59. Javitt JC, Wang F, Trentacost DJ et al. Outcomes of cataract Extraction with Multifocal Intraocular Lens Implantation - Functional Status and Quality of Life. Ophthalmology, 1997;104:589-599

60. Prager T, Chuang AZ, Glasser JH et al. The Houston Vision Assessment Test (HVAT): an assessment of validity. The Cataract Oucome Study Group. Ophthalmic Epidemiology, 2000;7:87-102

61. Sloane $M E$, Ball $K$, Owsley $C$ et al. The visual activities questionnaire: developing an instrument for assessing problems in everyday visual tasks. OSA Tech Dig Noninvasive Assess Vis Sys (washington, DC: Optical Society of America) 1:26-9, 1992.

62. Bergman B, Sjöstrand J. Vision and visual disability in the daily life of a representative population sample aged 82 years. Acta Ophthalmol, 1992;70:33-43 
63. Mangione CM, Phillips RS, Seddon JM et al. Development of the 'Activities of Daily Vision Scale'. A measure of visual functional status. Med Care, 1992;30:1111-1126

64. Valbuena M, Bandeen-Roche K, Rubin GS et al. Self-reported assessment of visual function in a population-based study: the SEE-project. Invest Ophthalmol Vis Sci, 1999;40:280-288

65. Brenner $\mathrm{MH}$, Curbow B, Javitt JC et al. Vision change and quality of life in the elderly. Response to cataract surgery and treatment of other chronic ocular conditions. Arch Ophthalmol, 1993;111:680-685

66. Scott IU, Schein OD, West $S$ et al. Functional status and quality of life measurement among ophthalmic patients. Arch Ophthalmol, 1994;112:329-335

67. Alonso J, Espallargues M, Andersen TF et al. International applicability of the VF-14: An index of visual function in patients with cataracts. Ophthalmology, 1997;104:799-807

68. Cassard SD, Patrick DL, Damiano AM et al., Reproducibility and responsiveness of the VF-14. An index of functional impairment in patients with cataracts. Arch Ophthalmol, 1995;113:15081513

69. Schein OD, Steinberg EP, Cassard SD et al. Predictors of outcome in patients who underwent cataract surgery. Ophthalmology, 1995;102:817-823

70. Lundstrom $M$, Roos $P$, Jensen $S$ et al. Catquest questionnaire for use in cataract surgery care: descriptuion, validity, and reliability. J Cataract Refract Surg, 1997;23:1226-1236

71. Lundstrom $M$, Stenevi $U$, Thorburn $W$ et al. Catquest questionnaire for use in cataract surgery care: assessment of surgical outcomes. J Cataract Refract Surg, 1998;24:968-974

72. Carta A, Braccio $L$, Belpoliti $M$ et al. Self-assessment of the quality of vision: association of questionnaire score with objective clinical tests. Current Eye Research, 1998;17:506-511

73. Frost NA, Sparow JM, Durant JS et al. Development of a questionnaire for measurement of vision-related quality of life. Ophthalmic Epidemiology, 1998;5:185-210

74. Mangione $C M$, Lee PP, Pitts J et al. Psychometric properties of the national eye institute visual function questionnaire (NEI-VFQ). Arch Ophthalmol, 1998;116:1496-1504

75. Pesudovs $K$, Coster DJ. An instrument for assessment of subjective visual disability in cataract patients. Br J Ophthalmol, 1998;82:617-624

76. Crabtree $\mathrm{H}$, Hildreth $\mathrm{AJ}, \mathrm{O}^{\prime}$ Connell JE et al. Measuring visual symptoms in British cataract patients: the cataract symptom scale. Br J Ophthalmol, 1999;83:519-523

77. Chang-Godinich $A$, Ou R, Koch D. Functional improvement after phacoemulsification cataract surgery. J Cataract Refract Surg, 1999;25:1226-1231

78. Keeffe J, McCarty CA, Hassell JB et al. Description and measurement of handicap caused by vision impairment. Australian and New Zealand Journal of Ophthalmology, 1999;27:184-186

79. Weih L, Hassell J, Keeffe J, Assessment of the impact of vision impairment. Invest Ophthalmol Vis Sci, $2002 ; 43: 927-935$

80. Leyland $M$, Langan $L$, Goolfee $F$ et al. Prospective randomised double-masked clinical trial of bilateral multifocal, bifocal or monofocal intraocular lenses. Eye, 2002;16:481-490

81. Grosskopf U, Wagner R, Jacobi FK et al. Twilight vision and glare sensitivity in monofocal and multifocal pseudophakia. Ophthalmologe, 1998;95:432-437

82. Dick $H B$, Krummenauer $F$, Schwenn $O$ et al. Objective and subjective evaluation of photic phenomena after monofocal and multifocal intraocular lens implantation. Ophthalmology, 1999;106:1878-1886 
83. Schmitz $\mathrm{S}$, Dick $H B$, Krummenauer $F$ et al. Contrast sensitivity and glare disability by halogen light after monofocal and multifocal lens implantation. Br J Ophthalmol, 2000;84:1109-1112

84. Pieh S, Hanselmayer G, Lackner B et al. Tritan colour contrast sensitivity function in refractive multifocal intraocular lenses. $\mathrm{Br} J$ Ophthalmol, 2001;85:811-815

85. Pieh S, Lackner $B$, Hanselmayer $G$ et al. Halo size under distance and near conditions in refractive multifocal intraocular lenses. $\mathrm{Br} J$ Ophthalmol, 2001;85:816-821

86. Haring $G$, Dick $H B$, Krummenauer $F$ et al. Subjective photic phenomena with refractive multifocal and monofocal intraocular lenses - results of a multicenter questionnaire. J Cataract Refract Surg, 2001;27:245-249

87. Jacobi PC, Dietlein TS, Luke $C$ et al. Multifocal intraocular lens implantation in prepresbyopic patients with unilateral cataract. Ophthalmology, 2002;109: 680-686

88. Orme ME, Paine AC, Teale CW et al. Cost-effectiveness of the AMOArray multifocal intraocular lens in cataract surgery. J Refract Surg, 2002;18:162-168 



\section{Chapter 2}

\section{Determinants of patient satisfaction after cataract surgery in 3 settings}

Published as Marjan D. Nijkamp, Rudy M.M.A. Nuijts, Bart van den Borne, Carroll A.B. Webers, Frans van der Horst, Fred Hendrikse. "Determinants of patient satisfaction after cataract surgery in 3 settings"; Journal of Cataract and Refractive Surgery 2000; 26: 1379-1388. 


\section{Abstract}

\section{Purpose}

To analyse the determinants of satisfaction and postoperative visual functioning after cataract surgery in three different settings in the Netherlands.

\section{Setting}

University Hospital Maastricht (outpatient care), Atrium Medical Centre Heerlen (inpatient care), and Medical Centre Maastricht Annadal (outpatient care).

\section{Methods}

This cross-sectional study consisted of 150 patients in the age of 50 years and older, who underwent first eye phacoemulsification with intraocular lens implantation. Data were collected by a written questionnaire. The following parameters were measured: medical outcome, postoperative functioning, patient satisfaction with regard to the medical outcome and hospital care, and overall patient satisfaction.

\section{Results}

In general, patients were very satisfied (mean score 8.43 on a 10 -point scale ranging from $1=$ 'very bad' to $10=$ 'excellent'). The three centres did not differ regarding the patient satisfaction ( $p=0.092)$. However, postoperative visual functioning $(p=0.012)$, counselling $(p=0.010)$ and waiting time $(p<0.001)$ were found to be different in the three settings. Patient satisfaction with regard to hospital care had a stronger correlation with overall satisfaction than patient satisfaction with regard to the medical outcome $(r=0.669$ versus $\mathrm{r}=0.543$, respectively).

\section{Conclusions}

A causal model of patient satisfaction was tested, indicating that patient satisfaction was related to preoperative expectations of the patient and to the quality of care given during hospital stay and follow-up in the outpatients' clinic. This emphasizes the relevance of patient education (to set realistic expectations) and counselling (need for care) by hospital staff in cataract surgery. 


\subsection{Introduction}

It is generally agreed upon that modern cataract surgery is very effective in terms of postoperative increase in vision and safe with respect to the low incidence of surgical complications. ${ }^{1}$ However, the measurement of visual functioning after cataract surgery is a better outcome measure than visual acuity alone. ${ }^{2}$ Therefore, it is clear that present outcome studies in cataract surgery should focus on both functional status and quality of life after surgery. ${ }^{3}$ Nevertheless, although most patients after cataract surgery benefit from an increase in visual acuity, visual functioning, and improvement in quality of life, patient satisfaction may be limited because of a lack in perceived quality of care. By combining the evaluation of functional and technical quality of care aspects, clinician and patient evaluations regarding the quality of care can be related. ${ }^{4}$ A general problem of satisfaction studies is the high number of satisfied patients which accounts for the low sensitivity of the measurement methods. ${ }^{5}$ To improve the sensitivity of the study, problem definitions are based upon a classification of satisfaction into three dimensions: satisfaction with regard to cure (the medical outcome), satisfaction with regard to the care given during hospital stay and follow-up in the outpatient clinic, and an overall-satisfaction. A research model was formed to map the expected relationships between the various research variables (Figure 2.1).

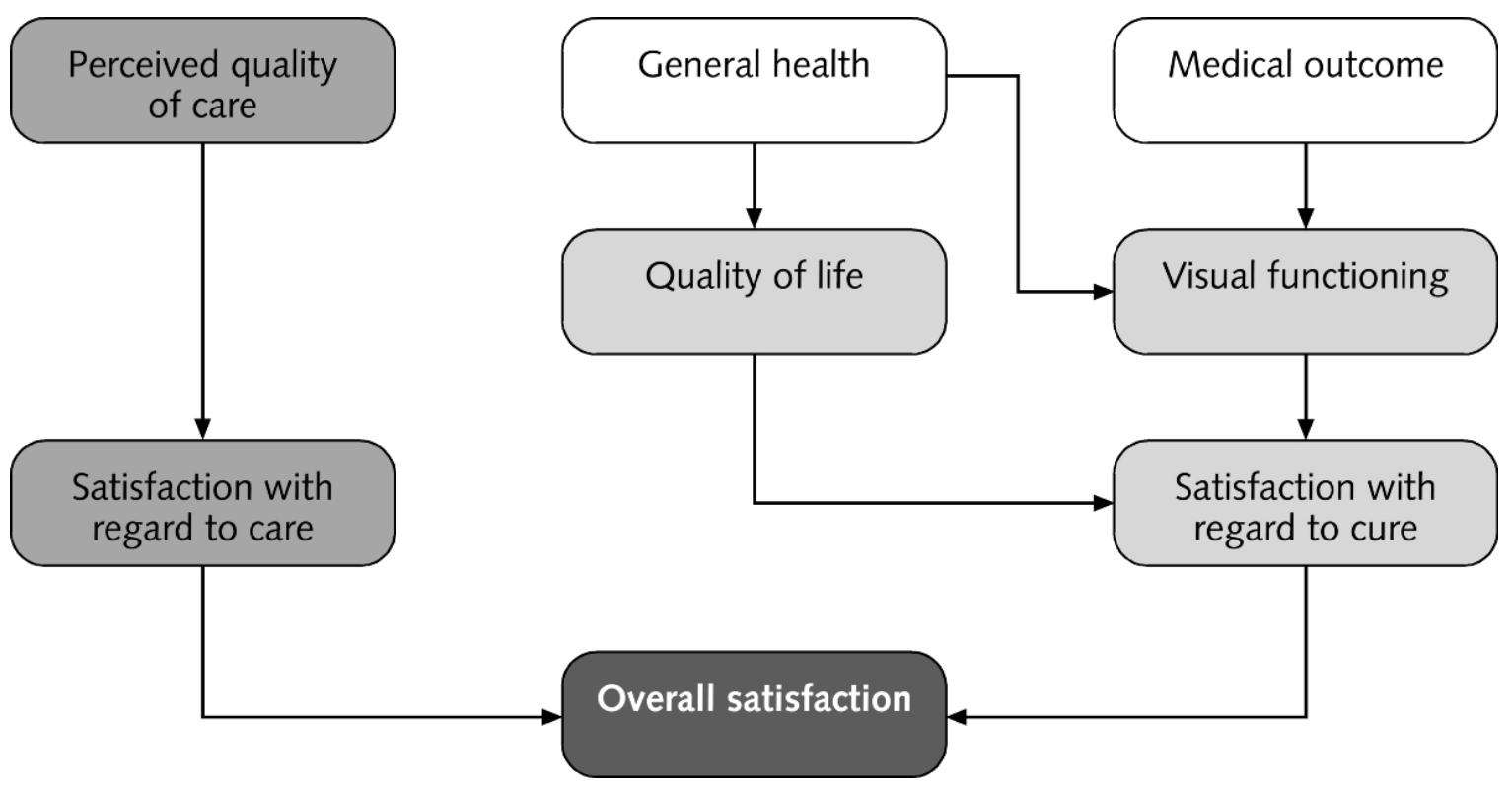

Figure 2.1: Research model

- this model summarizes the expected relationships between the research variables

The aim of the present study was to analyse the determinants of satisfaction and postoperative functioning in patients with cataract surgery. Three different treatment settings were compared, providing cataract surgery on an inpatient as well as an outpatient basis. 


\subsection{Patients and Methods}

The research population consisted of three subgroups based on the institution where the cataract surgery was performed. One group of patients treated in a general hospital (Atrium Medical Centre Heerlen; $\mathrm{AMCH}$ ) on an inpatient basis, one group treated in a private day care centre (Medical Centre Maastricht Annadal; MCMA), and one group treated in an academic hospital on an outpatient basis (University Hospital Maastricht; UHM). Inclusion criteria were first eye cataract surgery, to prevent bias from earlier experiences, and an age greater than 50 years old. The required sample size of 150 patients was calculated by means of a power analysis. To correct for an anticipated non-response in total 235 patients were asked to participate in the study. The response-rate to the questionnaire was 64\% (150 of 235 patients). Mean age \pm standard deviation (SD) was different in the three settings: $77.4 \pm 7.48$ (range 54-90), $74.6 \pm 9.74$ (range 51-94) and $72.3 \pm 9.95$ (range 52-89) years for UHM, MCMA and $\mathrm{AMCH}$, respectively $(\mathrm{p}=0.022)$. The male/female ratio was comparable at the three settings: 21/30, 27/31 and 16/25 for UHM, MCMA and $\mathrm{AMCH}$, respectively $(\mathrm{p}=0.731)$. There were no significant differences in education level $(p=0.727)$ or in civil status parameters $(p=0.253$, Table 2.1).

\begin{tabular}{|c|c|c|c|c|}
\hline & $\mathrm{AMCH}$ & MCMA & UHM & $p$-value \\
\hline Age $[$ mean $\pm S D]$ & $72.3 \pm 9.95 \#$ & $74.6 \pm 9.74$ & $77.4 \pm 7.48 \#$ & 0.022 \\
\hline Sex [ratio] & $16 / 25$ & $27 / 31$ & $21 / 30$ & 0.731 \\
\hline Education [frequency (\%)] & & & & 0.727 \\
\hline Primary school & $20(48.8)$ & $26(44.8)$ & $19(37.3)$ & \\
\hline College/University & $0(0)$ & $2(3.4)$ & $4(7.8)$ & \\
\hline Other & $21(51.2)$ & $30(51.8)$ & $28(54.9)$ & \\
\hline Civil status [frequency (\%)] & & & & 0.253 \\
\hline Living alone & $21(51.2)$ & $28(48.3)$ & $20(39.2)$ & \\
\hline
\end{tabular}

Legend

$\mathrm{SD}=$ standard deviation

\# Post hoc-test Bonferroni showing which variables differ significantly 


\subsubsection{Procedures}

Cataract surgery was performed in the period from January until July 1997 by four different surgeons using a standard divide and conquer phacoemulsification technique. The technique consisted of a $3.2 \mathrm{~mm}$ corneoscleral incision with implantation of a PMMA intraocular lens (SN53, Allergan, Irvine, Ca, USA).

\subsubsection{Outcome measures}

The determinants of patient satisfaction were investigated by analysing objective medical outcome measurements and subjective patient evaluations. Medical outcome parameters for patient satisfaction were postoperative visual acuity expressed by the logarithm of the minimal angle of resolution scale (logMAR) and vision improvement defined as at least a 2 lines improvement on the Snellen scale. ${ }^{6}$ In addition, the incidence of peroperative complications, the vision of the contralateral eye, and ocular co-morbidity were registered. Ocular co-morbidity consisted of glaucoma, corneal disease, age-related macular degeneration (ARMD), diabetic retinopathy (DRP), retinal detachment, amblyopia, and uveitis. A questionnaire was sent six months after surgery to the patients to measure subjective patient evaluations.

To evaluate postoperative functioning, the following variables were studied: ability to perform specific vision-dependent activities (Dutch version of the VF-14) together with a question reflecting overall trouble with vision, 5 questions related to patient's opinion about quality of life, and three questions regarding the subjective general health. Patient satisfaction was measured for three different dimensions: satisfaction with regard to the medical outcome, with regard to care and an overall satisfaction score. The VF-14 has been described in detail by Steinberg et al. ${ }^{2}$ The VF-14 was adapted for use in the Netherlands giving considerable attention to conceptual and cultural equivalence as well as ensuring that the instrument was translated accurately (translation-back translation method, Table 2.2). The questions 7, 9, and 10 were changed because they referred to handwork (crocheting), a game (mahjong), and sports (golf) less familiar to the Dutch population. Moreover we added 2 questions related to cycling (during day- and nighttime) and one question concerning the use of public transport, which also are common activities for the older population in the Netherlands. Otherwise, the questions and scoring were performed as described by Steinberg et al. VF-14 scores ranged from 0 (worst level of function) to 100 (best level of function/no disability). ${ }^{27}$ Validity and reliability of the Dutch version of VF-14 were tested by an expert-panel and in a pilot study in a similar fashion as reported by Alonso et al. ${ }^{8}$ Cronbach's alpha was similar to the original American VF-14 ( $\alpha=0.98$ ), and factor analysis supported the Dutch version of VF-14 to be a single index of visual function. The criterion validity of the VF-14 instrument was assessed by examining the correlation between VF-14 scores and visual acuity, and between VF-14 scores and patient satisfaction regarding their vision. The correlation between VF-14 and visual acuity and between VF-14 and satisfaction with regard to vision was 0.28 and 0.64 , respectively. These values in our study of 150 patients are comparable to the values in the study of Steinberg et al. ${ }^{2}$ 


\begin{tabular}{|c|c|}
\hline Original English - United States & Adapted Dutch - The Netherlands \\
\hline $\begin{array}{l}\text { A1 Reading small print such as labels on medicine bottles, a } \\
\text { telephone book, food labels }\end{array}$ & $\begin{array}{l}\text { A1 Kleine lettertjes te lezen zoals in telefoonboeken, op } \\
\text { medicijnpotjes, enzovoort } \\
\text { B Reading small print such as a telephone book, labels on } \\
\text { medicine bottles, etcetera }\end{array}$ \\
\hline A2 Reading a newspaper or a book & $\begin{array}{l}\text { A2 Een krant of een boek te lezen } \\
\text { B2 Reading a newspaper or a book }\end{array}$ \\
\hline A3 Reading a large print book or numbers on a telephone & $\begin{array}{l}\text { A3 Een grootletterboek te lezen of de nummers op de } \\
\text { toetsen/draaischijf van uw telefoon-toestel te herkennen } \\
\text { B3 Reading a large print book or numbers on a telephone }\end{array}$ \\
\hline A4 Recognizing people when they are close to you & $\begin{array}{l}\text { A4 Mensen te herkennen als ze dichtbij } u \text { in de buurt staan } \\
\text { B4 Recognizing people when they are close to you }\end{array}$ \\
\hline A5 Seeing steps, stairs, or curbs & $\begin{array}{l}\text { A5 Stoepen, trottoirbanden of afstapjes te zien } \\
\text { B5 Seeing sidewalks, curbs, or steps }\end{array}$ \\
\hline A6 Reading traffic signs, street signs, store signs & $\begin{array}{l}\text { A6 Verkeersborden en wegwijzers te lezen } \\
\text { B6 Reading traffic signs and signposts }\end{array}$ \\
\hline $\begin{array}{l}\text { A7 Doing fine handwork like sewing, knitting, crocheting, } \\
\text { carpentry }\end{array}$ & $\begin{array}{l}\text { A7 Fijn handwerk te verrichten zoals naaien, breien, of } \\
\text { timmerwerk } \\
\text { B7 Doing fine handwork like sewing, knitting or carpentry }\end{array}$ \\
\hline A8 Writing checks or filling out forms & $\begin{array}{l}\text { A8 Een giro uit te schrijven of een brief te schrijven } \\
\text { B8 Writing checks or letters }\end{array}$ \\
\hline $\begin{array}{l}\text { A9 Playing games such as bingo, dominos, card games, } \\
\text { mahjong }\end{array}$ & $\begin{array}{l}\text { A9 Spelletjes te doen als bingo, domino of kaartspelen } \\
\text { B9 Playing games such as bingo, dominos or card games }\end{array}$ \\
\hline A10 Taking part in sports like bowling, handball, tennis, golf & $\begin{array}{l}\text { A10 Deel te nemen aan sportactiviteiten zoals bowlen, tennis } \\
\text { of fietsen } \\
\text { B10 Taking part in sports like bowling, tennis or cycling }\end{array}$ \\
\hline A11 Cooking & $\begin{array}{l}\text { A11 Te koken } \\
\text { B11 Cooking }\end{array}$ \\
\hline A12 Watching television & $\begin{array}{l}\text { A12 De ondertiteling op de TV te lezen } \\
\text { B12 Reading subtitles when watching television }\end{array}$ \\
\hline A13 Driving during day & $\begin{array}{l}\text { A13 Autorijden overdag } \\
\text { B13 Driving during day }\end{array}$ \\
\hline A14 Driving at night & $\begin{array}{l}\text { A14 Autorijden 's avonds/'s nachts } \\
\text { B14 Driving at night }\end{array}$ \\
\hline B15 Cycling during day B16 Cycling at night & A15 Fietsen overdag A 16 Fietsen's avonds/'s nachts \\
\hline B17 Use of public transport & A 17 Gebruik maken van openbaar vervoer \\
\hline
\end{tabular}

\section{Legend}

Legend: $A$ = original version; $B=$ back translation NB: Italic not in original VF 14 
In addition, patients were asked to rate their overall amount of trouble with vision. Response options were "none" (score 4), "a little" (3), "a moderate amount" (2), and "a great deal" (1). ${ }^{7,9}$ Patient's opinion about their postoperative quality of life and subjective general health were measured on a three-point scale by asking patients if five specific indicators of their quality of life (self management, feelings of loneliness, life satisfaction, activity, and happiness) or general health had changed postoperatively ( $1=$ got worse, $2=$ stayed the same, and $3=$ got better). Face validity was tested by an expert panel and a pilot study among patients.

Satisfaction with regard to the medical outcome was categorized with response options "very dissatisfied" (score 1), "dissatisfied" (score 2), "neither satisfied nor dissatisfied" (score 3), "satisfied" (score 4), and "very satisfied" (score 5). In addition patients were asked if their vision and visual functioning had changed as expected, response options were "better than expected" (score 3), "as expected" (score 2), and "less than expected" (score 1).

For evaluation of patient satisfaction with regard to care a service quality measurement scale (SERVQUAL) was used. ${ }^{10}$ The SERVQUAL-questionnaire was designed to be applicable across a broad spectrum of services. It was empirically evaluated for its potential usefulness in a hospital service environment by Babakus et al. ${ }^{11}$ Minor changes were made to tailor this quality of health services instrument to the specific characteristics of the department of ophthalmology. Translation to the Dutch language was based on translations by Kunst et al. ${ }^{12}$ Content validity was tested by an expert-panel and a pilot-study among patients in the same way as described by Babakus et al. ${ }^{11}$ The final scale consisted of 13 quality perception statements measured on a five-point scale with end points labeled "very good" (score 5) and "very poor" (score 1). Factor-analysis revealed three dimensions: education, counselling, and waiting time. Reliability analysis resulted in Cronbach's alpha's of $0.84,0.88$ and 0.59 for education, counselling, and waiting time respectively.

In addition, patients were asked to rate their satisfaction with regard to the care on a five point scale varying from 1 (very dissatisfied) to 5 (very satisfied). Overall-satisfaction was scored on a categorical Visual Analogue Scale ranging from 1 (very bad) to 10 (excellent). In addition a "have it again" score, based on an "intention-to-return" score developed by Babakus, was formulated as follows: "If I had to undergo a second eye cataract surgery, I would want to receive my treatment there again". ${ }^{11}$ This statement was measured on a five-point "strongly agree" (score 5) - "strongly disagree" (score 1) scale.

\subsubsection{Statistical analysis}

Both descriptive and inferential data analyses were performed by means of SPSS 7.0. In preparation to data reduction, a correlational analysis was performed. A mean relative score [sum score/(number of items - missing values)] was calculated in scale construction, to solve the problem of missing values. The research model was tested by multiple linear regression. The level of significance for this study was $p<0.05$. 
Ordinal data based on multi-item factors were interpreted as interval data in the statistical analysis as described by Tabachnick et al. and Swanborn. ${ }^{13,14}$ Because various items were related to the same concept, and sum scores were calculated, reliability of this procedure is high. The assumption of an underlying normally distributed continuum was checked by item-analyses, in which the following indicators were taken into account: internal consistency (Cronbach's alpha), skewness, kurtosis, median and mean value, and distribution.

\subsection{Results}

\subsubsection{Response versus non-response}

Response and non-response were compared with respect to sex, setting, complications, ocular co-morbidity, pre- and postoperative vision and vision improvement. No significant difference was found between respondents and non-respondents. For ordinal variables this was tested by means of one way ANOVA and for nominal parameters by means of Chisquare.

\subsubsection{Objective medical outcome}

Vision improvement was found in $88.8 \%$ of the cases (Figure 2.2, Table 2.3). While preoperatively $91.8 \%$ of the patients had a visual acuity of less than $20 / 40$ on the Snellen scale, vision improved to a median score of 20/25 postoperatively.

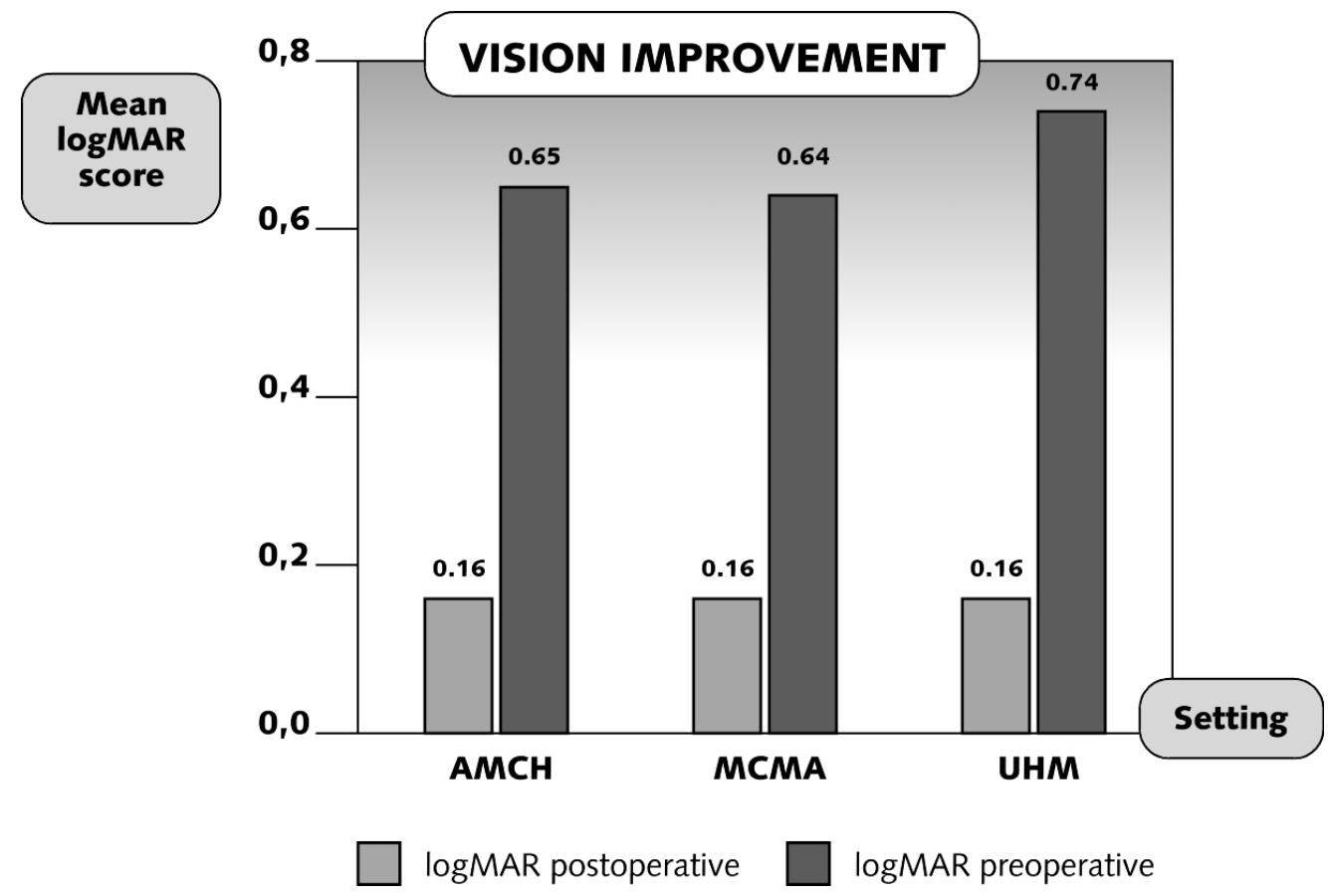

Figure 2.2: Vision improvement 
There was no significant difference between the three settings in pre- and postoperative visual acuity $(p=0.580 ; p=0.710)$ nor vision improvement $(p=0.229)$.

In two cases a posterior capsule rupture without vitreous loss occurred. The medical outcome is found to be effected by the pre-existing ocular pathology $(\mathrm{r}=0.264)$ and the preoperative visual acuity $(\mathrm{r}=0.282)$. The incidence of ocular co-morbidity is summarized in Table 2.3. The three settings did not differ significantly regarding the incidence of ocular co-morbidity $(p=0.517)$. In total $27.3 \%$ of the research population suffered from preexisting ocular pathology.

\begin{tabular}{|c|c|c|c|c|}
\hline & $\mathrm{AMCH}$ & MCMA & UHM & $p$-value \\
\hline LogMAR preoperative $[\text { mean } \pm S D]^{*}$ & $0.65 \pm 0.39$ & $0.64 \pm 0.49$ & $0.74 \pm 0.60$ & 0.580 \\
\hline LogMAR postoperative [mean \pm SD] & $0.16 \pm 0.25$ & $0.16 \pm 0.26$ & $0.16 \pm 0.27$ & 0.710 \\
\hline$\Delta \log M A R[$ mean $\pm \mathrm{SD}]$ & $0.49 \pm 0.43$ & $0.49 \pm 0.48$ & $0.63 \pm 0.52$ & 0.355 \\
\hline Snellen score contralateral eye [median] & $20 / 40$ & $20 / 30$ & $20 / 40$ & 0.418 \\
\hline $\begin{array}{l}\text { Number of Snellen lines improvement } \\
{[\text { mean } \pm S D]}\end{array}$ & $4.6 \pm 3.4$ & $4.1 \pm 3.1$ & $5.4 \pm 3.1$ & 0.229 \\
\hline Comorbidity [frequency (\%)] & & & & 0.517 \\
\hline ARMD & $3(7.3)$ & $3(5.2)$ & $3(5.9)$ & \\
\hline Glaucoma & $2(4.9)$ & $5(8.6)$ & $6(11.8)$ & \\
\hline DRP & $3(7.3)$ & $1(1.7)$ & $2(3.9)$ & \\
\hline Corneal disease & $1(2.4)$ & $6(10.3)$ & $5(9.8)$ & \\
\hline Uveitis & $0(0)$ & $1(1.7)$ & $0(0)$ & \\
\hline Retinal detachment & $0(0)$ & $0(0)$ & $1(2.0)$ & \\
\hline Amblyopia & $0(0)$ & $0(0)$ & $1(2.0)$ & \\
\hline Total & $9(21.9)$ & $16(27.5)$ & $18(35.3)$ & \\
\hline Peroperative complications [frequency (\%)] & & & & 0.140 \\
\hline Capsel rupture without vitreous loss & $0(0)$ & $0(0)$ & $2(3.9)$ & \\
\hline
\end{tabular}

\section{Legend}

* All visual acuity scores are measured with best correction (BSCVA)

LogMAR $=-\log$ Snellen score operated eye

$\Delta=$ difference

p-values are computed by one way analysis of variance for interval and ratio scales, chi-square for nominal variables ARMD = age-related macula degeneration

$\mathrm{DRP}=$ Diabethic retinopathy 


\subsubsection{Subjective patient evaluations}

Postoperative functioning: The mean \pm SD score on the Dutch version of the VF-14 was $80.79 \pm 25.31,92.17 \pm 14.53$, and $86.73 \pm 16.94$ for $\mathrm{AMCH}, \mathrm{MCMA}$, and UHM, respectively ( $p=0.012$, Table 2.4). The determinants of visual functioning were postoperative visual acuity $(r=-0.283)$ and general health $(r=0.331)$. Regression-analysis showed no significant relation between logMAR visual acuity of the contralateral eye (mean $0.36 \pm 0.43)$ and visual functioning $(p=0.264)$. Overall trouble with vision was evaluated with a median score of 3.00, 4.00, and 3.00 for AMCH, MCMA, and UHM, respectively (Kruskal-Wallis test; $p=0.023$ ). Five patients from the three different settings stated they were bothered very much by their postoperative vision in everyday life (score 1 on the overall amount of trouble question). Four of these patients had pre-existing ocular pathology (glaucoma, ARMD, DRP or retinal detachment). The other patient suffered from an implant power error: achieved minus predicted refraction was 6.79 Diopters. Sixty one percent of the patients stated their general health did not change as a result of the cataract surgery. Yet, $31.5 \%$ of the patients felt that their general health had improved after cataract surgery (mean 3.40 \pm 0.87 ). No significant difference was found between the three settings $(p=0.881)$. Quality of life is evaluated with a mean \pm SD score of $2.22 \pm 0.45$, $2.31 \pm 0.35$, and 2.28 \pm 0.39 for $\mathrm{AMCH}, \mathrm{MCMA}$, and $\mathrm{UHM}$, respectively $(\mathrm{p}=0.524)$. In total $62.7 \%$ of the patients felt their quality of life had improved after surgery. In patients who stated their quality of life worsened postoperatively, visual acuity had not improved by surgery. Patient's opinion about postoperative quality of life was related to subjective general health $(r=0.563)$ and visual functioning $(r=0.303)$. Civil status (living together versus alone) did not have an additive predictive value on patient's opinion about the quality of life.

\begin{tabular}{|c|c|c|c|c|}
\hline & $\mathrm{AMCH}$ & MCMA & UHM & $p$-value \\
\hline Self-reported trouble with vision & 3.00 & 4.00 & 3.00 & 0.023 \\
\hline \multicolumn{5}{|l|}{$\begin{array}{l}\text { [median] } \\
\text { distribution [\%] }\end{array}$} \\
\hline None & 31.7 & 55.2 & 45.1 & \\
\hline A little & 36.6 & 36.2 & 33.4 & \\
\hline Moderate & 26.8 & 5.2 & 17.6 & \\
\hline A great deal & 4.9 & 3.4 & 3.9 & \\
\hline VF-14 [mean \pm SD] & $80.79 \pm 25.31 \#$ & $92.17 \pm 14.53 \#$ & $86.73 \pm 16.94$ & 0.012 \\
\hline $\begin{array}{l}\text { Patient's opinion about the quality of life } \\
\text { [mean } \pm S D]\end{array}$ & $2.22 \pm 0.45$ & $2.31 \pm 0.35$ & $2.28 \pm 0.39$ & 0.524 \\
\hline Subjective General Health [mean \pm SD] & $3.54 \pm 0.64$ & $3.71 \pm 0.71$ & $3.65 \pm 0.72$ & 0.483 \\
\hline \multicolumn{5}{|l|}{ Legend } \\
\hline
\end{tabular}


Satisfaction with regard to the medical outcome: The mean \pm SD satisfaction score with regard to the medical outcome was $4.12 \pm 1.17,4.51 \pm 0.79$, and $4.16 \pm 0.98$ for $\mathrm{AMCH}$, MCMA, and UHM, respectively ( $p=0.089)$. Eighty percent of the respondents scored 4 or 5 (satisfied or very satisfied) on this five-point scale measuring satisfaction with regard to the medical outcome. Nine patients stated that the results of surgery were (very) dissatisfactory for them (score 1 or 2). These patients all had a pre-existing eye-disease. By means of a series singular linear regression analysis the determinants of this satisfaction score were analysed. As proposed in the research model (Figure 2.1), visual functioning and patient's opinion about change in quality of life were mediators in the relationship between respectively objective medical outcome or general health, and the satisfaction with regard to the medical outcome (Figure 2.3).

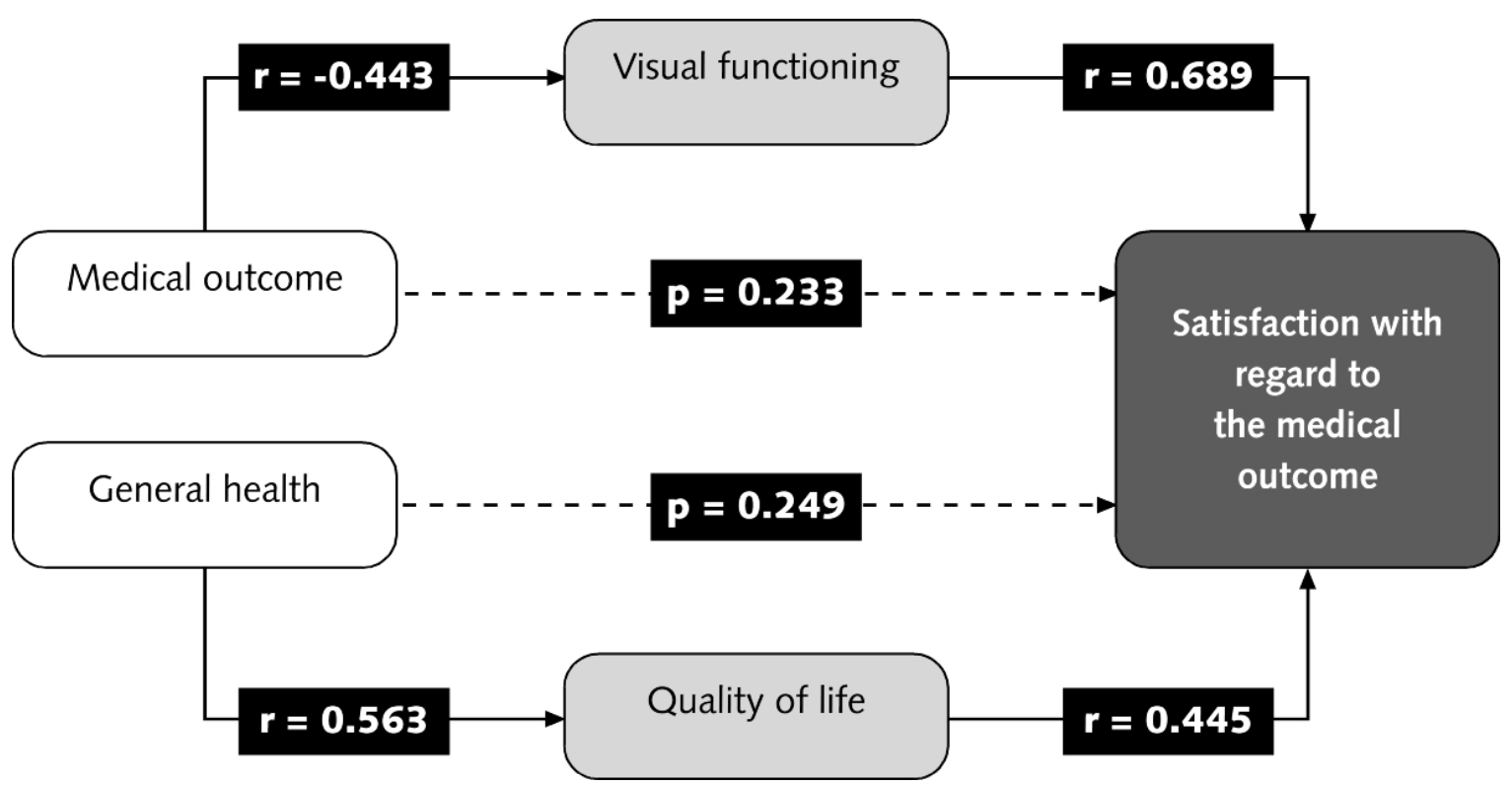

Figure 2.3: Mediation

- all correlations ( $r$ significant at the 0.01 level (two-tailed)

Perceived quality of care: The mean \pm SD satisfaction score related to the quality of care was $4.45 \pm 0.51,4.48 \pm 0.56$, and $4.34 \pm 0.65$ for $\mathrm{AMCH}, \mathrm{MCMA}$, and UHM, respectively $(p=0.43)$. The quality of care was satisfactory (score 4 or 5$)$ for $90 \%$ of all patients. The patients evaluated the waiting time for cataract surgery the least positive in comparison to the other care aspects (Table 2.5). Significant differences were found regarding the evaluation of the waiting time: $2.61 \pm 0.83,3.61 \pm 0.77$, and $2.62 \pm 0.79$ for $\mathrm{AMCH}$, MCMA, and UHM, respectively $(\mathrm{p}<0.001)$. However, the waiting time for cataract surgery did not have a predictive value for patient satisfaction with regard to care $(p=0.992)$. Patient education was appreciated with a mean score of $3.54 \pm 1.01,3.79 \pm 0.80$, and $3.43 \pm 1.02$ for $\mathrm{AMCH}, \mathrm{MCMA}$, and $\mathrm{UHM}$, respectively $(\mathrm{p}=0.120)$. Yet, $20 \%$ of the patients said to be educated poorly (score 1 and 2). The respondents evaluated patient 
counselling with a mean score of $4.25 \pm 0.54,4.50 \pm 0.49$, and $4.20 \pm 0.58$ for $\mathrm{AMCH}$, MCMA, and UHM, respectively $(p=0.010)$. Regression analysis indicated that counselling by ophthalmologists accounted for the greater part for the satisfaction with regard to the quality of care $(\mathrm{r}=0.674)$ in comparison to patient education $(\mathrm{r}=0.534)$.

\begin{tabular}{|c|c|c|c|c|}
\hline & $\mathrm{AMCH}$ & MCMA & UHM & $p$-value \\
\hline Counseling $[$ mean \pm SD] & $4.25 \pm 0.54$ & $4.50 \pm 0.49 \#$ & $4.20 \pm 0.58 \#$ & 0.010 \\
\hline Education [mean \pm SDI & $3.54 \pm 1.01$ & $3.79 \pm 0.80$ & $3.43 \pm 1.02$ & 0.120 \\
\hline Wait [mean \pm SD] & $2.61 \pm 0.83$ & $3.61 \pm 0.77 \#$ & $2.62 \pm 0.79$ & $<0.001$ \\
\hline Satisfaction with regard to care [mean \pm SD] & $4.45 \pm 0.51$ & $4.48 \pm 0.56$ & $4.34 \pm 0.65$ & 0.430 \\
\hline \multicolumn{5}{|l|}{ Legend } \\
\hline
\end{tabular}

Overall-satisfaction: Postoperatively, patients were asked to evaluate the treatment they received on a categorical visual analogue scale ranging from 1 (very bad) to 10 (excellent). The mean overall satisfaction score was $8.37 \pm 1.30,8.66 \pm 1.24$, and $8.18 \pm 1.31$ for $\mathrm{AMCH}, \mathrm{MCMA}$, and UHM, respectively ( $\mathrm{p}=0.146)$. Moreover, $91 \%$ of the respondents wanted to be treated in the same centre if they had to undergo a second eye surgery. The median "have it again" score was 4.00, 5.00, and 4.00 for AMCH, MCMA, and UHM respectively $(p=0.083)$. The following parameters were found to be predictors of the overall-satisfaction: if the preoperative expectation concerning the medical outcome came true $(\mathrm{r}=0.407)$, the satisfaction with regard to the quality of care $(\mathrm{r}=0.669)$, and the judgement about the counselling $(r=0.674)$. Patient education and counselling correlated stronger with overall-satisfaction than medical outcome $(r=0.669$ versus $r=0.543)$. 


\subsection{Discussion}

In the present study, determinants of patient satisfaction after cataract surgery were analysed. Therefore objective and subjective outcomes of cataract surgery were compared. Former studies have proven the usefulness of a patient questionnaire for outcome studies in cataract surgery. ${ }^{2,16-19}$ Various instruments (VF-14, NEI-VFQ, ADVS) have been developed to assess subjective visual disability and self-rated quality of vision in patients with ocular diseases. We have chosen the VF-14 questionnaire as developed by the Cataract PORT group, because it has proven test-retest reliability, responsiveness and international validity in cataract patients specifically. $8,9,20$ We modified the VF-14 for the Dutch situation and showed validity and reliability comparable to the international validated VF-14 instruments by Alonso et al. ${ }^{8}$

The present study revealed that cataract surgery is an effective treatment in terms of improvement of visual acuity, postoperative functioning, and patient's opinion about the quality of life. This multidimensional influence of cataract surgery was manifested in a high satisfaction rate of $80 \%$ (score 4 or 5 ) with regard to the medical outcome. These findings are comparable to former studies. ${ }^{9,21,22}$ The high rate of success achieved by modern cataract surgery ${ }^{1}$ has created a situation in which patient expectations regarding visual functioning after cataract surgery are very high, and in most cases such expectations are fulfilled. ${ }^{23}$ One has to be careful interpreting these positive results with regard to selective drop-outs. The non-response of $36 \%$ can threaten the generalizability of the results. However, when comparing non-response and response on available data (sex, setting, complications, co-morbidity, pre- and postoperative vision, and vision improvement), the two groups did not differ significantly on these factors. As stated in the introduction satisfaction studies among patients, as consumers of care, should also be directed at the quality of care given during treatment. The Medical Outcomes Study advised to include the following variables in outcome studies: clinical endpoints, functional status, general wellbeing, and satisfaction with care. ${ }^{24}$ However, only few studies have actually focussed on all four dimensions of outcome. ${ }^{15,21}$ 
This study compared three different settings, Atrium Medical Centre Heerlen (AMCH), Medical Centre Maastricht Annadal (MCMA) and University Hospital Maastricht (UHM), with respect to comparable dimensions of outcome: clinical endpoints, visual functioning, patient's opinion about the postoperative quality of life, subjective general health, and patient satisfaction with regard to the medical outcome and the care. Analysis of variance showed significant differences between the three settings with regard to age, visual functioning, patient evaluations regarding counselling, and the waiting time. Visual functioning was significantly better in MCMA $(92.17 \pm 14.53)$ in comparison to $\mathrm{AMCH}$ $(80.79 \pm 25.31 ; p=0.012)$. However, the determinants of visual functioning, postoperative visual acuity, and general health did not differ between the settings ( $p=0.710$ and $p=0.483$, respectively). While the determinant age differed significantly between the three settings, regression analysis revealed that the difference in visual functioning could not be explained by the difference in age ( $p=0.395)$. Further research is needed to explain this difference in visual functioning between the settings. Differences in evaluation of patient counselling

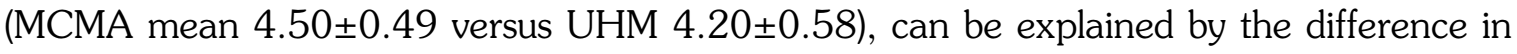
the doctor-patient relationship at the two settings. UHM is an academic hospital and the patient at this setting are treated by various doctors. In MCMA the patient are seen by only one or two ophthalmologists, which might likely be beneficial for the optimisation of a doctor-patient relationship.

During the study the patient waiting time varied significantly between the three centres. While patients visiting MCMA only had to wait three months to be treated, the waiting time at the other two settings was about one year. It is obvious that patient evaluations reflect this difference. However, no direct relationship was found between evaluation of the waiting time and patient satisfaction with regard to care. This might be explained by the supporting role of patient education; when the patient is adequately informed about the waiting time, patients are willing to accept this.

Multiple linear regression analysis showed that patient counselling has more predictive value with regard to the overall patient satisfaction than the medical outcome itself. This result emphasizes the relevance of support and patient education by hospital staff in cataract surgery. In conclusion, to improve overall patient satisfaction after cataract surgery more emphasis should be directed towards making patients' expectations regarding postoperative vision and visual functioning come true. In general, we believe that nowadays the medical outcomes of routine cataract surgery are excellent and that therefore quality improvement of this procedure should focus more extensively on patient education and counselling. 


\section{References}

1. Powe NR, Schein OD, Gieser SC et al. Synthesis of the literature on visual acuity and complications following cataract extraction with intraocular lens implantation. Arch Ophthalmol, 1994; 112: 239-252

2. Steinberg EP, Tielsch JM, Schein OD et al. The VF-14. An index of functional impairment in patients with cataract. Arch Ophthalmol, 1994; 112: 630-638

3. Javitt JC, Brenner MH, Curbow B et al. Outcomes of cataract surgery. Improvement in visual acuity and subjective visual function after surgery in the first, second, and both eyes. Arch Ophthalmol, 1993; 111: 686-691

4. Desai $P$, Reidy $A$, Minassian $D C$ et al. Gains from cataract surgery: visual function and quality of life. Br J Ophthalmol, 1996; 80: 868-873

5. Lebow JL. Research assessing consumer satisfaction with mental health treatment: A review of findings. Evaluation and Program Planning, 1983; 6: 211-236

6. Westheimer G. Scaling of visual acuity measurements. Arch Ophthalmol, 1979; 97: 327-330

7. Steinberg EP, Tielsch JM, Schein OD et al. National study of cataract surgery outcomes. Variation in 4-month postoperative outcomes as reflected in multiple outcome measures. Ophthalmology, 1994; 101: 1131-1140

8. Alonso J, Espallargues M, Anderson TF et al. International applicability of the VF-14: An index of visual function in patients with cataracts. Ophthalmology, 1997; 104: 799-807

9. Uusitalo RJ, and Tarkkanen A. Outcomes of small incision cataract surgery. J Cataract Refract Surg, 1998; 24: 212-221

10. Parasuraman A, Zeithaml VA, and Berry LL. A conceptual model of service quality and its implications for future research. Journal of Marketing, 1985; 49: 41-50

11. Babakus $E$, and Mangold WG. Adapting the SERVQUAL scale to hospital services: an empirical investigation. Health Serv Res 1992; 26: 767-786

12. Kunst $P$, Lemmink J, and Prins R. Meten en verbeteren van kwaliteit in dienstverlening Handboek Integrale Kwaliteitszorg, beleid-methodiek-toepassing, 1995

13. Tabachnick BG, and Fidell LS. Using multivariate statistics, Third Edition. Chapter 14.5.6, p. 764765. New York: HarperCollins College Publishers, 1996

14. Swanborn PG. Schaaltechnieken; theorie en praktijk van acht eenvoudige procedures. Hoofdstuk 4. Meppel:Boom, 1982

15. Bernth Petersen P. Visual functioning in cataract patients. Methods of measuring and results. Acta Ophthalmol Copenh, 1981; 59: 198-205

16. Pesudovs $\mathrm{K}$, and Coster DJ. An instrument for assessment of subjective visual disability in cataract patients. Br J Ophthalmol, 1998; 82: 617-624

17. Carta $A$, Braccio $L$, Belpoliti $M$ et al. Self-assessment of the quality of vision: association of questionnaire score with objective clinical tests. Curr Eye Res, 1998; 17: 506-511.

18. Mangione, C.M., Philips, R.S., Seddon, J.M. et al., Development of the 'Activities of Daily Vision Scale'. A measure of visual functional status. Med Care, 1992. 30(12): p. 1111-1126

19. Mangione $C M$, Lee PP, Pitts J et al. Psychometric properties of the national eye institute visual function questionnaire (NEI-VFQ). Arch Ophthalmol, 1998; 116: 1496-1504 
20. Cassard SD, Patrick DL, Damiano AM et al. Reproducibility and responsiveness of the VF-14. An index of functional impairment in patients with cataracts. Arch Ophthalmol, 1995; 113: 15081513

21. Legro MW. Quality of life and cataracts - A review of patient-centered studies of cataract surgery outcomes. Ophthalmic Surg, 1991; 22: 431-443

22. Tielsch JM, Steinberg EP, Cassard SD et al. Preoperative functional expectations and postoperative outcomes among patients undergoing first eye cataract surgery. Arch Ophthalmol, 1995; 113: 1312-1318

23. Schein OD, Steinberg EP, Cassard SD et al. Predictors of outcome in patients who underwent cataract surgery. Ophthalmol, 1995; 102: 817-823

24. Tarlov AR, Ware JE Jr, Greenfield S et al. The Medical Outcomes Study. An application of methods for monitoring the results of medical care. JAMA, 1989; 262: 925-930 


\section{Chapter $3 a$}

\section{Quality of care from the perspective of the cataract patient: the QUOTE-Cataract questionnaire}

Published as Marjan D. Nijkamp, Herman J. Sixma, Hennie Afman, Frans Hiddema, Steven A. Koopmans, Bart van den Borne, Fred Hendrikse, Rudy M.M.A. Nuijts. "Quality of care from the perspective of the cataract patient: QUOTE-Cataract questionnaire"; Journal of Cataract and Refractive Surgery 2002; 28: 1924-1931. 


\section{Abstract}

\section{Purpose}

Valid assessments of quality of care should not only focus on objective and subjective outcome parameters, but should also measure the process and structure of care. Aim of this study is to examine the potential of a questionnaire that measures the quality of care from the perspective of cataract patients, in quality assurance or improvement programs.

\section{Methods}

Cataract patients $(n=540)$ who had cataract surgery 2-8 months ago rated 31 quality of care aspects on importance (range: 0 'not important' to 10 'extremely important') and performance (0 'yes', 1 'no'). An arithmetic combination of the two parameters generates quality impact factors $(\mathrm{Q}$, range: 0 indicating the best quality of care to 10 , this aspect needs improvement according to every respondent), which are useful in identifying bottlenecks in your quality of care.

\section{Results}

Aspects concerning patient education were scored as the most important quality aspects by the patients. Top 3 of quality impact factors was: inform patients what to do in emergency situations $(\mathrm{Q}=3.39)$, inform patients about the risks of treatment $(\mathrm{Q}=3.00)$, and minimise the number of ophthalmologists to one per patient $(Q=2.79)$.

\section{Conclusions}

The QUOTE-cataract is an effective instrument to measure quality of care in cataract surgery at different hospital settings and provides practical information for quality assurance programs. 


\section{3a.1 Introduction}

Patient satisfaction after cataract surgery is particularly determined by the satisfaction about the doctor's counselling. ${ }^{1}$ However, studies regarding patient satisfaction after cataract surgery focused mainly on clinical outcomes and vision related functioning. ${ }^{2-6}$ Assessing the quality of ophthalmic services from the patients' perspective should consider all components that contribute to the quality of these services: objective outcome criteria (functional tests), subjective outcome criteria (patient satisfaction), and criteria related to the way the services are provided (structure and process of care). ${ }^{3,7-9}$ To respond to this need, an instrument (QUOTE-cataract questionnaire) that measures quality of care from the perspective of cataract patients was developed.

The development process of the QUOTE-cataract instrument - the acronym 'QUOTE' stands for Quality Of care Through the Users' Eyes - closely resembles the work that was carried out regarding other QUOTE-instruments as described by Sixma et al. ${ }^{10-12}$ The QUOTE-family of instruments can be seen as a representative of a new generation quality of care instruments that focus on 'reports' rather than highly subjective ratings of excellence or patient satisfaction. ${ }^{13}$ As a result these evaluations are related to patient's specific needs and expectations. All QUOTE-instruments include a generic part, which is applicable to a range of users of health care (i.e. patients), and a disease-specific part consisting of care aspects related to a specific patient group. The generic part includes a structure dimension (e.g. continuity of care, accessibility, costs, and assessment procedures) and a process dimension (e.g. courtesy, professional competence, information, and perceived autonomy). ${ }^{12}$ The QUOTE-cataract was developed as a self-administered measure, using both qualitative and quantitative research methods. For validity reasons patients were involved in the development process of the instruments from the very beginning. ${ }^{14}$

The QUOTE concept has been applied to various groups of patients, e.g. rheumatic, COPD, diabetic, and AIDS patients. ${ }^{10,11,15-17}$ These disease-specific QUOTE questionnaires have shown good validity and reliability and provide practical information for quality assurance policies. ${ }^{10,11,17}$ The reliability of the QUOTE-cataract was adequate (Cronbach's alpha $=0.80$ ) and the psychometric properties will be reported in a separate paper.

QUOTE-questionnaires can be used in quality assessment studies to evaluate the quality of health care services from the patients' perspective in a very general way, but also in studies that aim at quality improvement at the level of specific quality aspects. ${ }^{15}$ The aims of this paper are threefold: (1) to describe the development of an instrument measuring quality of care from the perspective of cataract patients, (2) to present the results from a multicentre study of patient's reports about the relative importance and performance of quality of care aspects at the department of ophthalmology, and (3) to examine the potential of the QUOTE-cataract instrument in quality assurance and improvement programs at three hospital settings. 


\section{3a.2 Patients and Methods}

\section{3a.2.1 Patients}

Cataract patients who were involved in the development process of the questionnaire were recruited from the department of ophthalmology at University Hospital Maastricht and at University Hospital Groningen $(n=74)$. These patients were comparable to the respondents of the multicentre study regarding socio-demographic characteristics and in- and exclusion criteria. The study population of the quantitative multicentre study consisted of three subgroups of patients who had recently undergone cataract surgery. Two groups of patients were treated at an academic hospital: University Hospital Maastricht (UHM, n=166) and University Hospital Groningen (UHG, n=130), the other group of patients was treated at a disease specific hospital, the Rotterdam Eye Hospital (REH, $n=244)$. All cataract surgeries took place on an outpatient basis using the phacoemulsification technique with implantation of an intraocular lens.

The mean age \pm standard deviation of the patients was $71.8 \pm 8.0(\mathrm{UHM}) ; 73.9 \pm 9.2$ (UHG), and $71.9 \pm 9.3(\mathrm{REH})$, respectively. The male-female ratio was 0.6 for all three settings. At REH more patients were categorised as medium/higher educated' in comparison to UHM and UHG (Kruskal-Wallis, $\mathrm{p}<0.01$ ). General health was scored 'good' according to the majority of the patients, but differed significantly between the three settings (Kruskal-Wallis, $\mathrm{p}<0.01$; see Table 3a.1). Criteria for participation in the study were: 1). treated for age-related cataract, 2). had no ocular co-morbidity, and 3). had first or second eye cataract surgery 2 to 8 months ago. Before inclusion in the study, all patients were informed and signed a consent form. 


\begin{tabular}{|c|c|c|c|}
\hline & UHM & UHG & REH \\
\hline \multicolumn{4}{|l|}{ Age } \\
\hline $47-64$ & $25(15.1)$ & $23(17.7)$ & $52(21.3)$ \\
\hline $65-74$ & $72(43.4)$ & $31(23.8)$ & 77 (31.6) \\
\hline $75-84$ & $64(38.6)$ & $55(42.3)$ & $98(40.2)$ \\
\hline $85+$ & $3(1.8)$ & $14(10.8)$ & $9(3.7)$ \\
\hline \multicolumn{4}{|l|}{ Sex } \\
\hline Men & $61(36.7)$ & $50(38.5)$ & $94(38.5)$ \\
\hline Women & $105(63.3)$ & $80(61.5)$ & $150(61.5)$ \\
\hline \multicolumn{4}{|l|}{ Education* } \\
\hline Low (primary school) & $90(54.4)$ & $73(56.2)$ & $85(34.8)$ \\
\hline Medium-high & $63(38)$ & $42(32.2)$ & $139(57)$ \\
\hline Unknown/no answer & $13(7.8)$ & $15(11.5)$ & $20(8.2)$ \\
\hline \multicolumn{4}{|l|}{ Subjective health* } \\
\hline Excellent & $8(4.8)$ & $8(6.2)$ & $32(13.1)$ \\
\hline Very good & $18(10.8)$ & $22(16.9)$ & 44 (18) \\
\hline Good & $89(53.6)$ & $62(47.7)$ & $133(54.5)$ \\
\hline Fair & $46(27.7)$ & $34(26.2)$ & $31(12.7)$ \\
\hline Poor & $1(0.1)$ & $2(1.5)$ & $0(0)$ \\
\hline
\end{tabular}

\section{3a.3.2 Development of the Questionnaire}

Four separate focus group interviews with cataract patients (total $n=24$ ) generated a pool of quality of care aspects as possible indicators for quality of care, and selected the vocabulary used in the questionnaires. ${ }^{18,19}$ Interviews lasted approximately two hours and were chaired by two experienced moderators. The sessions were audiotaped and then transcribed. Analysis of the transcriptions by two independent researchers (from Maastricht University and NIVEL) resulted in 45 quality of care aspects.

Subsequently the number of aspects was reduced to 32 by a concept mapping procedure, in which cataract patients $(n=50)$ were asked to arrange the quality of care aspects in order of importance and similarity. The software supporting the concept mapping analysis procedure uses multidimensional scaling and clustering algorithms to produce twodimensional map representations of the location of the aspects, the relative weight of their ratings, clusters of aspects, and the relative strength of these clusters. ${ }^{20}$ 
The development of the QUOTE-cataract based upon these qualitative and quantitative methods was presented in detail on 5 September 1999 at the XVIIth ESCRS congress in Vienna and on 15 June 2000 at the XIIIth Congress of the German Society of Medical Psychology in Aachen. The 32 remaining aspects were included in a pilot-study among 43 cataract patients. This pilot-study resulted in minor changes in formulation of the aspects, and one item was deleted based upon its ambiguousness.

\section{3a.3.3 Scoring and use of the QUOTE-cataract}

In the final QUOTE-cataract questionnaire, as used in the multicentre study, importance and perceived performance were measured by 31 quality of care aspects (15 generic and 16 specific aspects). However, at UHG four disease-specific items were not included in the QUOTE-cataract because they were characteristic for UHM and REH (aspect 2.2, 2.3, 2.12, 2.14, see Table 3a.2). Participating patients were asked to rate the relative importance of the different aspects (e.g. "My ophthalmologist (or the department of Ophthalmology) should inform me clearly about what I may and may not do after cataract surgery') and to rate the performance of the health care services on each of the quality aspects (e.g. 'My ophthalmologist (or the department of Ophthalmology) informed me clearly about what I may and may not do after cataract surgery'). 


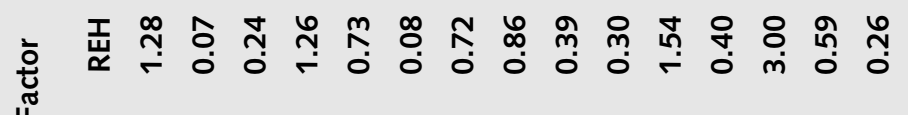
芯

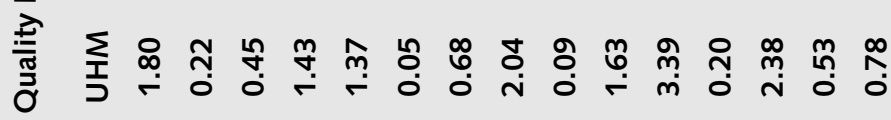

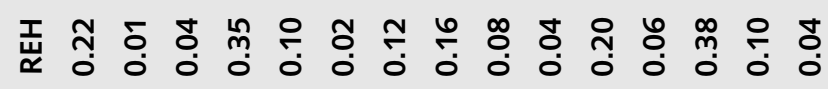
壱

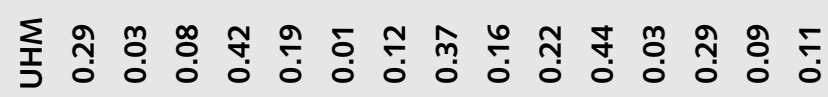
至 感

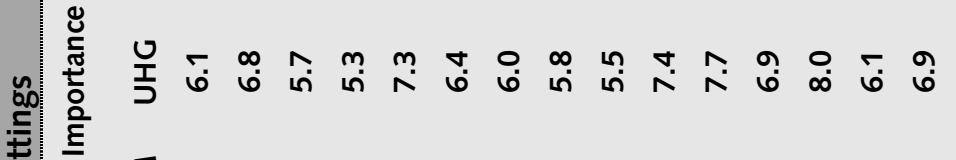

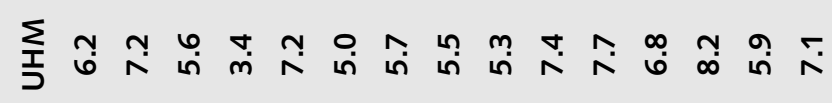




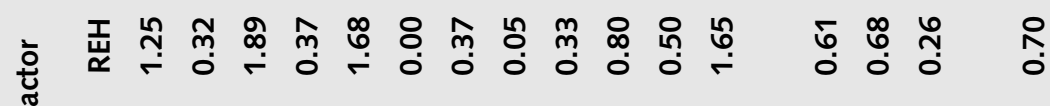

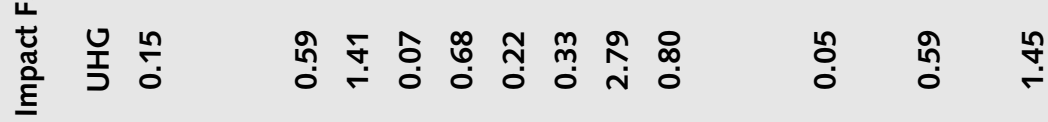

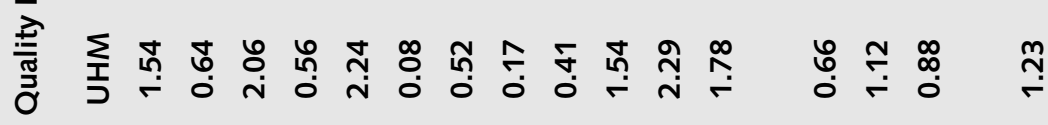

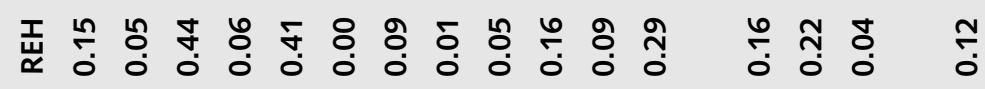

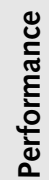

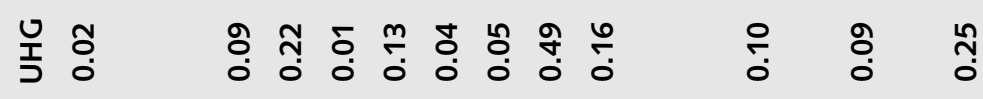

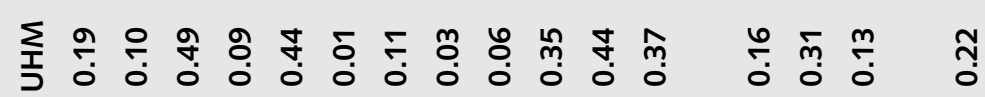

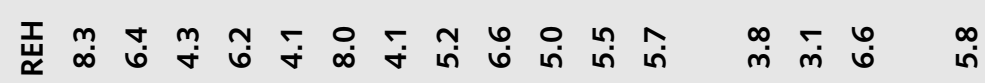
บำ

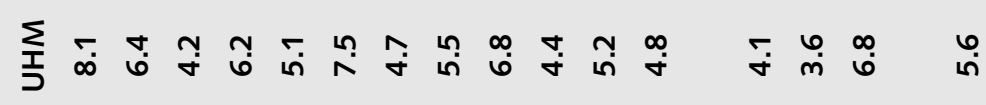
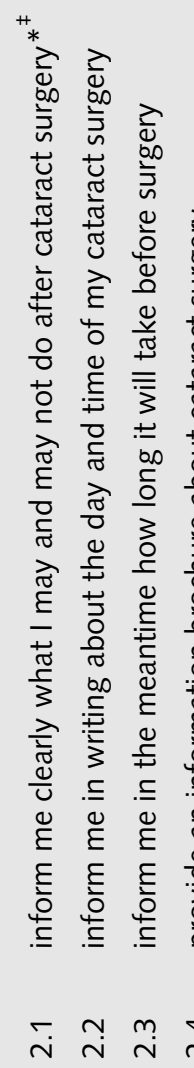
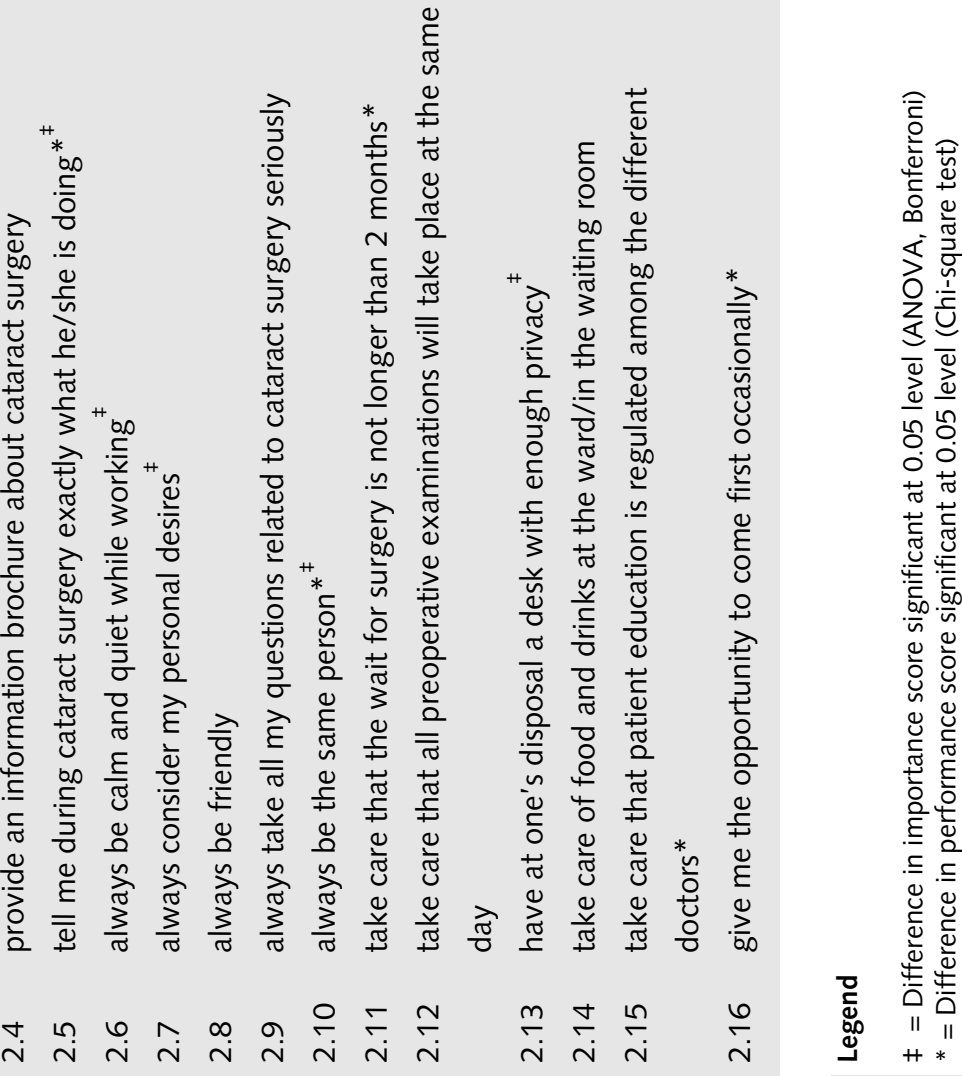
Scores for the importance categories ( $1=$ 'not important', 2= 'fairly important', 3= 'important', and $4=$ 'extremely important') were calculated by linear transformation of standardized values (Z-scores) to values between 0 and $10 .{ }^{13,21,22}$ Response options for perceived performances ( 1 = 'no', 2 = 'not really', 3 = 'on the whole, yes', and 4 = 'yes') were dichotomised into respondents who did (values 3 and 4 were recoded into value 0 ) or did not (values 1 and 2 were recoded into value 1) perceive the particular quality aspect as being performed by the ophthalmologist or the department of ophthalmology. Performance scores were expressed as a proportion of patients who reported the aspect to be absent. ${ }^{11,17}$ In the best situation, all quality of care aspects would receive a 0.00 performance score, indicating that nobody reported a particular aspect absent. Scores between 0.00 and 0.10 hardly need any improvement, and can therefore be regarded as 'optimal'. Individual (i) performance (P) and importance scores (I) on different quality of care aspects (j) are used to calculate quality impact factors $(\mathrm{Q})$, applying the formula $\mathrm{Qij}=\mathrm{Pij}$ * Iij. Quality impact factors can be interpreted as a weighted performance score. Theoretically a quality impact score can vary from 0 to 10 ('0' means: $0 \%$ of the patients reported this particular aspect to be absent, indicating the best possible quality of care; ' 10 ' means: All of the respondents think that this aspect is extremely important and $100 \%$ of the patients report that it needs improvement). Given that users of health and social care services are usually highly satisfied, high impact scores refer to values above ' 1.0 '. ${ }^{12,23} \mathrm{~A}$ value of ' 1 ' is based on an average importance score of 6.0 and a corresponding performance score of 0.16 , which indicates that $16 \%$ of the respondents did not receive that particular service and demonstrates a sufficient need for improvement. In this way bottle necks and benchmarks, pointing toward both deficient and outstanding practices, can be formulated.

Sixma et al. described three different strategies to use the QUOTE questionnaire in quality assurance and improvement programs. ${ }^{11}$ Two strategies were applied to the three hospitals in this study. Questions included for methodological reasons referred to perceived health and socio-demographic characteristics (Table 3a.1). The importance of information on health status for patient satisfaction was presented in previous studies. ${ }^{24}$ Questions regarding perceived health are derived from the Medical Outcome Study SF-36 questionnaire. ${ }^{25}$ In order to ensure a high response rate, prepaid envelopes and a cover letter guaranteeing patients' confidentiality were enclosed.

\section{3a.3.4 Statistical analysis}

The instrument QUOTE-cataract should be useful and applicable to clinical practice. The feasibility of the instrument is indicated by descriptive statistics of importance scores, performance scores, and the resulting quality impact factors at three different hospital settings. Differences in importance scores between the three settings were tested using analysis of variance (ANOVA) with Bonferroni correction. Differences in performance scores, which are based upon proportions, were analysed using the Chi-square test. Pvalues lower than 0.05 were considered significant. Analyses were performed using SPSS $10.0^{\circledR}$ for Windows (Chicago II) software. 


\section{3a.4 Results}

\section{3a.4.1 Response to questionnaires}

The total number of completed questionnaires returned was 166 (response rate 92.7\%), 30 (response rate 65\%) and 244 (response rate 74.4\%) for UHM, UHG and REH respectively (Chi-square test, $\mathrm{p}<0.05$ ).

\section{3a.4.2 Importance rates}

Not all quality aspects included in the QUOTE-cataract were valued equally on importance by the cataract patients. Some quality aspects were highly valued, whereas others were judged as less important or even unimportant by some patients (Table 3a.2). The mean importance score was $6.0 \pm 1.22$ (range from 0 to 10). According to the patients in this multicentre study top 3 of importance scores in quality of care was (3 settings aggregated to calculate mean importance score): 'tell me clearly what I may and may not do after cataract surgery' (mean I=8.0), 'always inform me about the risks of a treatment' (mean I=8.0), and 'tell me what to do in case of emergency' (mean I=7.7). The three aspects with the lowest importance scores were 'provide food and drinks at the ward/in the waiting room' (mean $\mathrm{I}=3.4$ ), 'never let me wait in the waiting room longer than 15 minutes' (mean I=4.1), and 'inform me in the interim how long it will be before surgery' (mean $\mathrm{I}=4.3$ ). Overall, the three settings scored similar on distribution of the items regarding importance (ANOVA, $\mathrm{p}=0.13$ ). However, on item level differences were found in importance scores concerning aspects 1.4, 1.6, 1.15, 2.1, 2.5, 2.6, 2.7, 2.10, and 2.13 (ANOVA, Bonferroni correction).

\section{3a.4.3 The performance component}

The performance score of Table 3a.2 relates to the proportion of patients that reported that particular aspects were not performed as stated. The three settings differed regarding the aspects that had the highest performance scores. UHM scored highest on the following aspects: 'tell me what to do in case of emergency' $(\mathrm{P}=0.44)$ and 'ensure that the wait for surgery is not longer than two months' $(\mathrm{P}=0.44)$. Furthermore, 'inform me in the interim how long it will be before surgery' $(\mathrm{P}=0.49,0.44)$ and 'tell me during cataract surgery exactly what he/she is doing' $(\mathrm{P}=0.44,0.41)$ were scored relatively high at both UHM and REH. UHG scored highest on 'always be the same person' $(\mathrm{P}=0.49)$ and 'never let me wait in the waiting room longer than 15 minutes' $(\mathrm{P}=0.35)$. Aspects that could be categorised as optimal $(\mathrm{P}<0.10)$ at all three settings were: 'take me seriously', 'keep appointments punctually', 'have a room accessible for wheelchair users/disabled', 'provide an information brochure about cataract surgery', 'always be calm and quit while working', 'always be friendly', and 'always take all my questions related to cataract surgery seriously'. Differences could be found in 15 out of 31 performance scores between the three settings (Chi-square, see Table 3a.2). 


\section{3a.4.4 Quality impact factors}

The top five of quality impact factors for the 3 settings is represented in Table 3a.3. According to these quality impact factors, efforts to improve the quality of care should focus on patient education especially (always inform me about the risks of a treatment, tell me during cataract surgery exactly what he/she is doing). These aspects show impact factors well above 1 at all three settings. When looking at the three settings separately, quality improvement programmes should be directed at e.g., telling patients what to do in emergency situations $(Q=3.39)$, minimising the number of care givers to one ophthalmologist per patient $(\mathrm{Q}=2.79)$, and informing patients about the risks of a treatment $(\mathrm{Q}=3.00)$ at $\mathrm{UHM}, \mathrm{UHG}$, and $\mathrm{REH}$ respectively. On the other hand, an ophthalmologist who is calm and quiet while working is judged as relatively important (mean I=7.6), but here the needs of patients are almost completely met by the performance of the ophthalmologist or the department of ophthalmology $(\mathrm{P}=0.00-0.01)$. There is hardly any need for further improvement regarding this aspect $(\mathrm{Q}=0.00-0.08$, see third column in Table 3a.2).

\begin{tabular}{|c|c|c|c|}
\hline & UHM & UHG & REH \\
\hline 1 & $\begin{array}{l}\text { tell me what to do in case of } \\
\text { emergency }(Q=3.39)\end{array}$ & $\begin{array}{l}\text { always be the same person } \\
(\mathrm{Q}=2.79)\end{array}$ & $\begin{array}{l}\text { always inform me about the risks } \\
\text { of a treatment }(Q=3.00)\end{array}$ \\
\hline 2 & $\begin{array}{l}\text { always inform me about the } \\
\text { risks of a treatment }(\mathrm{Q}=2.38)\end{array}$ & $\begin{array}{l}\text { never let me wait in the waiting } \\
\text { room longer than } 15 \text { minutes } \\
(\mathrm{Q}=1.86)\end{array}$ & $\begin{array}{l}\text { inform me in the interim how long } \\
\text { it will be before surgery }(\mathrm{Q}=1.89)\end{array}$ \\
\hline 3 & $\begin{array}{l}\text { ensure that the wait for surgery } \\
\text { is not longer than two months } \\
(\mathrm{Q}=2.29)\end{array}$ & $\begin{array}{l}\text { give preferential treatment } \\
\text { occasionally }(\mathrm{Q}=1.45)\end{array}$ & $\begin{array}{l}\text { tell me during cataract surgery } \\
\text { exactly what he/she is doing } \\
(Q=1.68)\end{array}$ \\
\hline 4 & $\begin{array}{l}\text { tell me during cataract surgery } \\
\text { exactly what he/she is doing } \\
(\mathrm{Q}=2.24)\end{array}$ & $\begin{array}{l}\text { always inform me about the } \\
\text { risks of a treatment }(\mathrm{Q}=1.44)\end{array}$ & $\begin{array}{l}\text { ensure that all preoperative } \\
\text { examinations will take place on } \\
\text { the same day }(Q=1.65)\end{array}$ \\
\hline 5 & $\begin{array}{l}\text { inform me in the interim how } \\
\text { long it will be before surgery } \\
(Q=2.06)\end{array}$ & $\begin{array}{l}\text { tell me during cataract surgery } \\
\text { exactly what he/she is doing } \\
(\mathrm{Q}=1.41)\end{array}$ & $\begin{array}{l}\text { tell me what to do in case of } \\
\text { emergency }(Q=1.54)\end{array}$ \\
\hline
\end{tabular}




\section{3a.4.5 Strategies in quality assurance or improvement using the QUOTE- cataract}

To illustrate the use of the QUOTE-cataract in quality assurance or improvement programs, two strategies as described by Sixma et al. were applied to the three hospital settings. ${ }^{11}$ According to Table 3a.3, UHM patients scored rather high on the quality of care aspect 'tell me what to do in case of emergency' with a $\mathrm{Q}$ of 3.39 as a result of a relatively high importance rate (7.7) and a relatively high performance score (0.44). This aspect would have highest priority in a quality improvement program at UHM using the quality impact factor approach. The most important quality of care aspects with performance scores $>$ 0.10 were summarized in Table 3a.4. In this case 'always inform me about the risks of a treatment' would get highest priority at UHM $(\mathrm{I}=8.2, \quad \mathrm{P}=0.18)$ and UHG ( $\mathrm{I}=8.0, \mathrm{P}=0.18)$, and 'inform me clearly what I may and may not do after cataract surgery' would get the highest priority at $\mathrm{REH}(\mathrm{I}=8.3, \mathrm{P}=0.15)$ in a quality improvement program directed at optimal quality of care.

\begin{tabular}{|c|c|c|c|}
\hline & UHM & UHG & REH \\
\hline 1 & $\begin{array}{l}\text { always inform me about the } \\
\text { risks of a treatment }(I=8.2 \text {, } \\
P=0.29)\end{array}$ & $\begin{array}{l}\text { always inform me about the } \\
\text { risks of a treatment }(I=8.0 \text {, } \\
P=0.18 \text { ) }\end{array}$ & $\begin{array}{l}\text { inform me clearly what I may and } \\
\text { may not do after cataract surgery } \\
(\mathrm{I}=8.3, \mathrm{P}=0.15)\end{array}$ \\
\hline 2 & $\begin{array}{l}\text { inform me clearly what I may } \\
\text { and may not do after cataract } \\
\text { surgery }(I=8.1, P=0.19)\end{array}$ & $\begin{array}{l}\text { tell me what to do in case of } \\
\text { emergency }(I=7.7, P=0.14)\end{array}$ & $\begin{array}{l}\text { always inform me about the risks } \\
\text { of a treatment }(I=7.9, P=0.38)\end{array}$ \\
\hline 3 & $\begin{array}{l}\text { tell me what to do in case of } \\
\text { emergency }(I=7.7, P=0.44)\end{array}$ & $\begin{array}{l}\text { know my health status very well } \\
(I=7.4, P=0.15)\end{array}$ & $\begin{array}{l}\text { tell me what to do in case of } \\
\text { emergency }(I=7.7, P=0.20)\end{array}$ \\
\hline 4 & $\begin{array}{l}\text { know my health status very } \\
\text { well }(I=7.4, P=0.22)\end{array}$ & $\begin{array}{l}\text { tell me during cataract surgery } \\
\text { exactly what he/she is doing } \\
(\mathrm{I}=6.4, \mathrm{P}=0.22)\end{array}$ & $\begin{array}{l}\text { give me good directions for use of } \\
\text { the prescribed medicine }(I=7.3 \text {, } \\
P=0.10)\end{array}$ \\
\hline 5 & $\begin{array}{l}\text { give me good directions for use } \\
\text { of the prescribed medicine } \\
(\mathrm{I}=7.2, \mathrm{P}=0.19)\end{array}$ & $\begin{array}{l}\text { allow me to decide on which } \\
\text { treatment/help to get }(I=6.1 \text {, } \\
P=0.14)\end{array}$ & $\begin{array}{l}\text { be easily accessible by phone } \\
(I=6.0, P=0.12)\end{array}$ \\
\hline
\end{tabular}




\section{3a.5 Discussion}

One of the strengths of the QUOTE-cataract instrument is that not only does it attempt to overcome the conceptual and methodological problems associated with patient satisfaction surveys, but also patients were directly involved in its development. The QUOTE-cataract focused on 'reports' rather than highly subjective ratings of satisfaction. ${ }^{21}$ The measurement instrument included generic (applicable to all users of health care) and disease-specific (typically related to a specific disease e.g. cataract) aspects, which were derived from qualitative and quantitative research methods.

The questionnaire as developed in Maastricht and Groningen was shown to be applicable to the Rotterdam Eye Hospital. However, 4 aspects seemed to be institute-specific for UHM and REH and were found to be inapplicable to patients from the UHG. The higher response rate at UHM (92.7\% versus 65\% and 74.4\%) could be explained by the way in which the surveys were distributed. At UHM the questionnaires were hand-delivered to patients in the hospital, whereas patients at UHG and REH received them by mail. Despite this difference, the response rate for all settings is quite satisfactory taking into account the patient's mean age and the expected response to postal questionnaires. ${ }^{21,22}$ The overrepresentation of women (60\%) in this study was normal for this age-group. ${ }^{1,21}$

The feasibility of the questionnaire was indicated by descriptive statistics of University Hospital Maastricht, University Hospital Groningen, and the Rotterdam Eye Hospital. Overall, patient's importance rates for the quality of care aspects were similar at the three settings (ANOVA, $\mathrm{p}=0.13$ ). The three aspects with the highest importance scores were all related to dissemination of information, which emphasises the importance of good patient education according to the opinion of patients. Patient education was emphasized before as an important quality of care aspect in cataract surgery. ${ }^{1}$ The aspects with the highest performance scores, indicating a need for improvement, differed between the three settings (Chi-square, $\mathrm{p}<0.01$ ). Differences could be found in performance scores in 15 out of the 31 aspects, leading to differences in what should be on the agenda for quality improvement from a patient's perspective (=quality impact index) in setting-specific quality improvement projects. At both academic settings (UHM and UHG) one third to half of the patients indicated that their ophthalmologist was not the same person every visit. This could be explained by the training of residents and medicine students at academic settings. Moreover, this study showed that waiting times for cataract surgery of more than two months is reported more frequently at UHM $(\mathrm{P}=0.44)$ in comparison to UHG $(\mathrm{P}=0.16)$ and the REH $(\mathrm{P}=0.09)$. Future research should find out the reason for this difference. The first straightforward strategy in quality assurance and improvement programs is to use sorted quality impact factors, which indicate the need for improvement in descending order per quality of care aspect and per setting. The second method for policy making starts from the idea that quality of care should be optimal for the most important quality of care aspects. Optimal was defined by at least $90 \%$ positive evaluations $(\mathrm{P}<0.10)$. 
These strategies for policy planning advised the head of the department of ophthalmology at the University Hospital Maastricht to focus on improving the care regarding the information patients get in case of emergency, and to motivate ophthalmologists to always inform cataract patients about the risks of the treatment. On the other hand, managers at the University Hospital Groningen should improve their information regarding the risks about the treatment and reduce the number of ophthalmologists to one per patient. At the Rotterdam Eye Hospital highest priority in a quality assurance or improvement program should be directed at the information supply regarding the risks of treatment, and to tell patients clearly what they may and may not do after cataract surgery. However, one should not expect that quality improvement programs using the QUOTE-cataract can result in optimal quality of care regarding every single aspect. Verkruisen suggested the law of preservation of discontent in this context: "The medical care people desire adjusts in such a way that in a given population there are always 15 to $30 \%$ who are dissatisfied with their contacts with medical practitioners". Verkruisen demonstrated this law by reports of patients on individual and macro-level who adjust their level of desired treatment as a result of which they keep their level of dissatisfaction relatively constant. ${ }^{26}$ Significant differences in performance scores, and therefore differing quality impact factors, indicate responsiveness of the QUOTE-cataract instrument.

Future research will have to clarify not only the relationship between the QUOTE-cataract and other quality of care instruments (criterion validity), and differences within subgroups of cataract patients (e.g. male/female, subjective health and education level), but also this responsiveness of the questionnaire with respect to changes in structure and process of health care services as a result of quality management. In addition, a follow-up study is currently being conducted to add an outcome-component to the QUOTE-cataract questionnaire. As stated in the introduction, an ideal questionnaire should include aspects related to the complete triad of quality of care (process, structure and outcome). As described by Calnan et al. the QUOTE-instruments could be used on a regular basis to review and monitor changes in quality standards and to evaluate service changes and innovations. ${ }^{12}$ As presented in this article it could also be used to compare different settings regarding their priorities in and perceptions of the quality of care. It should be recognised that many ophthalmologists would prefer a questionnaire less resource intensive that provides an adequate quick scan of the quality of care at their department. From a patient's perspective a shorter version of the QUOTE-cataract would be less arduous and timeconsuming for the patients to complete. This QUOTE-cataract 'checklist' should contain the core indicators of the QUOTE-cataract instrument representing all subscales, and should be tested on reliability, validity and feasibility at the local department. The full 31-item version as suggested in this paper, possibly with some local topics added, is recommended if the instrument is to be used at the start of a continuous quality assurance and improvement program.

In addition, it is important that the instrument is reviewed regularly so that it remains sensitive to the needs and experiences of both patient and ophthalmologist. ${ }^{12}$ 


\section{References}

1. Nijkamp MD, Nuijts RMMA, Borne van den HW et al. Determinants of patient satisfaction after cataract surgery in three different settings. J Cataract Refract Surg 2000; 26:1379-1388

2. Bloom BS, Krueger N. Cost and quality effects of outpatient cataract removal. Inquiry 1988; 25 : 383-387

3. Desai P. Assessing ophthalmic services. Eye 1995; 9: 677-678

4. Donderi DC, Murphy SB. Predicting activity and satisfaction following cataract surgery. J Behav Med 1983; 6: 313-328

5. Hart PM, Chakravarthy U, Stevenson MR. Questionnaire-based survey on the importance of quality of life measures in ophthalmic practice. Eye 1998;12:124-126

6. Steinberg EP, Tielsch JM, Schein OD et al. The VF-14: An index of functional impairment in patients with cataract. Arch Ophthalmol 1994;112: 630-638

7. Spaeth GL. Why measuring quality of care, a vitally important task, is presently being done improperly. Ophthalmic surgery 1989; 20: 165-167

8. Lledo R, Rodriguez T, Fontenla JR et al. Cataract surgery: an analysis of patient satisfaction with medical care. Int Ophthalmol 1998-99; 22: 227-232

9. Pankow L. Seeing through the patient's eyes. J Am Optom Assoc 1992; 63: 678-679

10. Sixma HJ, Kerssens JJ, Campen $C$ van et al. Quality of care from the patients' perspective: from theoretical concept to a new measuring instrument. Health Expectations 1998a; 1: 82-95

11. Sixma HJ, Campen van C, Kerssens JJ et al. De QUOTE-vragenlijsten - Kwaliteit van zorg vanuit patiëntenperspectief; vier nieuwe meetinstrumenten. Utrecht, the Netherlands, NIVEL Nederlands instituut voor onderzoek van de gezondheidszorg, 1998b

12. Calnan S, Sixma HJ, Calnan MW et al. Quality of local authority occupational therapy services: developing an instrument to measure the user's perspective. British Journal of Occupational Therapy 2000; 63: 155-162

13. Cleary DC, Edgman-Levitan S. Health care quality; incorporating consumer perspectives. J Am Med Assoc 1997; 278:1608-1612

14. Delbanco TL. Quality of care through the patient's eyes. BMJ 1996; 313: 832-833

15. Campen van $\mathrm{C}$, Sixma $\mathrm{HJ}$, Kerssens $\mathrm{JJ}$ et al. Assessing noninstitutionalized asthma and COPD patients' priorities and perceptions of quality of health care: The development of the QUOTECNSLD instrument. J Asthma 1997; 34: 531-538

16. Sixma HJ, Spreeuwenberg PMM, Pasch van de MAA. Patient satisfaction with the general practitioner - A two-level analysis. Med Care 1998; 36: 212-229

17. Campen van $\mathrm{C}$, Sixma HJ, Kerssens JJ et al. Assessing patients' priorities and perceptions of the quality of health care: The development of the QUOTE-rheumatic -patients instrument. British Journal of Rheumatology 1998; 37:362-367

18. Kitzinger J. The methodology of Focus Groups: the importance of interaction between research participants. Soc Health Illness 1994; 16: 103-121

19. Witkin BR, Altschuld JW. Planning and conducting needs assessment. Thousand Oaks, CA, SAGE Publications, 1995

20. Trochim WMK. The Concept System (software and manual). Ithaca, NY, Concept systems, 1993

21. Sixma HJ, Campen van C, Kerssens JJ et al. Quality of care from the perspective of elderly people: The QUOTE-Elderly instrument. Age Ageing 2000; 29: 173-178 
22. Swanborn PG. Methoden van sociaal-wetenschappelijk onderzoek. Meppel, the Netherlands, Boom, 1993

23. Schouten GM, Sixma HJ, Friele RD. Kwaliteit van zorg vanuit het perspectief van mensen met diabetes. Utrecht, the Netherlands, Netherlands institute of primary health care, 2000

24. Harris LE, Swindle RW, Mungai SM et al. Measuring patient satisfaction for quality improvement. Med Care 1999; 37: 1207-1213

25. Ware JE, Snow KK, Kosinski M et al. SF36 Health Survey; Manual and Interpretation Guide. Boston, MA, The Health Institute - New England Medical Centre, 1993

26. Verkruisen WG. Dissatisfied patients: their experiences, interpretations and actions. Groningen, the Netherlands, University of Groningen, 1993 
Chapter $3 b$

\section{Quality of care from the perspective of the cataract patient: the reliability and validity of the QUOTE- cataract}

Published as M.D. Nijkamp, H.J.M. Sixma, H. Afman, F. Hiddema, S.A. Koopmans, B. van den Borne, F. Hendrikse, R.M.M.A. Nuijts. "Quality of care from the perspective of the cataract patient: the reliability and validity of the QUOTE-Cataract"; British Journal of Ophthalmology 2002; 86: 840-842. 


\section{Abstract}

\section{Background/aims}

To assess reliability and validity of the QUOTE-cataract: a questionnaire that measures the quality of care from the perspective of cataract patients.

\section{Methods}

The QUOTE-cataract was tested in a multicenter study among 540 cataract patients in 3 different hospitals. Reliability was represented by internal consistency (Cronbach's $\alpha$ ) and repeatability (intraclass correlation coefficient (ICC)). Validity was evaluated qualitatively and by factor-analyses.

\section{Results}

A strong internal consistency coefficient (0.89) and high repeatability (ICC=0.76) demonstrated good reliability. Content validity was assured by involvement of patients in the development of the questionnaire. Factor analysis confirmed an underlying taxonomy of generic and disease-specific items.

\section{Conclusion}

The QUOTE-cataract has good reliability and provides a valid assessment of quality of care in cataract surgery. 


\section{3b.1 Introduction}

In studies assessing the effectiveness of cataract surgery the importance of the patient's perspective has been recognised. Besides clinical outcomes like visual acuity, assessments are directed at subjective measures of vision related functioning. ${ }^{1,2}$ However, a valid assessment of the quality of ophthalmic services from the patient's perspective should consider all components that contribute to the quality of these services: objective outcome criteria (functional tests), subjective outcome criteria (patient satisfaction), and criteria related to the way the services are provided (structure and process of care). ${ }^{3-6}$ Previous research examining quality of care from the user's perspective has been dominated by patient satisfaction surveys. ${ }^{7}$ Doubts have been cast on the validity of such research for two main reasons. Firstly, these studies usually do not involve patients in the development of instruments. Therefore outcomes tend to reflect the perspective of managers and/or professional and/or researchers, rather than the distinct view of the patient. ${ }^{8}$ Secondly, results show little insight into user views because satisfaction ratings are usually highly skewed, while no recognition is given to the fact that some quality aspects of care are more important than others. ${ }^{9,10}$ This has led reviewers to conclude that research into user views of quality of care has suffered from methodological weakness and low specificity of results. ${ }^{11-13}$ We developed the QUOTE-cataract questionnaire (QUality Of care Through the patient's Eyes) that measures the quality of care from a cataract patient's perspective, which attempts to overcome these problems. The QUOTE-cataract closely resembles the work that was carried out on other QUOTE-instruments (e.g. QUOTE-Rheumatic-Patients and QUOTE-Elderly) as described by Sixma et al. ${ }^{8,14}$ This instrument produces data on the importance and performance of health care services, which are related to the specific needs and expectations of cataract patients. Besides being useful and applicable to clinical practice, an instrument like the QUOTE-cataract should satisfy scientific quality standards. Aim of this study was to assess the reliability and validity of the QUOTE-cataract questionnaire. 


\section{3b.3 Patients and Methods}

\section{3b.3.1 Patients}

This study consisted of patients that were treated at 3 settings: University Hospital Maastricht (UHM, n=166), University Hospital Groningen (UHG, $\mathrm{n}=130$ ), and the Rotterdam Eye Hospital (REH, $\mathrm{n}=244)$. The mean age \pm standard deviation (SD) of the patients was $71.8 \pm 8.0$ years $(\mathrm{UHM}) ; 73.9 \pm 9.2$ years $(\mathrm{UHG})$, and $71.9 \pm 9.3$ years $(\mathrm{REH})$, respectively. The male-female ratio was 0.6 for all three settings. At REH more patients were categorised as 'medium/higher educated' in comparison to UHM and UHG (Kruskal-Wallis, $\mathrm{p}<0.01$ ). General health was reported as 'good' by most patients, but differed significantly between the three settings with the highest scores at REH (KruskalWallis, $\mathrm{p}<0.01$ ). Criteria for participation in the study were first or second eye surgery for age-related cataract 2 to 8 months ago and absence of ocular co-morbidity.

All cataract surgeries took place on an outpatient basis using a standardized phacoemulsification technique with implantation of an intraocular lens.

\section{3b.3.2 The questionnaire}

The QUOTE-cataract includes a generic and a disease-specific part (see Table 3b.1). To generate these items, focus group interviews with cataract patients and concept mapping were performed. ${ }^{15,16}$ Generic questions $(\mathrm{i}=15)$ are applicable to a range of users of health care (i.e., patients) and refer to process and structure related care aspects, whereas diseasespecific items $(\mathrm{i}=16)$ are tailored to cataract patients. Four disease-specific items were not included in the QUOTE-cataract at UHG because they were characteristic for UHM and $\mathrm{REH}$. The items incorporated in the questionnaire measure the relative importance of the different quality aspects (e.g. 'My ophthalmologist should inform me clearly about what I may and may not do after cataract surgery') and the performance of the health care services on each of the quality aspects (e.g. 'My ophthalmologist informed me clearly about what I may and may not do after cataract surgery'). Response options of the importance categories are 'not important', 'fairly important', 'important', and 'extremely important'. Scores were calculated by linear transformation of standardized values (Z-scores) to values between 0 ('not important') and 10 ('extremely important'). ${ }^{14,17}$ Response options for perceived performances (1='no', $2=$ 'not really', 3='on the whole, yes', and 4='yes') were expressed as proportions of respondents who did not (score 1 or 2) perceive the particular quality aspect as being performed. ${ }^{8}$ Individual (i) performance (P) and importance scores (I) on different quality of care aspects (j) are used to calculate quality impact indices (Q), applying the formula $\mathrm{Qij}=\mathrm{Pij}$ x Iij. Theoretically a quality impact score can vary from 0 (best possible quality of care) to 10 (all respondents think that this aspect is extremely important and $100 \%$ of the patients report that it needs improvement). 


\section{3b.3.3 Reliability and validity testing}

A postal survey involved 540 patients who had undergone cataract surgery. Cronbach's alpha was used to represent the internal consistency of the QUOTE-cataract based on one rating. A 'benchmark' of 0.80 was considered as an acceptable value. In accordance with previous reports on the assessment of test-retest stability (repeatability), scoring of the QUOTE-cataract instrument was repeated after two to three weeks by 289 cataract patients from the UHG and REH. ${ }^{18}$ A Bland and Altman plot of agreement and the intraclass correlation coefficient demonstrated variation in test-retest. ${ }^{19,20}$ Content validity was optimised by involving cataract patients in the development process. Moreover, a question was included to check if patients felt that particular aspects of relevance to them, were missing in the questionnaire. Furthermore, factor analysis was performed to examine the taxonomy/structure of the quality of care concept.

\section{3b.3.4 Statistical analysis/Statistics}

Importance scores were used in statistical tests to assess the reliability and validity of the scales. While performance scores will change when situations in health care services change, importance scores are less subject to situational changes as they are linked to the attitudes and opinions of patients. ${ }^{8}$ Cases with more than $10 \%$ missing values on the importance scores were excluded from reliability and factor analyses, remaining missing values were replaced by the mean. The Bland and Altman-plot indicated stability of test results by demonstrating variation in scores as part of unreliability. One-way ANOVA (random effect model) was used to obtain the intraclass correlation coefficient for retestreliability according to the following formula: ICC $=1$ - (within subject variance/between subject variance). Factor analysis (principal component) was carried out to represent the internal structure of the questionnaire. The appropriateness of the factor analytic model was tested using the Kaiser-Meyer-Olkin (KMO) measure of sampling adequacy and Bartlett's test of sphericity. Analyses were performed using SPSS $10.0^{\otimes}$ for Windows (SPSS Inc., Chicago, IL) software. 


\section{Table 3b.1: Quality aspects listed in the QUOTE-cataract}

\section{Generic indicators}

1.1 allow me to decide on which treatment/help to get

1.2 take me seriously

1.3 keep appointments punctually

1.4 never let me wait in the waiting room longer than 15 minutes

1.5 give me good directions for use of the prescribed medicine

1.6 take care that prescribed medicines are free of charge

1.7 be easily accessible by phone

1.8 take care that I can consult a specialist within 2 weeks

1.9 take care of fine-tuned care of different caregivers

1.10 know my health status very well

1.11 tell me what to do in case of emergency

1.12 have a room accessible for wheelchair users/disabled

1.13 always inform me about the risks of a treatment

1.14 always take enough time for me

1.15 be willing to talk about affairs I did not like

\section{Cataract-specific indicators}

2.1 inform me clearly what I may and may not do after cataract surgery

2.2 inform me in writing about the day and time of my cataract surgery*

2.3 inform me in the meantime how long it will take before surgery*

2.4 provide an information brochure about cataract surgery

2.5 tell me during cataract surgery exactly what he/she is doing

2.6 always be calm and quiet while working

2.7 always consider my personal desires

2.8 always be friendly

2.9 always take all my questions related to cataract surgery seriously

2.10 always be the same person

2.11 take care that the wait for surgery is not longer than 2 months

2.12 take care that all preoperative examinations will take place at the same day*

2.13 have at one's disposal a desk with enough privacy

2.14 take care of food and drinks at the ward/in the waiting room*

2.15 take care that patient education is regulated among the different doctors

2.16 give me the opportunity to come first occasionally

\section{Legend}

* = quality of care aspects not included in the QUOTE-cataract at UHG 


\section{3b.4 Results}

\section{3b.4.1 Response to questionnaires}

The total number of completed questionnaires returned was 166 (response rate 92.7\%), 30 (response rate 65\%) and 244 (response rate 74.4\%) for UHM, UHG and REH respectively. The mean \pm standard deviation of the importance scores was similar comparing the three settings: $6.1 \pm 1.6,6.2 \pm 1.2$, and $5.8 \pm 1.2$ for UHM, UHG, and REH respectively (ANOVA, $\mathrm{p}=0.13$ ). Performance sores ranged from 0.01 to 0.49 , from 0.01 to 0.49 , and from 0.00 to 0.44 for UHM, UHG, and REH respectively. Importance scores were less skewed in our data set than the perception scores (range -0.58 to 0.30 and 0.43 to 11.3 , respectively). Quality impact factors ranged from 0.05 to 3.39 (UHM), from 0.05 to 2.79 (UHG), and from 0.00 to 3.00 (REH), with skewness scores ranging from 0.70 to 1.58 .

\section{3b.4.2 Reliability}

The mean internal consistency coefficient of the three hospitals was $0.89,0.84$, and 0.85 for the QUOTE-cataract in total, generic subscales, and disease-specific subscales respectively. The mean $\pm \mathrm{SD}$ importance scores for first and second assessments were 6.2 \pm 1.2 and $6.2 \pm 1.3$ for UHG, and $5.8 \pm 1.2$ and $5.9 \pm 1.4$ for REH (paired t-test, $\mathrm{p}=0.89 / 0.61$ ). The differences in first and second assessments were plotted against the mean QUOTE-cataract score for each patient (Figure 3b.1), which showed no relationship between the measurement error and the true value.

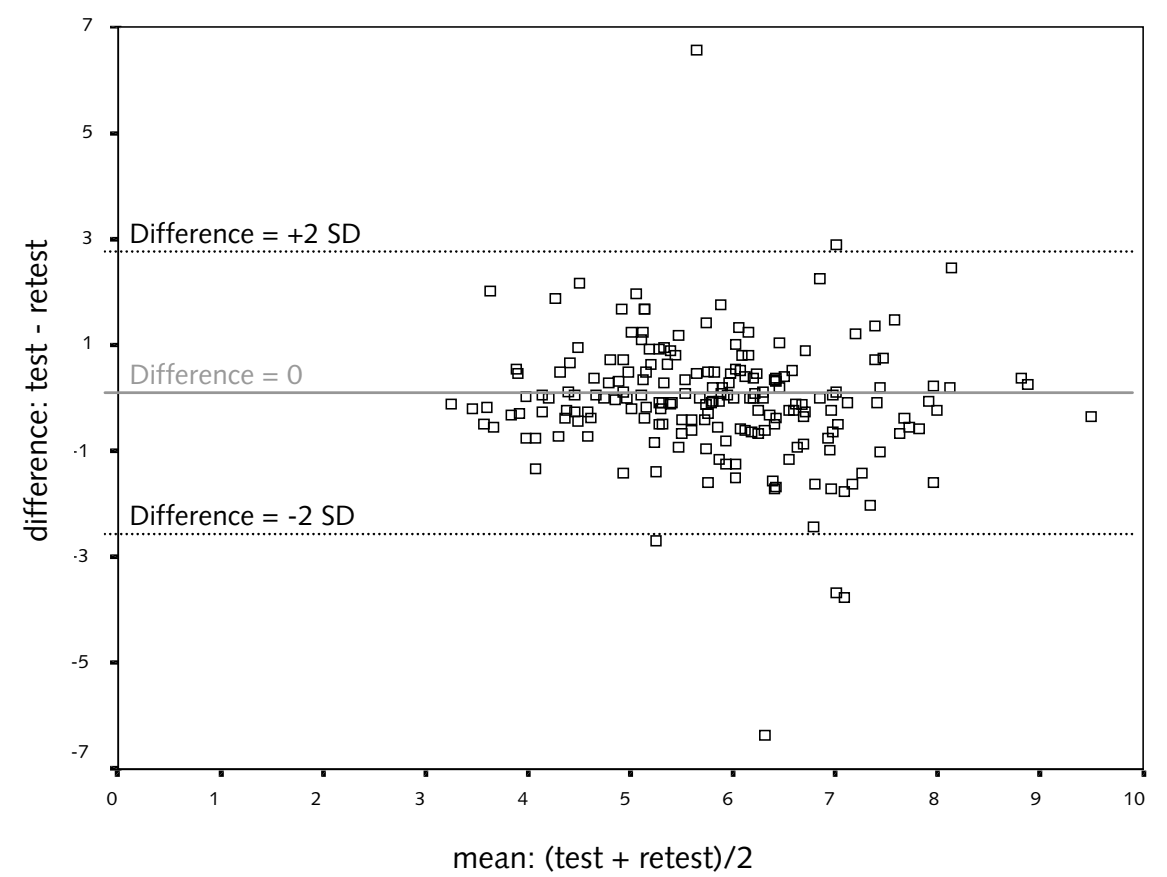

Figure 3b.1: Repeatability of the QUOTE-cataract

- Bland and Altman plot of agreement in importance scores between test and retest. The mean of the test and retest scores is plotted on the $x$-axis and the differences between the two scores on the $y$-axis. The horizontal interrupted lines represent the limits of agreement (within 2 standard deviations from the mean). 
The mean of the differences between the pairs was negligible (mean difference $=-0.04$ ). Furthermore, the limits of agreement were small, an individual measurement difference is expected within a range from -2.34 to 2.34 . A strong intraclass correlation coefficient confirmed this consistency (average measure ICC $=0.76$ ).

\section{3b.4.3 Validity}

The appropriateness of the factor analytic model was assessed by KMO (0.92) and Bartlett (Chi-square $=4131,5, \mathrm{p}<0.01$ ), which demonstrated legitimacy of the procedure. Unrotated factor analysis identified 2 common factors that explained $35.3 \%$ of the variance. When analysing generic and specific items separately, both generic and disease-specific items clustered into one factor with moderate factor loadings (range 0.45 to 0.69). Explained variances were $31.6 \%$ and $33.7 \%$ respectively. The percentage of patients that responded affirmatively to the question "Were any quality of care aspects missing in this questionnaire?" was 27.1, 26.9 and 22.5 or UHM, UHG and REH respectively (Chi-square test, $\mathrm{p}=0.49$ ). However, most answers related to alternative expressions of items already included in the QUOTE-cataract. Real new aspects, formulated by 6.7\% of the patients, concerned the anaesthesiology before cataract surgery $(n=3)$, follow-up visits (prescription of glasses, and information about secondary cataract or other complications; $n=22$ ), reassurance $(n=4)$, costs $(n=4)$, and technical competence $(n=3)$. 


\section{3b.5 Discussion}

Former research emphasized the relevance of process and structure related quality of care with respect to satisfaction after cataract surgery. ${ }^{1}$ However, the reliability and validity in measuring the multidimensional concept satisfaction has been criticized frequently based upon the global approach and problems regarding methodological weakness (e.g. highly skewed). ${ }^{11-13}$ The QUOTE-cataract instrument was developed to assess patient's interests in a more specific and direct way, as recommended by Fitzpatrick. ${ }^{21}$ We showed that the QUOTE-cataract had low skewness scores in comparison to distributions of 80 to $90 \%$ generally categorized as satisfied. ${ }^{1}$ The internal consistency of the questionnaire was shown to be as good as the QUOTE-Rheumatic-Patients and QUOTE-Elderly with Cronbach's alphas of 0.92 and 0.93 respectively. 8,14

Test-retest data for the QUOTE-cataract confirmed repeatability, there being negligible differences between pairs using the method of Bland and Altman, and a high intraclass correlation coefficient (ICC=0.76). Factor analysis showed that category-specific items clustered into one component, which was also comparable to the QUOTE-RheumaticPatients and QUOTE-Elderly. . $^{8,14}$ Four percent of the patients missed an aspect regarding 'follow-up visits' in the questionnaire.

Future research should indicate whether this missing aspect is of additional value for the questionnaire. The questionnaire as developed at UHM and UHG was shown to be applicable to the REH although 4 aspects were not included in the QUOTE-cataract at UHG. These aspects seemed to be institute-specific for UHM and REH. One should recognise that subtle differences in communities require differences in assessment. ${ }^{22}$ Therefore it is recommended to validate the QUOTE-cataract at each specific setting and location before its administration. Since process and structure related quality of care (e.g. patient education and counselling) have been proven to be highly correlated with patient satisfaction, ${ }^{1}$ we believe that the QUOTE-cataract may be an adequate instrument to measure patient satisfaction after cataract surgery in a more reliable and valid way. 


\section{References}

1. Nijkamp MD, Nuijts RM, van den Borne B et al. Determinants of patient satisfaction after cataract surgery in 3 settings. J Cataract Refract Surg 2000;26:1379-1388

2. Steinberg EP, Tielsch $J M$, Schein OD et al. The VF-14. An index of functional impairment in patients with cataract. Arch Ophthalmol 1994;112:630-638

3. Desai P. Assessing ophthalmic services. Eye 1995;9:677-678

4. Spaeth $\mathrm{GL}, \mathrm{MD}$. Why measuring quality of care, a vitally important task, is presently being done improperly. Ophthalmic surgery 1989;20:165-167

5. Lledo R, Rodriguez T, Fontenla JR et al. Cataract surgery: an analysis of patient satisfaction with medical care. Int Ophthalmol 1999;22:227-232

6. Pankow L. Seeing through the patient's eyes. Journal of the American Optometric Association 1992;63:678-679

7. Campen van $\mathrm{C}$, Sixma $\mathrm{H}$, Friele RD et al. Quality of care and patient satisfaction: A review of measuring instruments. Med Care Res Rev 1995;52:109-133

8. Campen van C, Sixma HJ, Kerssens JJ et al. Assessing patients' priorities and perceptions of the quality of health care: The development of the QUOTE-rheumatic-patients instrument. British Journal of Rheumatology 1998;37:362-367

9. Sitzia J and Wood N. Patient satisfaction: a review of issues and concepts. Soc Sci Med 1997;45:1829-1843

10. Zastowny TR, Stratmann WC, Adams EH et al. Patient satisfaction and experience with health services and quality of care. Quality Management in Health Care 1995;3:50-61

11. Rubin H. Patient evaluations of hospital care: A review of literature. Med Care 1990;28:S3-S9

12. Williams B. Patient satisfaction: a valid concept? Soc Sci Med 1994;38:509-516

13. Ross C, Steward C, Sinacore J. A comparative study of seven measures of patient satisfaction. Med Care 1995;33:392-406

14. Sixma $H$, Campen van $C$, Kerssens J et al. Quality of care from the perspective of elderly people: the QUOTE-Elderly instrument. Age Ageing 2000;29:173-178

15. Morgan DL. Focus Groups as qualitative research. Beverly Hills: SAGE Publications Inc., 1988

16. Trochim WMK. The Concept System. Ithaca: Concept Systems, 1993

17. Swanborn PG. De Likertschaal. In: Schaaltechnieken: Theorie en praktijk van acht eenvoudige procedures. Meppel: Boom, 1982: 96-103

18. Deyo RA, Diehr P, Patrick DL. Reproducibility and responsiveness of health status measures. Statistics and strategies for evaluation. Control Clin Trials 1991;12:142s-158s

19. Bravo G, Potvin L. Estimating the reliability of continuous measures with Cronbach's alpha or the intraclass correlation coefficient: toward the integration of two traditions. J Clin Epidemiol 1991;44:381-390

20. Bland J, Altman D. Statistical methods for assessing agreement between two methods of clinical measurement. Lancet 1986; February 8:307-310

21. Fitzpatrick R, Hopkins A. Problems in the conceptual framework of patient satisfaction research: an empirical exploration. Sociology of Health and Illness 1983;5:297-311

22. Pesudovs $K$, Coster DJ. An instrument for assessment of subjective visual disability in cataract patients. Br J Ophthalmol 1998;82:617-624 


\section{Chapter $4 a$}

\section{Factors related to fear in patients undergoing cataract surgery}

A qualitative study focusing on factors associated with fear and reassurance among patients who need to undergo cataract surgery

Published as Marjan D. Nijkamp, Robert A.C. Ruiter, Marijke Roeling, Bart van den Borne, Frans Hiddema, Fred Hendrikse, Rudy M.M.A. Nuijts. "Factors related to fear in patients undergoing cataract surgery: a qualitative study focusing on factors associated with fear and reassurance among patients who need to undergo cataract surgery"; Patient Education and Counseling 2002; 47: 265-272. 


\section{Abstract}

\section{Aim}

The aim was to identify factors that are related to fear among patients who need to undergo cataract surgery.

\section{Methods}

The data were collected by focus group interviews ( $\mathrm{n}=27)$.

\section{Results}

The doctor-patient relationship, patient education, the wait, hospital organisation, social support, sensations, previous experience, outcome of surgery, and coping strategies were identified as the main factors that contribute to feelings of fear related to cataract surgery. Five stages of fear were identified: at home after diagnosis, during preparation for surgery at the hospital, the day of surgery, the postoperative visits, and the period after these follow-up visits at home.

\section{Conclusion}

A model regarding the factors related to fear in patients awaiting cataract surgery was developed, which emphasizes the importance of a good doctor-patient relationship and the need for patient education that is tailored to the individual patients. 


\section{4a.1 Introduction}

Senile cataract is an age-related vision problem. It is an eye disease characterized by opacification of the crystalline lens. ${ }^{1}$ Symptoms commonly reported by patients with cataract include double or distorted vision, glare and halo's, blurred vision, changed colour perception, and decrease of visual acuity. ${ }^{2}$ Cataract can only be treated by surgery. During cataract surgery the opaque lens is removed and replaced by an artificial implant lens. It is generally agreed that modern cataract surgery is effective in terms of postoperative improvement in vision and safe with respect to a low incidence of surgical complications. ${ }^{3}$ Despite the high success rate, a large proportion of the patients that have to undergo cataract surgery report increased levels of fear. ${ }^{4-7}$ In a study by Morgan and Schwab (1986) $48 \%$ of the patients reported being nervous about their cataract surgery. ${ }^{8}$ In general, fear arousal in patients awaiting medical care is highly acknowledged. ${ }^{9-15}$

A stressor, such as the need for surgery, provokes physiological (e.g. increase of heart rate, blood pressure, and release of adrenalin), cognitive (e.g. beliefs about negative consequences, and inability to concentrate), emotional (e.g. anxiety, depression) and behavioural ("fight and flight" reactions) responses in patients. ${ }^{16}$ Efforts have been made to explain preoperative anxiety or fear, which is the concept examined here. Fear is defined as an unpleasant emotional state that is triggered by the perception of threatening stimuli. ${ }^{17}$ Psychologists distinguish fear from anxiety because they differ in one important respect. Fear has an obvious cause, and once the cause is eliminated, the fear will subside. In contrast, anxiety is less clearly linked to specific events or stimuli, leading to a more pervasive condition. ${ }^{18}$ The subject's perceptions seem to be more relevant to preoperative fear than the actual risks or discomfort associated with the need for surgery and admission into a hospital. ${ }^{9}$ Cohen and Lazarus introduced the term 'cognitive appraisal' in this context: "...the mental process of judging events with respect to their significance for the person's well-being (primary appraisal) or the resources and options available for coping (secondary appraisal)" (p. 608). ${ }^{19}$ Specifically, Cohen and Lazarus argued that the primary appraisal process results in a perception of threat if the danger presented is evaluated as being personally relevant and as having severe negative consequences. The secondary appraisal process, in turn, results in an evaluation of the person's ability to avert the perceived threat in terms of the effectiveness and feasibility of possible coping strategies. Fear will be experienced if people perceive the stressor as a high threat, and do not feel capable to cope with the threat. It is further assumed that situational (e.g. patient education) and personal (e.g. previous experience) factors influence the type of appraisals that are made. ${ }^{20}$

To understand the causes underlying feelings of fear, it is important to identify these personal and situational factors. Only if these factors are identified can interventions be developed that successfully reduce feelings of fear. ${ }^{21}$ Studies specifically related to fear of a cataract operation have been published previously. However, little is known about personal and situational factors that relate to fear of cataract surgery. 
Spina et al. examined 1200 letters sent to a popular magazine written by patients suffering from cataract or their relatives. ${ }^{5}$ The tone of these letters reflected fear regarding the possible failure of the operation. Patients were worried about becoming permanently blind, in particular when they experienced a disturbing vision loss due to the cataract. In another study, Fagerström (1991) showed that patients waiting for cataract surgery were anxious, and scored high on depressive mood, somatic concern, and tension. ${ }^{7}$ In addition to these preoperative worries, patients may experience fear per-operatively. Patients who received local retrobulbar anaesthesia before cataract surgery, reported sight of a variety of colours, flashes, movements, surgical instruments, and even the surgeon's hands and fingers, which may increase levels of fear. ${ }^{22}$ Another study focused on auditory accompaniment during cataract surgery. ${ }^{4}$ Although no significant evidence was found for a reduction in fear among patients who were exposed to relaxing music during surgery rather than being exposed to the normal operation room noise, patients in the relaxing music condition seemed to have felt somewhat more satisfied and relaxed than patients in the control condition. Furthermore, the intensity of fear seems to change over time: scores on fear scales increase between admission and the immediate preoperative stage, and decline again postoperatively. ${ }^{10,11}$ Fagerström reported that old persons whose vision was very poor were most hopeful regarding the operation, often saying that they would loose nothing if the operation did not restore their vision. ${ }^{6}$ De Beurs indicated that hearing and eyesight problems were risk factors for older persons becoming fearful, and that changes in fear over time were best predicted by being female and having a high neuroticism score. ${ }^{23}$

To further extend the previous studies, the present study aims to identify relevant personal and situational factors that are related to fear during the preoperative, per-operative, and postoperative stages of cataract surgery. Because a systematic analysis of these factors seems to be missing in the literature, a qualitative approach was adopted rather than a quantitative approach. Utilizing a qualitative approach allows investigators to obtain an understanding of the factors that are related to fear, the relative impact of which may then be assessed using quantitative measures. A growing literature within health and patient education argues for such a systematic approach in designing psycho-educational interventions. Typically, this systematic approach starts with a needs assessment in which relevant factors (i.e., determinants) that influence the identified problem (e.g. fear for cataract surgery) are identified. These factors then serve as focal points (objectives) for interventions that should alleviate the identified problem. Research has continuously shown that interventions that are based on a proper needs assessment and systematic process of development are more effective than interventions that lack a systematic approach. ${ }^{21}$ 


\section{4a.2 Methods}

\section{4a.2.1 Subjects}

Consecutive patients who had routine phacoemulsification and intraocular lens implantation in the period from March until May 2000 at the University Hospital Maastricht (UHM) or the Rotterdam Eye Hospital (REH), were asked to participate in the study.

Patients were selected according to the following inclusion criteria: suffering from senile cataract, aged 50 years or older, no ocular co-morbidity, and being able to speak and read Dutch. Eligible candidates were invited to participate in the study by means of a letter. This letter stated that group interviews were organised to survey the experiences of patients who had cataract surgery 1 to 5 months ago. In total, 27 patients (15 women and 12 men) participated in four focus group sessions, with 5 to 8 patients per session. Two focus groups were conducted at each hospital setting. The mean age of the subjects was 72.2 years (range 50 to 87 years). Patients at both hospitals received standard preoperative medication including mydriatic eye drops in the eye to be operated. The standardized technique for local anaesthesia used at both settings was a retrobulbar block. Additionally, all patients in the Rotterdam Eye Hospital received $7.5 \mathrm{mg}$ of dormicum [Roche; The Netherlands] for sedation. This was given intravenously just before the retrobulbar block.

\section{4a.2.2 Organisation of care}

Prior to conducting the focus groups, observations of the procedures surrounding cataract operations were carried out to obtain an understanding of the processes involved in the pre-, per-, and postoperative stages. Over a period of several days, the third author accompanied cataract patients at both hospitals to define the stages at which a cataract patient might experience fear (from diagnosis through the period after discharge). The observations were standardised by means of a checklist, which allowed for comparison between the two hospitals. The checklist was comprised of the following questions: What happens where, when and who is involved? What information and counselling do patients receive during the pre-, per-, and postoperative stage? The University Hospital Maastricht (UHM) is a large academic centre including a variety of specialities with a traditional policy regarding patient education. The Rotterdam Eye Hospital (REH) is a specialised hospital with an innovative policy regarding patient education. The medical process was similar at both hospitals, with three exceptions: the time point used for calculating the intraocular lens power, the more detailed tasks performed by nurses at REH during the preparatory visit compared to UHM, and the type of patient education provided. At UHM patients received oral and written information on cataract surgery, while at $\mathrm{REH}$ patients were informed using a multimedia approach. At $\mathrm{REH}$, patients were presented with a video about the procedures for cataract surgery, an interactive cd-rom, a live-surgery report on videotape, and patient education through the Internet in addition to oral and written information. In both hospitals, all cataract surgeries were performed at the outpatient clinic, and patients were asked to bring their partner or a relative to pre-, per-, and postoperative visits. 


\section{4a.2.3 Focus group interviews}

A focus group methodology was used to formulate the perceptions, considerations, opinions, and emotions of the patients regarding their surgery. The focus group interviews lasted approximately 2 hours and were led by an experienced moderator and an assistant (both from Maastricht University), who were well informed about the objectives of the research and about cataract surgery. The interviews were held in conference rooms within the hospital.

The sessions were audiotaped to allow random quality checks, and were then transcribed. The focus group interviews were semi-structured by questions addressing possible determinants of fear. These questions focused on experiences encountered during the process of care involved in cataract surgery; 1). 'patient education', 2). 'doctor-patient relationship', 3). 'social support', and 4). 'coping strategies'.

\section{4a.2.4 Analysis}

The first and third author independently conducted content analysis on the focus group interviews. The methodology used was derived from the process described by van Assema and colleagues (1992), which was based upon Morgan's qualitative research methods. ${ }^{24,25}$ The basic data for analysis were transcripts of the group discussions. The framework of the analysis were the questions that structured the focus group interviews. Both researchers noted the most important keywords. A 'keyword' gives a short description of any discussion of a specific factor related to fear. ${ }^{25}$ Subsequently, each keyword was counted throughout the transcripts of the focus group interviews. No software was used to count keywords, because some keywords were ambiguous, e.g. 'know one's way around'. Segments of the text that contained the same keywords were clustered. The keywords were then summarised by code categories, which indicated the factors influencing fear.

\section{4a.3 Results}

Five distinct stages related to fear were identified using the time scheme of the medical procedures: at home after the diagnosis, during preparation for surgery, the day of surgery, postoperative visits at the hospital, and recovery at home up to five months after surgery. Analysis of the focus group interviews resulted in specification of factors influencing fear related to cataract surgery for each of the five stages defined above. The results of the focus group interviews are described both by a qualitative chronological summary illustrated with quotes (see below) and by a systematic coding via content analysis (Table 4a.1). An overview of relevant factors at the different stages is also given (Table 4a.2). 


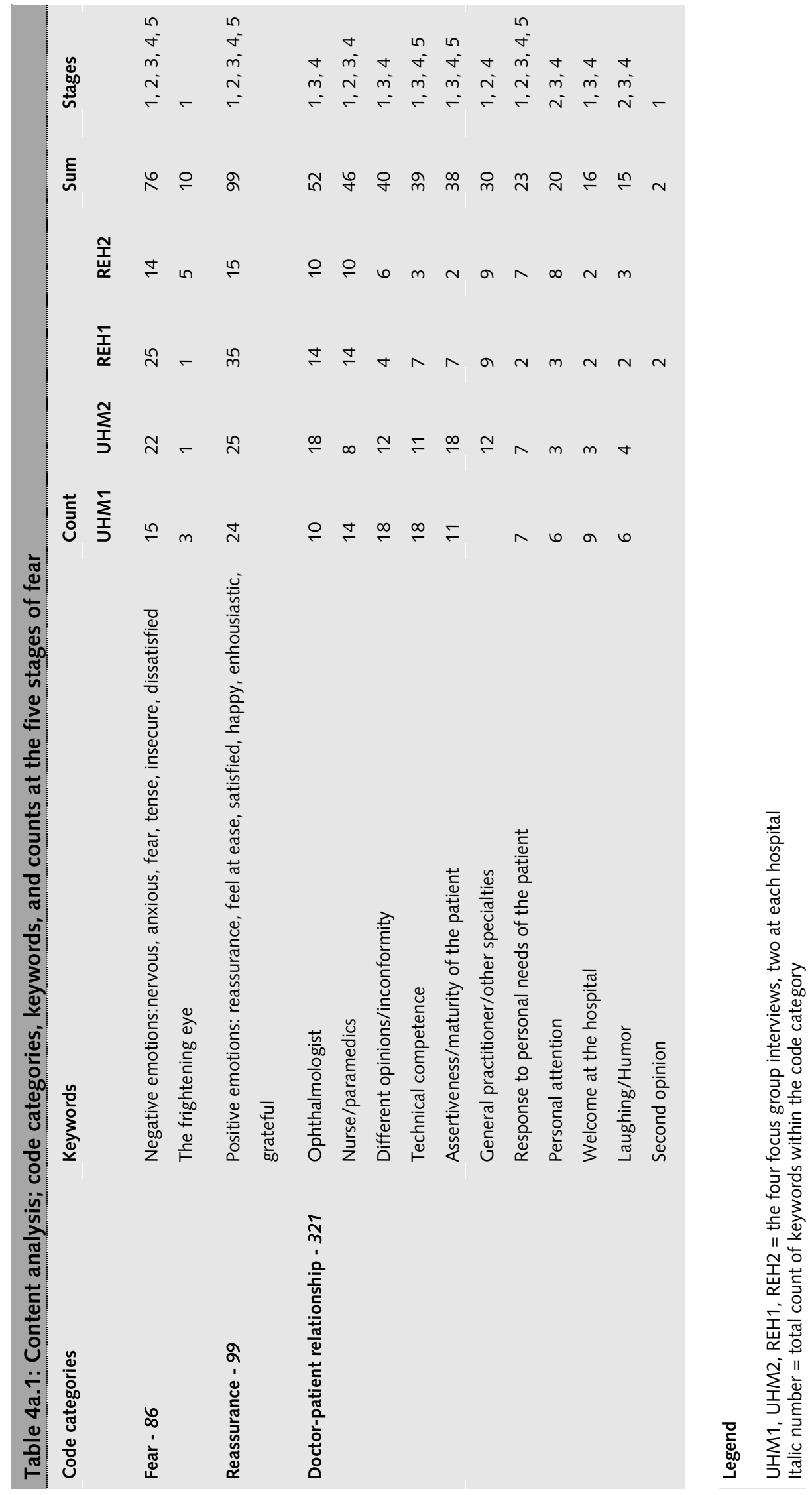




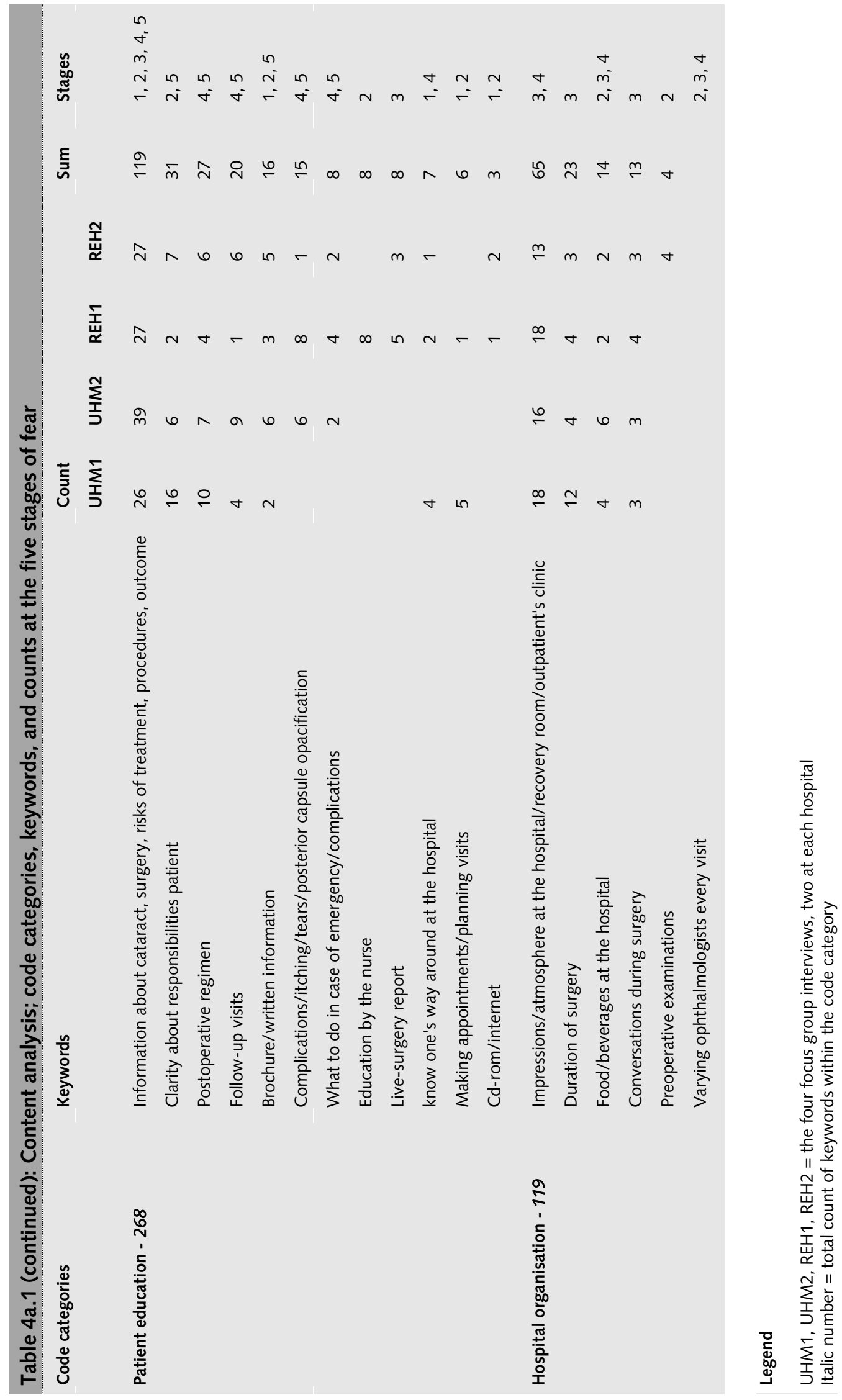




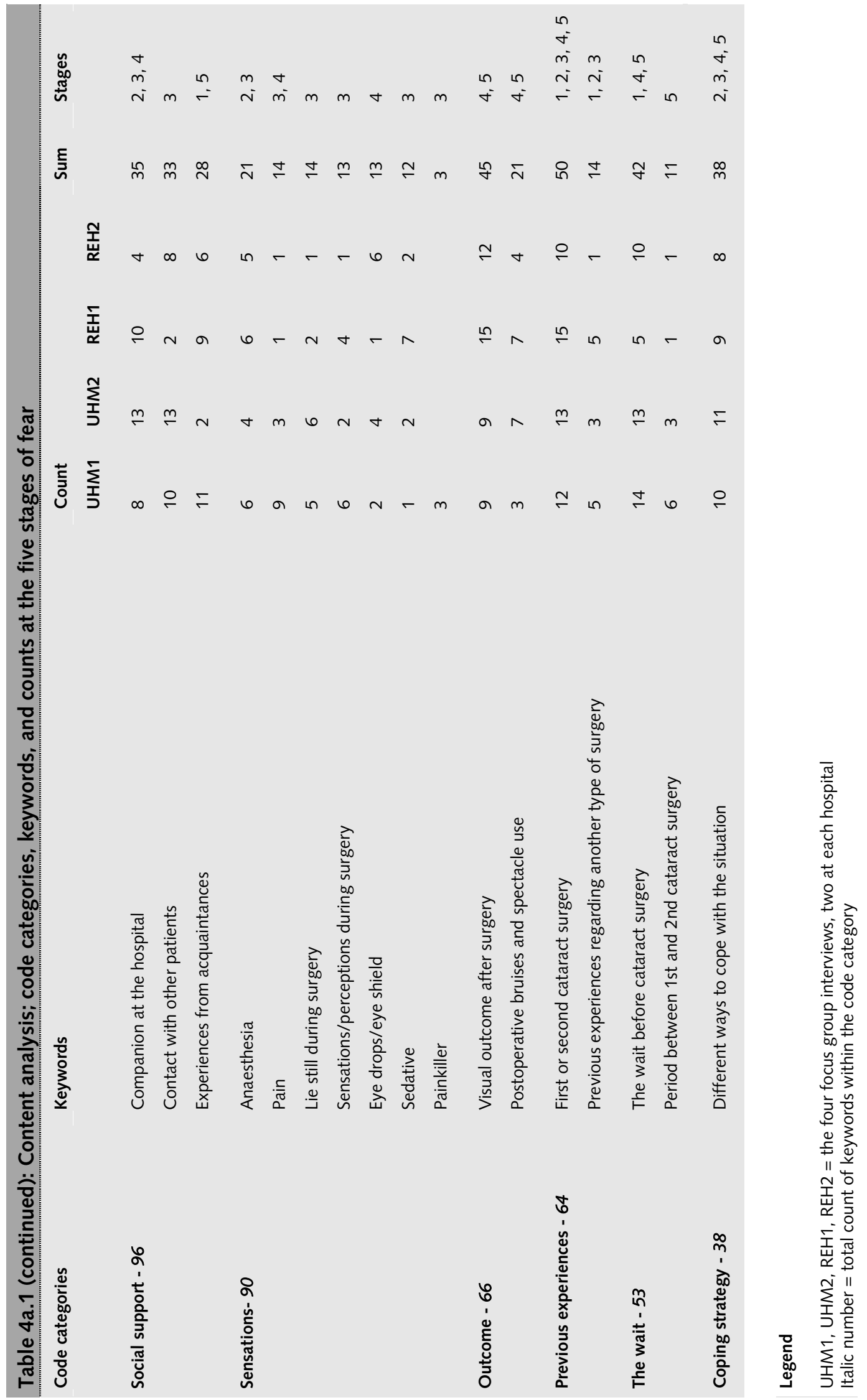




\begin{tabular}{|c|c|c|c|c|c|c|}
\hline & & \multicolumn{5}{|c|}{ Stages } \\
\hline & & 1 & 2 & 3 & 4 & 5 \\
\hline \multirow[t]{2}{*}{ Doctor-patient relationship } & $A$ & + & + & + & + & + \\
\hline & B & + & + & + & + & \\
\hline Patient education & & + & + & + & + & + \\
\hline Hospital organisation & & & + & + & + & \\
\hline \multirow[t]{3}{*}{ Social support } & C & + & & & & + \\
\hline & D & & & + & & \\
\hline & $\mathrm{E}$ & & + & + & + & \\
\hline Sensations & & & + & + & & \\
\hline Previous experience & & + & + & + & + & + \\
\hline Wait & & + & & & + & + \\
\hline Coping strategy & & & + & + & + & + \\
\hline Outcome & & & & & + & + \\
\hline
\end{tabular}

\section{Legend}

A Ophthalmologist
B Nurse
C Home Environment (relatives, neighbours, acquaintances)
D Fellow patients
E Companion at hospital visit (partner, relative, acquaintance)

Stages:

$1=$ at home after diagnosis, 2 = preparation for surgery, 3 = day of surgery,

$4=$ postoperative visits, $5=$ recovery period at home 


\section{4a.3.1 At home after diagnosis (stage 1)}

Because of their impaired vision patients indicated that they felt insecure about activities of daily living while awaiting cataract surgery at home. Furthermore, they reported fear about further deterioration of the visual acuity mostly ascribed to the long waiting period (the wait) and being unsure about what to expect from cataract surgery. One of the factors, which influenced this fear and insecurity appeared to be the information received from the ophthalmologist, which varied considerably. An identical brochure explaining cataract surgery was available at both hospitals, but patients were not always exposed to this written information. Patients reported to be reassured and relieved when the ophthalmologist or nurse told them that worsening of vision is common among patients with a cataract and that cataract surgery is a reliable and successful procedure (patient education). Furthermore, patients expected to receive personal attention from their doctor, and to have the opportunity to ask questions about their eye disease. However, they acknowledged that the department of ophthalmology was one of the busiest departments at the hospital, which meant that an ophthalmology visit was usually fairly brief (doctor-patient relationship). Family, neighbours, and acquaintances were seen as an important, but not always positive, source of information at this stage. Some patients mentioned that they felt worried because of negative evaluations of cataract surgery by other people. The majority seemed to be able to put these horror stories in perspective, while others were frightened by these experiences (social support). Patients who had already had first eye surgery, reported to be more relaxed about their second surgery than their first (previous experience). In summary, the wait, written and oral information given at admission, doctor-patient relationship, social support, and previous experience seemed to be important variables that were associated with fear when patients were still at home awaiting cataract surgery.

\section{4a.3.2 Preparation for surgery at hospital (stage 2)}

The preoperative process includes several steps: instructions about the preoperative regimen are given, the power of the intraocular lens is calculated by means of ultrasonic devices, and an internist or anaesthesiologist examines the patient's general health. While being prepared for surgery, patients reported that they were concerned about the anaesthetic injection and the operation itself. These concerns were believed to be related to the anticipation of sensations (e.g. pain) and not being able to lie quiet during surgery (e.g. the need to cough during surgery; sensations). In addition, worries were reported about the visual outcome of surgery. In the focus groups, patients suggested that these fears could be reduced by providing more comprehensive information about the procedure and what to expect from cataract surgery (patient education). Moreover, factors related to the hospital organisation (e.g. presence of food and beverages in the waiting room) seemed to influence the extent to which patients experienced their stay at the hospital as threatening or nonthreatening (hospital organisation). The amount and type of information that patients wanted to be exposed to varied among focus group participants. Some patients indicated that they were happy not knowing everything; "...You need to make your own choice about what information you want to be exposed to....". 
Others appreciated the doctor telling them that no surgery is without risk because this helped them feel more responsible for their own choice of having surgery (coping strategy). In general, patients preferred oral information over written or interactive information. According to the patients, oral information was more effective at reducing fear because of the interpersonal contact (doctor-patient relationship). Patients explained the advantage of bringing a companion to the preoperative visits, "...It's great to have a chat afterwards about what the doctor told you..." (social support). Patients who had already had a first eye surgery, reported experiencing less fear the second time. However, one patient awaiting second surgery reported to have mixed emotions because she knew what was going to happen the second time, while she felt more at ease the first time not knowing what lied ahead (previous experience). In summary, at the preparation stage the factors most strongly related to fear were anticipated sensations, patient education, hospital organisation, coping strategies, the doctor-patient relationship, social support, and previous experience.

\section{4a.3.3 Day of surgery (stage 3 )}

On the day of surgery, the most important stressors were reported to be the anaesthetic injection, the operation itself, and fear of experiencing pain or discomfort. According to the patients, trust in the surgeon was an important factor related to fear. Besides good technical skills, trust was instilled by reassuring comments from the ophthalmologist during surgery (doctor-patient relationship). Knowing that all of the surgeon's attention was focused on them during surgery made patients feel more at ease, along with the knowledge that they were not the only patients who needed to undergo cataract surgery. Everyone in the focus group interviews reported that having a person accompany them provided a positive support: "...The idea of having somebody familiar in a stressful situation...". Most patients found that contact with fellow patients was very supportive (social support). However, some patients did not appreciate this kind of social support, and found it to be annoying. Discomfort during surgery was also mentioned as a stressor. Patients reported a feeling of helplessness and oppression while lying underneath a cloth during surgery or shivering with cold in the operation theatre (hospital organisation). At $\mathrm{REH}$, patients were sedated before they got the retrobulbar block, which was evaluated as 'perfect' by everyone (sensations). The live-surgery report on video was also evaluated positively by most patients from REH (patient education). However, some patients did not want to be exposed to this type of information. They chose to look away from the monitor (coping strategy). During this stage, previous experience was also an important factor that influenced fear. Although some patients reported being nervous because the procedures differed from their first time, most patients felt less worried when they came in for their second eye cataract surgery (previous experience). In brief, the factors influencing fear on the day of surgery were the doctor-patient relationship, social support, hospital organisation, sensations, patient education, coping strategy, and previous experience. 


\section{4a.3.4 Postoperative visits (stage 4)}

With regard to the postoperative period up to three weeks after surgery, patients reported being fearful about complications, the vulnerability of the operated eye, and deterioration in vision. The long wait for follow-up visits and the wait between first and second eye surgeries were associated with the fear of possible deterioration in vision (the wait). Patients who had already had a first eye surgery tended to compare the postoperative visual acuity of both eyes. Perceived differences in acuity were a source of postoperative worry (outcome and previous experience). Furthermore, patients reported being worried about short-term compliance regarding the postoperative regimen. Patients reported being confused by unclear, incomplete, and contradictory patient education. Most patients blamed this confusion on the discontinuity of doctors at subsequent visits (hospital organisation). Most participants felt that a pat on the back and unambiguous guidelines regarding postoperative restrictions would generate reassurance (patient education and doctor-patient relationship). Some participants believed that having contact with patients who were also treated for cataract and had similar experiences would be reassuring (social support). However, not all patients reported this need for postoperative social support (coping strategy). Thus, the variables most frequently related to fear during postoperative visits were the wait, outcome of surgery, previous experience, hospital organisation, patient education, the doctor-patient relationship, social support, and coping strategies.

\section{4a.3.5 Recovery period at home, one to five months after surgery (stage 5)}

During the recovery period at home, patients feared deterioration in visual acuity, and some worried about becoming permanently blind. Patients who already had first eye surgery compared the outcome of the two eyes (previous experience). Among those who had their first eye surgery, some were worried about the long waiting period before their second eye surgery (the wait). Furthermore, patients were worried about the long-term compliance with their postoperative regimen. Visual acuity deteriorated for some patients (outcome) and if they were not properly informed, patients worried about this regression (patient education). The need for social support and reassuring information led one patient to suggest that a central phone number for questions about eyesight should be made available, without requiring an appointment with the ophthalmologist (social support, doctor-patient relationship). Other participants reported that they had visited the optician for advice (coping strategy). In summary, during the recovery period at home previous experience, the wait between first and second eye surgery, outcome of surgery, quality of patient education, social support, the doctor-patient relationship, and coping strategies were most frequently associated with fear. 


\section{4a.4 Conclusion and Discussion}

\section{4a.4.1 Conclusions}

Focus group interviews were carried out at two different hospitals to identify personal and situational factors that were associated with fear and reassurance among patients who had received cataract surgery.

Analysis of the group interviews showed that patients experienced fear at five different stages (Table 4a.2): the waiting period before cataract surgery (at home), preparation for surgery at the hospital, the day of surgery, follow-up at the hospital, and the recovery period at home, one to five months after surgery. During these various stages patients reported fear of deterioration in their vision, the surgery itself, the retrobulbar injection, pain and discomfort, the outcome of the surgery, and complications.

Although both hospitals had different policies regarding forms of patient education, the analysis of the focus group interviews showed no striking differences between the two hospitals (Table 4a.1). However, patients treated at REH seemed to report less fear with respect to the anaesthesia in comparison to patients at UHM, which may be due to sedation, which is only given at $\mathrm{REH}$. In general, patients emphasized the importance of patient education and counselling during the pre-, per-, and postoperative stages. Nevertheless, individual differences existed in the amount, type, and specificity of the information that patients wanted to receive. More specifically, content analyses of the group interviews revealed that situational factors, which included the doctor-patient relationship, information supply (patient education), hospital organisation, social support, and the wait, and personal factors, which included (the anticipation of) sensations, previous experiences, and coping strategies were identified as the most relevant factors related to fear of cataract surgery and the recovery. A research model was formulated on the basis of these focus group interviews (Figure 4a.1), which summarizes the factors that were related to fear of cataract surgery. The model was based on the cognitive appraisal model of Cohen and Lazarus (see introduction). ${ }^{19}$ Factors that were related to fear in patients who had to undergo cataract surgery were divided into personal and situational elements. The results of the present study confirmed findings from previous studies on stress and coping. The way in which patients perceive or interpret a stressor in terms of its severity and their vulnerability to it (primary appraisal), and the effectiveness and feasibility of their coping abilities, determine how patients deal with the stressors related to the undergoing of cataract surgery (i.e., coping strategy). ${ }^{19}$ Patients experience fear or reassurance depending on the effectiveness of their chosen coping strategies. 


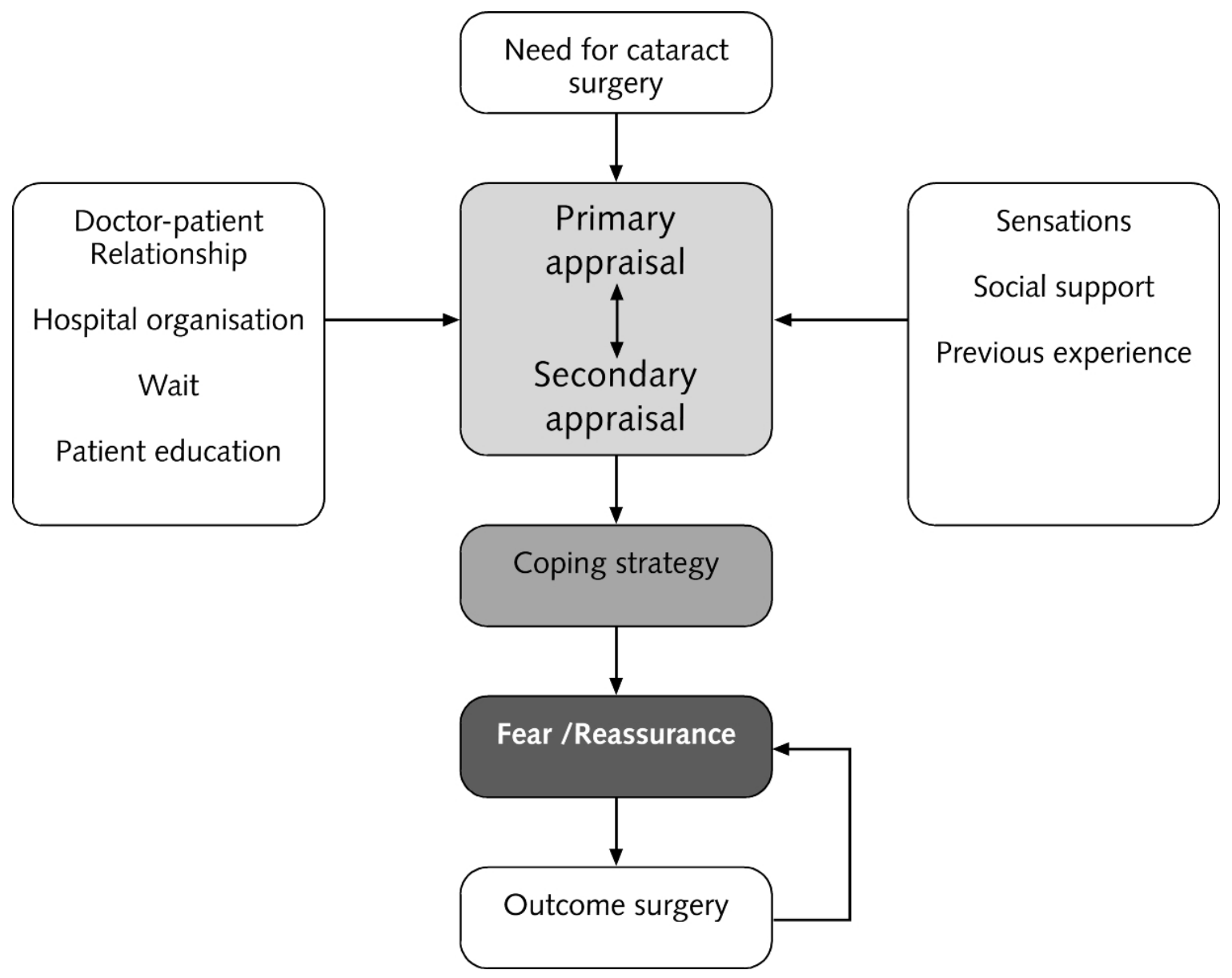

Figure 4a.1: Factors related to fear in patients during the process of cataract surgery

\section{4a.4.2 Practical implications}

The present study was designed to obtain a clearer understanding of personal and situational factors related to fear of cataract surgery. Using information from this study, it is possible to develop a psychosocial intervention to reduce fear in cataract surgery from a patient's perspective. To reduce the fear related to surgery, it is necessary to enhance the patient-doctor relationship, improving the continuity of care, and by providing sufficient time for consultation. Administrating pre-medication to all patients may help to alleviate pre- and per-operative fear. Patient education should be improved so that it is consistent and unambiguous, preferably concentrating on oral information delivered by personal conversations with the patients. Establishing a telephone service for patients staffed by knowledgeable personnel might also contribute to patient reassurance. Above all, it appears that individual patients have individual, not uniform, needs for information and care which should be taken into account during the entire treatment process. 


\section{4a.4.3 Limitations}

Focus group interviews have proven to be a useful and efficient research technique for identifying people's attitudes and norms. Hence, the utilization of both qualitative and quantitative methods has been advocated for patient education. ${ }^{25,26}$ However, semistructured interviews might not provide as much differentiated information as would be possible with a truly qualitative investigation based on individual in-depth interviews. In the final analysis, the factors related to fear and reassurance were reported according to 9 separate code categories, but considerably more were used in the coding process (Table 4a.1). The reason for this approach was an inability to predict in advance the count of every keyword, and prematurely collapsing keywords could have caused us to miss important distinctions. In the content analysis, simple counts and quotes were reported and no attempt was made to weight keywords in any way. Furthermore, one should take into account that self-reported determinants of fear can be biased by the subject being unable to verbally label or quantify their experience. ${ }^{11}$ Since the group interviews might also be biased by social desirability, patients might tend to hide their feelings related to fear. ${ }^{10}$ Another possibility is that patients might feel obliged to talk about feelings of fear, thus exaggerating their actual fear.

\section{4a.4.4 Recommendations for future research}

A follow-up study is being developed to quantify the findings presented here by means of a questionnaire. Apart from factors that relate to fear as represented in Figure 4a.1, followup research should take into account the influence of preoperative visual acuity, age, sex, and neuroticism score on fear. ${ }^{6,23}$ The age range of subjects was considerable in this study (50-87, mean 72.2 years). It is possible that different age groups have special needs that require differing care, not necessarily associated with their impaired vision. However, the relationship between age and fear or coping with stressful situations is controversial.

While Sapolsky (1994) stated that ageing can be defined as the progressive loss of the ability to deal with stress, Lazarus (1984) assumed that ageing per se brings no changes in coping, but that it depends on environmental conditions and impaired physical and mental resources. ${ }^{27,28}$ Furthermore, a study by Van der Ploeg (1988) indicated a difference in perception of the doctor-patient relationship for women versus men, which may lead to different levels of fear. ${ }^{29}$ Future research should explore these possible differences within subgroups of patients who need to undergo cataract surgery (male/female, different age categories). With the growing focus on patient satisfaction in clinical research, ${ }^{30}$ and increasing scientific evidence for a negative correlation between fear and satisfaction (fearful patients are often dissatisfied with their medical treatment), ${ }^{15}$ it is recommended that future research analyses the relationship between fear and satisfaction in patient care. 


\section{References}

1. Khaw PT, Hughes DS, Keightley SJ et al. Ophthalmology Revision Aid. London: BMJ Publishing Group, 1996

2. Steinberg EP, Tielsch $J M$, Schein $O D$ et al. National study of cataract surgery outcomes. Variation in 4-month postoperative outcomes as reflected in multiple outcome measures. Ophthalmology 1994;101:1131-1140

3. Powe NR, Schein OD, Gieser SC et al. Synthesis of the literature on visual acuity and complications following cataract extraction with intraocular lens implantation. Arch Ophthalmol 1994;112:239-252

4. Cruise CJ, Chung F, Yogendran S et al. Music increases satisfaction in elderly outpatients undergoing cataract surgery. Can J Anaesth 1997;44:43-48

5. Spina J Jr. The fear of cataract extraction: mental health aspects of a geriatric health problem [Clinical Comments]. Clinical Gerontologist 1984;2:68-70

6. Fagerström R. Fear of a cataract operation in aged persons. Psychol Rep 1993;72:1339-1346

7. Fagerström R. Correlation between psychic and somatic symptoms and vision in aged patients before and after a cataract operation. Psychol Rep 1991;69:707-721

8. Morgan LW and Schwab IR. Informed consent in senile cataract extraction. Arch Ophthalmol 1986;104:42-45

9. Gerdes EP and Guidi EJ. Anxiety in patients awaiting primary medical care. Med Care 1987;25:913-923

10. Velden v.d. BMC, Visser APh, Gerards FM et al. Anesthesievoorlichting en angstgevoelens van chirurgische patiënten. De invloed van een folder en een voorlichtingsbijeenkomst. Gedrag en Gezondheid 1992;20:1-9

11. Egan $V$, Miller E, McLellan I. Does the personal questionnaire provide a more sensitive measure of cardiac surgery related anxiety than a standard pencil-and-paper checklist? Person. Individ. Diff. 1998;24:465-473

12. Ploeg van der H. Stress. In: Molen van der GM, Schmidt AJM, ed. Psychologie voor de arts. Houten/Zaventem: Bohn Stafleu van Loghum, 1992:167-185

13. Breemhaar B. Development, implementation and evaluation of surgical patient education [dissertation]. Maastricht (the Netherlands): Maastricht University, 1997

14. Borne van den HW, Pruyn JFA, Geelen KRJ. Verwerken van levensbedreigende ziekten (Coping with life threatening illnesses). In: Damoiseaux V, Visser AP, ed. Patiëntenvoorlichting: een interdisciplinaire benadering. Assen/Maastricht: Van Gorcum \& Comp BV, 1988:209-224

15. Visser AP. Angst en patiëntenvoorlichting. In: Damoiseaux V, Visser AP, ed. Patiëntenvoorlichting: een interdisciplinaire benadering. Assen/Maastricht: Van Gorcum \& Comp BV, 1988:225-243

16. Taylor SE. Health psychology. New York: Mc Graw-Hill ,1995

17. Frijda N. The emotions. Cambridge: Cambridge University Press, 1986

18. Crooks RL and Stein J. Psychology: Science, Behavior and Life. New York: Holt, Rinehart and Winston Inc, 1988

19. Cohen F and Lazarus RS. Coping and adaptation in health and illness. In: Mechanic D, ed. Handbook of health, health care and the health professions. New York/London: The Free Press, 1983:608-635 
20. Lazarus RS. Psychological stress and the coping process. New York: McGraw-Hill, 1966

21. Bartholomew LK, Parcel GS, Kok G et al. Intervention Mapping: Designing theory- and evidence-based health promotion programs. Mountain View, CA: Mayfield, 2001

22. Eong KGA, Lim TH, Lee $\mathrm{HM}$ et al. Subjective visual experience during phacoemulsification and intraocular lens implantation using retrobulbar anesthesia. J Cataract Refract Surg 2000;26:842846

23. Beurs de E, Beekman ATF, Deeg DJH et al. Predictors of change in anxiety symptoms of older persons: results from the Longitudinal Aging Study Amsterdam. Psychol Med 2000;30:515-527

24. Assema van P, Mesters I, Kok G. Het focusgroep-interview: een stappenplan. T. Soc. Gezondheidsz., 1992;70:431-437

25. Morgan DL. Focus Groups as qualitative research. Qualitative research methods series 16 (Vol. 16). Beverly Hills: SAGE Publications Inc, 1988

26. Vries de $H$, Weijts $W$, Dijkstra $M$ et al. The utilization of qualitative and quantitative data for health education program planning, implementation, and evaluation: a spiral approach. Health Education Quarterly, 1992;19:101-115

27. Sapolsky RM. Why zebras don't get ulcers - A guide to stress, stress-related diseases, and coping. New York: WH Freeman and Company, 1994

28. Lazarus RS and Folkman S. Stress, appraisal, and coping. New York: Springer Publishing Company, 1984

29. Ploeg van der HM. Stressful medical events: a survey of patients' perceptions. In: Maes $S$, Spielberger CD, Defares PB and Sarason IG (eds.), Topics in Health Psychology. Chichester: John Wiley, 1988: 193-203

30. Nijkamp MD, Nuijts RMMA, Borne van den HW et al. Determinants of patient satisfaction after cataract surgery in 3 settings. J Cataract Refract Surg 2000;26:1379-1388 
Chapter $4 b$

\section{Determinants of surgery related anxiety in cataract patients}

Manuscript submitted for publication as: Chantal A. Kenens, Marjan D. Nijkamp, Anton J.M. Dijker, Robert A.C. Ruiter, Frans Hiddema, Rudy M.M.A. Nuijts. "Determinants of surgery related anxiety in cataract patients". 


\section{Abstract}

\section{Background/aims}

Not much is known about the relative importance of different determinants of anxiety in cataract patients. This study analysed the predictive value of factors related to this anxiety.

\section{Methods}

In 128 cataract patients, recruited from Medical Center Maastricht Annadal (MCMA) and Rotterdam Eye Hospital (REH), state anxiety was assessed at four different time points using the State-Trait Anxiety Inventory (STAI). The following predictive factors of anxiety were measured: trait anxiety, social support, stress, perceived behavior control, outcome expectation, perceived threat, doctor-patient relationship, coping strategies, first or second eye cataract surgery, and information supply. Repeated measures ANOVA, t-tests, multiple regression analysis, and correlations were used to analyse data.

\section{Results}

In general patients reported little anxiety. The level of anxiety (scale 1-4) was the highest before surgery (score $1.8 \pm 0.81$ one or two weeks preoperatively and $1.8 \pm 0.75$ just before surgery), decreased to $1.1 \pm 0.34$ immediately after surgery, and increased to $1.3 \pm 0.48$ after the postoperative visit. Patients with higher trait anxiety levels $(r=0.40 ; p<0.001)$ and women $(r=0.30 ; p<0.001)$ reported more anxiety. At the REH patients reported less anxiety (mean score $=1.41 \pm 0.57$ ) compared to the MCMA (mean score $=1.65 \pm 0.39$; $\mathrm{p}<0.01)$.

\section{Conclusion}

Women and patients with higher trait anxiety were more likely to experience higher levels of state anxiety. Patient education and a good doctor-patient relationship may decrease anxiety. 


\section{4b.1 Introduction}

Anxiety is an emotion that can be divided into two dimensions: state and trait anxiety. ${ }^{1}$ State anxiety is specifically triggered by a threatening situation and fluctuates over time. Trait anxiety is a stable natural anxiety disposition and may influence the state anxiety levels experienced during anxiety provoking situations. Anxiety in surgical patients is highly acknowledged. ${ }^{2}$ From former studies it seems that cataract patients can experience anxiety pre-, per-, and postoperatively. ${ }^{3-5}$ In a preceding study, ${ }^{5}$ a model regarding the factors related to anxiety in patients awaiting cataract surgery was suggested (Figure 4b.1).

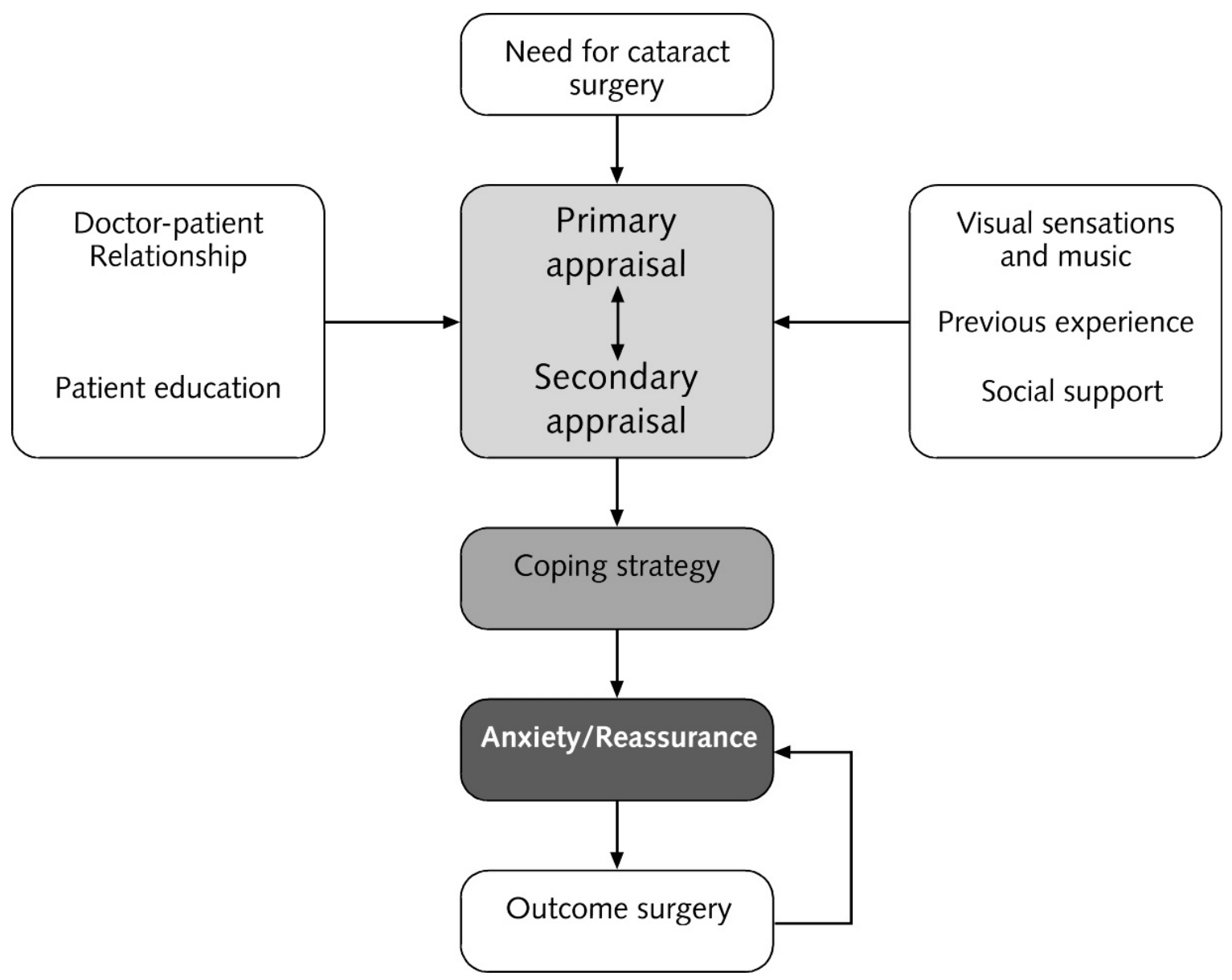

Figure 4b.1: Research model of anxiety related factors

This model is based on the cognitive appraisal model, developed by Cohen and Lazarus ${ }^{6}$, and includes the concepts of primary (perceived threat) and secondary appraisal (outcome expectancy and perceived behavioral control) as well as coping strategy. Patients can use different coping strategies to deal with upcoming surgery that depend on their primary and secondary appraisals. These strategies, in turn, can influence the level of anxiety. ${ }^{7}$ 
It is generally agreed that a good doctor-patient relationship can decrease anxiety among patients. ${ }^{8}$ Social support and information are also related to a reduction of anxiety ${ }^{2,9}$, whereas stress can have an anxiety increasing effect. ${ }^{7}$ Furthermore, former studies found that music and visual sensations perceived during surgery may influence anxiety in cataract patients. ${ }^{10-12}$ If patients already had first-eye cataract surgery, patients said this previous experience influenced their anxiety during the pre-, per-, and postoperative stages of their second surgery. ${ }^{5}$ Retrobulbar anesthesia used in cataract surgery causes anxiety ${ }^{5}$, which may be reduced by using sedatives in clinical practice. ${ }^{13-15}$ Demographic variables like age, gender, and education can also influence anxiety, especially women report higher anxiety levels. ${ }^{1}$ To our knowledge, no quantitative study has been performed yet that combined these variables in a single study, and tested their relationships with anxiety pre-, per-, and post-cataract surgery. The aim of the present study is to indicate the factors that are related to cataract surgery induced anxiety. Results of this study provide recommendations for future programs to reduce anxiety regarding one of the most frequently performed surgical procedures (about 100.000 surgeries a year in the Netherlands).

\section{4b.2 Patients and Methods}

\section{4b.2.1 Patients}

This study was carried out among 128 cataract patients who had routine cataract surgery with intraocular lens implantation in the period from June to September 2001 at the Medical Center Maastricht Annadal (MCMA, n=50) or the Rotterdam Eye Hospital (REH, $\mathrm{n}=78$ ). The research proposal was approved by the Medical Ethics Committee, and all patients signed an informed consent before inclusion in the study. Patients were selected according to the following inclusion criteria: suffering from cataract, aged 50 years or older, and suitable for outpatient surgery. Exclusion criteria were ocular co-morbidity, dementia, psychological disorders or deafness, and not being able to speak or read Dutch. The mean age of the patients was $73.2 \pm 8.6$ years (range 50 to 89 years). Fifty-eight percent were women and $42 \%$ men. Most patients (79\%) were categorized as low or medium educated. Forty-one percent of the patients reported previous cataract surgery on the fellow-eye. Except for age $(\mathrm{MCMA}=75.4 \pm 6.9$ years and $\mathrm{REH}=71.9 \pm 9.3$ years; $\mathrm{p}<0.05)$, there were no significant differences in patient characteristics between the two hospitals (Table 4b.1). Four patients were lost to follow-up during the study, because of refusing further participation $(n=3)$ and too much difficulty with answering the questions $(n=1)$. Their completed questionnaires were used for analyses. 


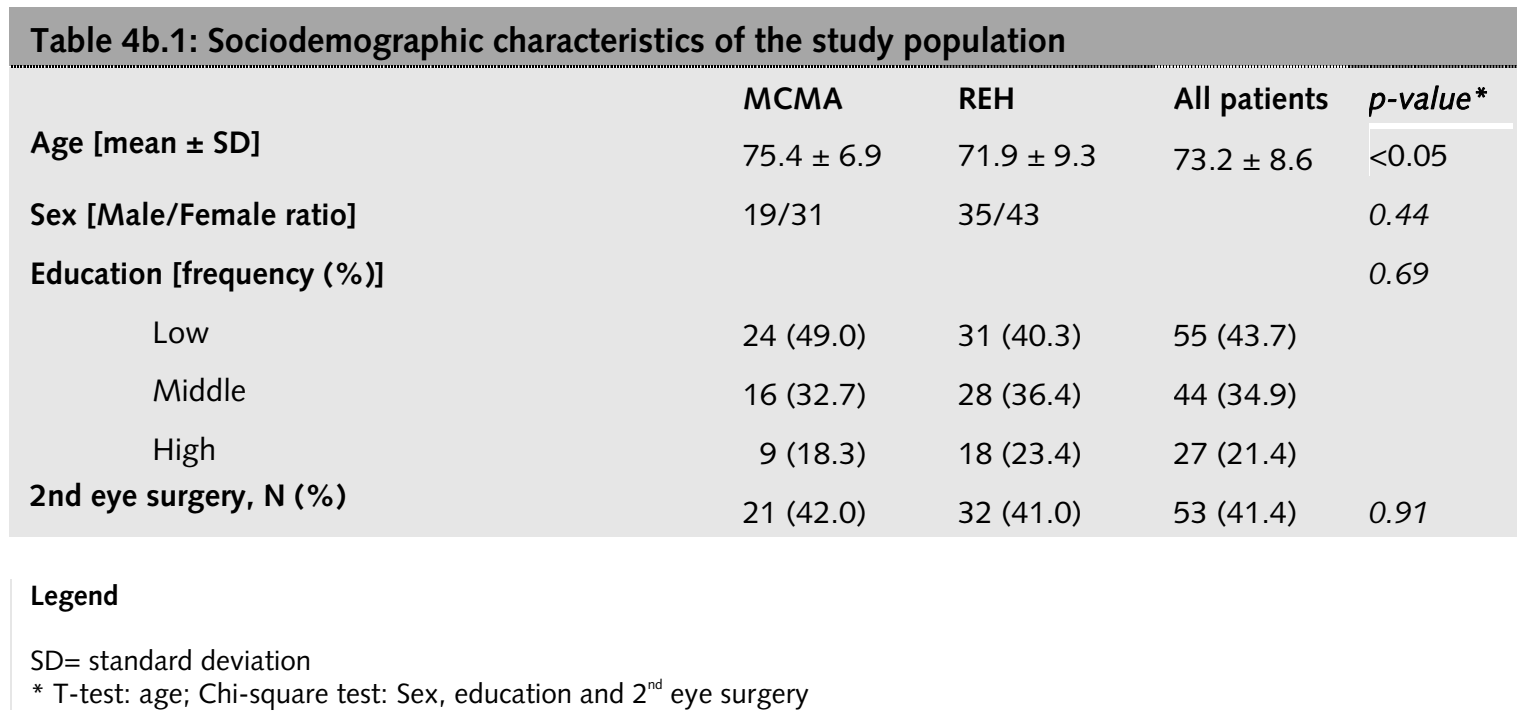

\section{4b.2.2 Surgical Technique}

Cataract surgeons at both hospitals performed standard phacoemusification with intraocular lens implantation and retrobulbar anesthesia. Patients at the $\mathrm{REH}$ received $7.5 \mathrm{mg}$ dormicum [Roche; The Netherlands] before local anesthesia, unlike patients at the MCMA.

\section{4b.2.3 Data gathering}

Patients were followed during the entire health care process and were asked to complete four different questionnaires at the hospital at four different points in time. The first questionnaire was administered immediately after the last preoperative visit one or two weeks before cataract surgery (t1). The second questionnaire was handed out a couple of minutes before surgery; at the MCMA before the retrobulbar block and at the REH before sedatives were given ( $\mathrm{t} 2$ ). Patients were asked to complete the third questionnaire immediately after surgery, while seated in the waiting room (t3). The last questionnaire was administered the day after surgery ( $\mathrm{t} 4)$. Patients received instructions before completing the questionnaires. Questionnaires 1 and 4 took approximately 20 minutes for patients to complete, while questionnaires 2 and 3 took about one minute.

\section{4b.2.4 Materials}

Most questions in the four questionnaires could be answered on 4-point scales varying from 'No!' (1), 'Not really' (2), 'On the whole, yes' (3) to 'Yes!' (4), based upon response options described by Sixma et al. ${ }^{16}$ On all scales, a higher score indicated a higher level of the factor measured. Anxiety was measured by the Dutch version ${ }^{17}$ of the Spielberger StateTrait Anxiety Inventory (STAI) ${ }^{1}$, which distinguishes between state anxiety and trait anxiety. Because of constraints in time at the day of surgery, the short version of the STAI was used, which has shown good validity. ${ }^{18}$ 
Furthermore, patients were asked to rate their state anxiety on a visual analogue scale (VAS) varying from 0 ('not at all anxious') to 10 ('extremely anxious'). State anxiety and the VAS were measured by all four questionnaires, while trait anxiety was measured only by the first questionnaire, because it is assumed to be a stable factor over time. ${ }^{1}$

Perceived threat and outcome expectancy were measured by 3 -item scales at $\mathrm{t} 1$. Perceived behavior control was measured at $\mathrm{t} 1$ and $\mathrm{t} 4$ by respectively 7 and 6 items (e.g. 'I felt prepared for surgery'). The variable doctor-patient relationship was measured by a 3-item scale at $\mathrm{t} 1$ and a 14-item scale at $\mathrm{t} 4$, including questions like 'The ophthalmologist treated me in a reassuring way' and 'The ophthalmologist told me immediately after surgery the outcomes of the surgery'. Coping strategy was measured at $\mathrm{t} 1$ by the Utrecht Coping List $(\mathrm{UCL})^{19}$, which has proven to be a valid and reliable instrument. ${ }^{20}$ The short (14-item) version focused on three coping strategies: problem based coping, denial coping, and emotional coping. Patients were asked how often they used the specific coping strategies: 'seldom or never', 'sometimes', 'often' and 'almost always'. Social support (t1) was measured on a 7-item scale and included questions like 'I can talk about my feelings with regard to cataract surgery with people in my social environment'. Stress (t1) was measured by a single item; 'I experience stress because of the upcoming cataract surgery'. Information supply ( $\mathrm{t} 4$ ) was measured by twenty questions about various aspects of cataract; for example questions concerning information about risks of treatment and information during surgery. Patients were asked whether they received the information at all, and whether they understood this information. Moreover, questions about music during surgery and perceived visual sensations were formulated. At $t 1$ patients were asked to what extent they felt anxious about the retrobulbar anesthesia. Additionally, patients were asked retrospectively at $t 4$ to what extent they felt anxious during local anesthesia. Furthermore, previous (cataract) surgical experiences and socio-demographic variables (age, gender, and education) were registered ( $\mathrm{t} 1$ ). In addition, a few open-ended questions (e.g. what patients found most reassuring) were included. At the $\mathrm{REH}$, interactive patient education is presented in addition to oral/written information as given at the MCMA. ${ }^{5}$ Therefore, these patients were asked to answer a few additional questions ( $\mathrm{t} 4$ ) about the interactive cataract $\mathrm{CD}-\mathrm{ROM}$, the $\mathrm{REH}$ website, the video tape, the live-surgery video report, and the sedation before the retrobulbar anesthesia.

The questionnaires 1 and 4 were tested at both hospitals among 18 cataract patients before onset of the study. Patients in this pilot-study were asked to fill in the questionnaire and to mark any indistinctness. As a result of these pilot-tests, the questionnaires were improved. Cronbach's alpha was used to calculate the internal consistency of the scales and showed satisfactory values, varying from 0.70 to 0.87 . The variable perceived behavior control was excluded from analyses based on a low Cronbach's alpha score $(\alpha<0.40)$. 


\section{4b.2.5 Statistical Analysis}

Data analyses were performed using SPSS 10.0 (SPSS Inc, Chicago). Before the main analyses were carried out, data were screened, recoded when necessary, and mean scores were calculated for constructed scales. Repeated measures analysis of variance (RM ANOVA) was used to show differences in levels of anxiety over time between hospitals. Independent and paired t-tests showed differences between groups and between times of measurement. Multiple linear regression analysis (ENTER method) was used to indicate the relative importance of separate variables in predicting anxiety. The factors stress and perceived threat were excluded from the regression model to prevent collinearity; these variables were highly correlated with experienced anxiety, $(r=0.69$ and $0.61 ; p<0.001$, respectively). ${ }^{21}$ Both Pearson correlations and regression coefficients were calculated for mean anxiety levels across the four measurement points. Patients who had per- or postoperative complications $(n=6)$ were excluded from postoperative analyses, because complications may affect the level of anxiety. 


\section{4b.3 Results}

Mean reported levels of state anxiety at $t 1$ to $t 4$ were $1.8 \pm 0.81,1.8 \pm 0.75,1.1 \pm 0.34$, and $1.3 \pm 0.48$, respectively. A RM ANOVA with state anxiety as within-subjects factor and hospital site as between-subjects factor showed a main effect of state anxiety over time $(\mathrm{p}<0.01)$. Paired-samples t-tests showed, across hospital sites, that state anxiety levels decreased immediately after surgery ( $\mathrm{t} 3)$ as compared to the measure at $\mathrm{t} 2(\mathrm{p}<0.001)$, and increased again the day after surgery $(p<0.001$, Figure 4b.2).

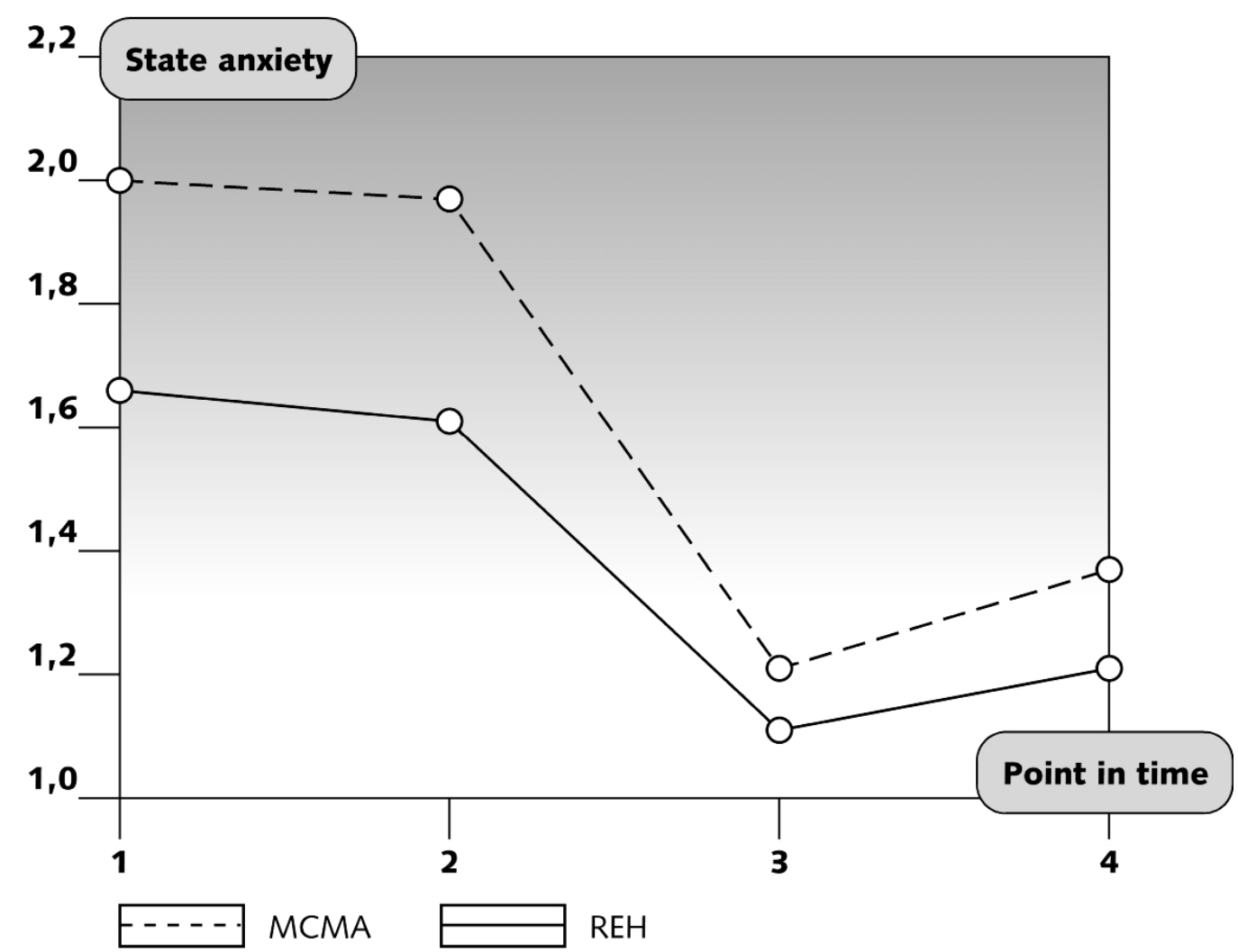

Figure 4b.2: Mean state anxiety scores per measurement point and per hospital

VAS scores showed a similar pattern. Across measurements patients at the MCMA reported higher levels of state anxiety (mean score $=1.65 \pm 0.39$ ) than patients at the REH (mean score $=1.41 \pm 0.57$ ). Although the main effect of hospital site was significant for this measure of anxiety $(p<0.01)$, no statistical support was found for the interaction between state anxiety and hospital site $(\mathrm{p}=0.07)$. This finding indicates a similar course in time of anxiety for both settings. Trait anxiety did not differ between the two hospitals $(p=0.66)$, neither between male and female patients $(p=0.26)$. Anxiety specifically related to local anesthesia (mean 1.97 \pm 1.18 ) also showed no difference between the two settings $(p=0.39)$. However, patients at the REH who received dormicum reported less anxiety 
during retrobulbar anesthesia in retrospect (mean score $=1.3 \pm 0.80$ ) as compared to MCMA patients who did not receive dormicum (mean score $=2.0 \pm 1.22, \mathrm{p}<0.001$ ).

Table 4b.2 shows the correlations between state anxiety and the hypothesized determinants, and the standardised regression weights of these determinants in predicting state anxiety aggregating the four measurements. Variables correlating significantly $(\mathrm{p}<0.05)$ with state anxiety were trait anxiety, outcome expectancy, doctor-patient relationship, social support, anxiety related to local anesthesia, gender, and hospital. Multiple linear regression analysis showed that trait anxiety, gender, and hospital had the most predictive influence on state anxiety, explaining $40.8 \%$ of the variance. Women, MCMA patients, and patients with higher trait anxiety scores reported higher state anxiety scores.

\begin{tabular}{|c|c|c|}
\hline \multicolumn{3}{|c|}{ 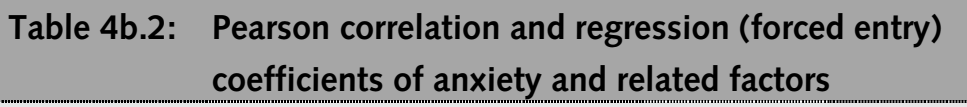 } \\
\hline Variables & $r$ & $\beta^{\dot{Y}}$ \\
\hline Trait anxiety & $0.400^{* *}$ & $0.360 * *$ \\
\hline Outcome expectancy & $-0.248 * *$ & -0.026 \\
\hline Doctor-patient relationship & $-0.206^{*}$ & -0.052 \\
\hline Problem based coping & -0.050 & 0.027 \\
\hline Emotional coping & 0.118 & 0.053 \\
\hline Denial coping & 0.067 & -0.062 \\
\hline Social support & $-0.331 * *$ & -0.170 \\
\hline Information & -0.157 & -0.025 \\
\hline Anxiety of local anaesthesia & $0.462 * *$ & \\
\hline Earlier cataract surgery & -0.048 & -0.035 \\
\hline Numbers of other surgery & 0.169 & 0.008 \\
\hline Age & 0.057 & -0.024 \\
\hline Gender & $0.298^{* *}$ & $0.200^{* *}$ \\
\hline Education & -0.083 & \\
\hline Hospital & $0.248^{* *}$ & $0.336^{* *}$ \\
\hline $\mathrm{R}^{2}$ (explained variance) & & $0.408^{* *}$ \\
\hline $\begin{array}{l}\text { Legend } \\
\begin{array}{l}* \quad \text { Significant at the } 0.05 \text { level } \\
\text { * Significant at the } 0.01 \text { level } \\
\dot{Y} \quad \text { Standardised betas }\end{array}\end{array}$ & & \\
\hline
\end{tabular}


There was no difference in anxiety immediately after surgery between patients who listened to music during surgery and those who did not $(\mathrm{p}=0.37)$. During surgery, 52 patients $(44 \%)$ perceived photopic phenomena like colors, light and hands. Five of these patients (9.6\%) experienced this as threatening. In response to the open-ended question asking what patients believed to be the most anxiety-arousing, 40 out of 82 patients answered they experienced no anxiety. Local anesthesia (20), the unknown (7), failure of surgery (3), and 22 other reasons (e.g. the threatening eye, to lie still during surgery) were the other responses to this question. What patients found most reassuring $(n=75)$ was information (11), the ophthalmologist (10), a quiet and restful atmosphere (8), personnel (6), dormicum sedation (6), the welcome (6), trust in expertise (5), being accompanied by a relative/acquaintance during the visits at the hospital (5), presence and stories of other cataract patients (5), and 13 other reasons (e.g. second eye surgery).

At the REH, 54\% of all patients watched the live cataract surgery video just before onset of surgery. Compared with patients who did not watch this video preoperatively, no difference was found in pre- and postoperative anxiety levels (immediately before surgery $p=0.93$; immediately after surgery $\mathrm{p}=0.93$ ). The live video was appraised as reassuring by $49 \%$ of all patients, $17 \%$ scored 'not really'. Ninety-one percent of the REH patients described the dormicum sedative as reassuring. After surgery this percentage increased to $97 \%$.

\section{4b.4 Discussion}

The average patient experienced little anxiety related to cataract surgery (mean $1.5 \pm 0.48$ ). Patients reported most anxiety preoperatively. Immediately after surgery, the level of anxiety dropped, probably due to the relief. These results agree with research by Foggitt. ${ }^{4}$ The next day anxiety increased, which may be provoked by new concerns regarding what to do and expect. ${ }^{5}$ During local anesthesia that was most frequently mentioned as anxiety trigger, patients at the REH experienced less anxiety than patients at the MCMA, which may be a consequence of receiving $7.5 \mathrm{mg}$ dormicum. ${ }^{13-15}$ It remains unclear why differences in anxiety related to anesthesia did not exist between hospitals in advance of the retrobulbar block, keeping in mind that patients at the $\mathrm{REH}$ could anticipate on sedation before local anesthesia. To obtain a greater reduction of anxiety during the days before surgery, patients should be informed better about the advantages of dormicum.

Corresponding with literature on STAI studies, ${ }^{22}$ trait anxiety seemed to be an important determinant of state anxiety. Specifically, patients with higher trait anxiety levels showed increased state anxiety levels. Higher trait levels were found among women in those studies, although we could not support that in our study. As expected, patients with higher outcome expectancies reported lower state anxiety levels. Although the overall information supply did not show a significant correlation with anxiety, patients noted information most frequently as being the most reassuring. The same non-significance was found with respect to the doctor-patient relationship in regression analysis, which was paradoxically mentioned 
as runner up reason for the most reassuring aspect. According to the patient's own words, those two factors may be of relatively high importance.

Unexpectedly, coping strategy was not related to anxiety, which may be a result of the expressed difficulties patients had answering these questions. Besides, questions are rising about the usefulness of coping measurements by means of checklists. ${ }^{23}$ Patients who received better social support reported less state anxiety, which recommends hospitals to ask patients to bring someone with them during hospital visits. Morrell ${ }^{24}$ showed that structured preoperative teaching can reduce anxiety in cataract patients, especially information regarding safety of cataract surgery. ${ }^{25}$ Former research showed rather low levels of knowledge with respect to cataract and misperceptions in cataract patients, who needed surgery in addition to limited information retention. ${ }^{25-27}$ Those poor information retention percentages were related to advanced age and lower educational level. ${ }^{27}$

This may have lead to the non-significance between the mean information score and state anxiety in our study. In accordance to former studies ${ }^{10,12}$, music did not influence anxiety levels. However, those studies did report an influence of music on blood pressure and satisfaction. No difference was found in anxiety between first and second eye surgery patients or number of other surgeries. Although not significant, patients undergoing their second cataract surgery reported less anxiety preoperatively, but postoperatively they reported more anxiety compared to first eye surgery patients. This was also found by Foggitt ${ }^{4}$, and may be explained by the fact that not a single cataract surgery is performed exactly in the same way, therefore things aren't going as expected, which could cause anxiety. ${ }^{5}$ Age and education showed no relation with state anxiety, while gender showed to be an important determinant. Women experienced more state anxiety compared to men, which is generally agreed upon in the literature. ${ }^{22}$

CD-ROMs with information about cataract surgery provided by the REH, were hardly used $(n=10)$. This may have been caused by renovations at the REH and by not telling patients about this possibility. Although high ages of cataract patients are not enhancing CD-ROM use, it is worthwhile to investigate the effects of this interactive information source on levels of anxiety by means of an experimental study, especially because recent CD-ROM education research among elderly cardiac patients showed good results. ${ }^{28}$

The analyses of this study showed that hospital setting is an important determinant of reported levels of state anxiety. Future research should therefore illustrate which specific hospital characteristics are predictive of differences in anxiety between the settings. Maybe information about complications differed between the two hospitals, which may induce these differences in reported state anxiety. 
The possibility that patients reported low state anxiety levels may be affected by artifacts (e.g. social desirability). These should temper a conclusion that patients are not very anxious for cataract surgery, although measurements were taken to prevent these artifacts (e.g. guaranteed anonymity). In addition, it may not be useful to attempt to reduce anxiety completely, because a low level of anxiety can be beneficial by promoting effective preparation and accurate expectations of discomfort, and thus preventing disappointment. ${ }^{29}$

In conclusion, to decrease anxiety, more emphasis should be focused on reassuring determinants by paying more attention to doctor-patient relationship and patient education. Especially for women and patients with a noticeably higher anxiety level. The routine aspect of cataract surgery may be emphasized to increase positive outcome expectancies. Furthermore, patients should be recommended to bring relatives or friends with them during hospital visits for social support. 


\section{References}

1. Spielberger CD. Manual for the State-Trait Anxiety Inventory. Palo Alto: Consulting Psychologists Press Inc., 1970

2. Breemhaar B, van den Borne HW, Mullen PD. Inadequacies of surgical patient education. Patient Education and Counseling 1996; 28:31-34

3. Fagerström R. Fear of a cataract operation in aged persons. Psychol Rep 1993; 72:1339-1346

4. Foggitt PS. Anxiety in cataract surgery: Pilot study. J Cataract Refract Surg 2001; 27: 1651-1655

5. Nijkamp MD, Ruiter RAC, Roeling $M$, et al. Factors related to fear in patients undergoing cataract surgery: a qualitative study focussing factors associated with the fear and reassurance among patients who need to undergo cataract surgery. Patient Education \& Counseling 2002; 47:265-272

6. Cohen F, Lazarus RS. Coping and adaption in health and illness. In: Mechanic D, editor. Handbook of health, health care and the health professions. London: The Free Press, 1983, 608-635

7. Taylor SE. Health Psychology. 3rd ed. New York: Mc Graw-Hill; 1995: 2258.

8. Visser APh. Angst en patiëntenvoorlichting. In: Damoiseaux V, Visser APh, eds. Patiëntenvoorlichting, een interdisciplinaire benadering. Assen: van Gorcum; 1988: 225-243

9. Gerdes EP, Guidi EJ. Anxiety in patients awaiting primary medical care. Med Care 1987; 25:913923

10. Allen $\mathrm{K}$, Golden $\mathrm{LH}$, Izzo Jr JL et al. Normalization of hypertensive responses during ambulatory surgical stress by perioperative music. Psychosom Med 2001; 63:487-492

11. Au Eong KG, Lim TH, Lee $H M$, et al. Subjective visual experience during phacoemulsification and intraoculair lens implantation using retrobulbar anesthesia. J Cataract Refract Surg 2000; 26:842-846

12. Cruise CJ, Chung F, Yogendran $S$ et al. Music increases satisfaction in elderly outpatients undergoing cataract surgery. Can J Anaesth 1997; 44:43-48

13. Kiefer RT, Weindler J, Ruprecht, KW. Oral low-dose midazolam as premedication for intraoculair surgery in retrobulbar anesthesia: cardiovasculair effects and relief of perioperative anxiety. Eur J Ophthalmol 1997; 7:185-192

14. Weindler J, Mohamed $G$, Lieblang $S$ et al. Perioperative physiological and cognitive functions following oral premedication with $3.75 \mathrm{mg}$ midazolam in operations with retrobulbair anesthesia. Anaesthesist 1996; 45:826-833

15. Janzen PR, Christys A, Vucevic M. Patient-controlled sedation using propofol in elderly patients in day-case cataract surgery. Br J Anaesth 1999; 82:635-636

16. Sixma HJ, Campan van C, Kerssens JJ et al. Onderzoeksprogramma Kwaliteit van Zorg. De QUOTE-vragenlijsten. Kwaliteit van zorg vanuit patiëntenperspectief; vier nieuwe vragenlijsten. Utrecht: NIVEL, 1998; 27

17. Ploeg van der HM, Defares PB, Spielberger CD. Handleiding bij de Zelf-Beoordelings Vragenlijst ZBV. Een Nederlandstalige bewerking van de Spielberger State-Trait Anxiety Inventory STAI-DY. Lisse: Swets en Zeitlinger, 1980

18. Marteau TM, Bekker H. The development of a six-item short-form of the Spielberger State-Trait Anxiety Inventory (STAI). Br J Clin Psychol 1992; 31:301-306 
19. Schreurs PJG, Van de Willige G, Brosschot JF et al. De Utrechtse Copinglijst: UCL. Omgaan met problemen en gebeurtenissen. Lisse: Swets \& Zeitlinger, 1993

20. Sanderman $\mathrm{R}$, Ormel, J. De Utrechtse Copinglijst (UCL): validiteit en betrouwbaarheid. Gedrag en Gezondheid 1992; 20:32-37

21. Tabachnick BG, Fidell LS. Using multivariate statistics. New York, NY, HarperCollins College Publishers, 1996; 86

22. Spielberger CD. State-Trait Inventory (STAI). In: het meten van de gezondheidstoestand. Beschrijving en evaluatie van vragenlijsten. Furer JW, König-Zahn C, Tax B, eds. Assen: Van Gorcum, 1995.

23. Coyne JC, Gottlieb BH. The mismeasure of coping by checklist. J Pers 1996; 64:959-991

24. Morrell G. Effect of structured preoperative teaching on anxiety levels of patients scheduled for cataract surgery. Insight 2001; 26:4-9

25. Spina Jr J. The fear of cataract extraction: Mental health aspects of a geriatric health problem. Clinical Gerontologist 1984; 2:69-70

26. O'Malley TP, Newmark TS, Rothman MI et al. Emotional aspects of cataract surgery. Int J Psychiatry Med 1989; 19:85-89

27. Morgan LW, Schwab IR. Informed consent in senile cataract extraction. Arch Ophthalmol 1986; 104:42-45

28. Strömberg $A$, Ahlén $H$, Fridlund $B$ et al. Interactive education on CD-ROM. A new tool in the education of heart failure patients. Patient Education and Counseling 2001; 46:75-81

29. Salmon $P$. The reduction of anxiety in surgical patients: an important nursing task or the medicalization of preparatory worry? Int J Nurs Stud 1993; 30:323-330 
Chapter 5

\section{Effectiveness of multifocal intraocular lenses to correct presbyopia after cataract surgery: a randomised controlled trial}

Manuscript submitted for publication as: Marjan D. Nijkamp, Maria G.T. Dolders, John de Brabander, Bart van den Borne, Fred Hendrikse, Rudy M.M.A. Nuijts. "Effectiveness of multifocal intraocular lenses to correct presbyopia after cataract surgery: a randomised controlled trial" 


\begin{abstract}

\section{Purpose}

Although monofocal intraocular lenses (IOLs) are effective in improving vision after cataract surgery, the loss of accommodation is not restored by implantation of these IOLs. Since multifocal IOLs may improve uncorrected distance and near vision, we compared the clinical outcome and patient satisfaction after implantation of monofocal and multifocal IOLs. Socio-demographics, eagerness for spectacle independence (ESI), and neuroticism were tested as predictors of satisfaction.
\end{abstract}

\title{
Design
}

Randomised controlled trial.

\section{Participants}

Cataract patients with no ocular co-morbidity were operated from August 1999 to January 2001, 75 patients were implanted with monofocal and 78 patients with multifocal IOLs.

\section{Methods}

Assessments were made preoperatively (t1), 3 months after first (t2), and 3 months after second eye surgery (t3). Primary outcomes were obtained by ophthalmic tests, while secondary outcomes were examined by interviews.

\section{Main Outcome Measures}

Primary outcomes consisted of near and distance visual acuity. Secondary outcomes related to spectacle dependence, vision related functioning, and patient satisfaction.

\section{Results}

Multifocal IOLs showed significantly better uncorrected near visual acuity, higher quality ratings of unaided near vision over time, and reduced spectacle dependence at $\mathrm{t} 2$ for near and at $\mathrm{t} 3$ for near and distance. Monofocal IOLs showed less bother from cataract symptom scores. Satisfaction related to preoperative expectations was similar in the monofocal and multifocal groups. The perceived quality of corrected near vision had the strongest relationship with patient satisfaction. Socio-demographics, ESI, and neuroticism could not predict patient satisfaction.

\section{Conclusions}

Overall patient satisfaction did not differ between the groups of mono- and multifocal IOLs. Independent of ESI or neuroticism scores, success of both IOLs depends on preoperative expectations and postoperative quality of aided near vision. 


\subsection{Introduction}

Cataract is an age-related eye disease that impairs patients in their daily functioning. Patients complain of loss of visual acuity, glare, and seeing halos at night. ${ }^{1}$ According to the World Health Organisation 18 million people are blind worldwide because of untreated cataract. ${ }^{2}$ In the absence of any proven safe and effective prevention of cataract, surgery is the only possibility to restore vision. The crystalline lens is removed and replaced by an artificial intraocular lens (IOL) usually with only one focal point (monofocal). Since the natural process of accommodation is not restored (=presbyopia), a monofocal IOL needs complementary reading or multifocal glasses to create good vision at more than one distance. Recently the implantation of lenses with more than one focal point (multifocal) has gained wide popularity. The beneficial effect of these lenses is better uncorrected near visual acuity, resulting in reduced spectacle dependence as compared to patients with monofocal intraocular lenses. ${ }^{3-7}$ Drawbacks may be a loss of contrast sensitivity, and perception of halos, although this has not been proven to be of importance in the daily activities of patients consistently. ${ }^{8-11}$ It has been suggested that neurotic personalities might have a negative likelihood of postoperative patient satisfaction. ${ }^{4}$ In contrary, patients who are eager to be spectacle independent would be more willing to accept the visual side effects described before. ${ }^{12}$ The present study was initiated to evaluate whether multifocal IOLs are effective for the correction of presbyopia after cataract surgery, and to identify predictors of patient satisfaction.

\subsection{Methods}

\subsubsection{Study participants}

In this randomised controlled trial (RCT) patients were operated from August 1999 to January 2001 at University Hospital Maastricht (UHM), Medical Centre Maastricht Annadal (MCMA) or Atrium Medical Centre Heerlen (AMCH). The medical files of 1218 patients awaiting cataract surgery were screened by the following inclusion criteria: bilateral senile cataract, astigmatism $=1.5$ dioptres $(\mathrm{D})$, spectacle sphere power between $-6 \mathrm{D}$ and $+4 \mathrm{D}$, axial eye length between $19.5 \mathrm{~mm}$ and $26 \mathrm{~mm}$, no professional night driver, able to complete questionnaires in Dutch, and no mental retardation (as diagnosed in the medical file or concluded from contact by telephone). Additionally, subjects were required to have no eye disease other than cataract that might limit their postoperative vision. The nature and purpose of this study, including effects and possible side effects of the treatment were explained to eligible subjects by the ophthalmologist in attendance. Additionally, a patient information brochure and an informed consent form were constructed and sent to all eligible patients planned for cataract surgery. The ethical committee of the UHM and the review boards of all trial centres approved the research protocol. In order to control for possible bias due to per- or postoperative complications or (acquired) ocular co-morbidity, medical data were recorded 1 week and 4 weeks after surgery. Patients with complications or eye diseases other than secondary cataract were excluded from the study. 
Patients who suffered from secondary cataract, indicated by (planned) Nd:YAG capsulotomy, were compared to patients with clear lens capsules on primary and secondary outcome measures. To identify patient characteristics for successful implantation we assessed the influence of socio-demographics, eagerness for spectacle independence (ESI), and neuroticism on patient satisfaction. The ESI questionnaire focussed on perceived advantages and disadvantages of spectacles, and resulted from individual interviews with spectacle wearers. In a pilot study $(\mathrm{n}=25)$ the questions showed sufficient variability in the responses; varying from 1 'very eager to be spectacle independent' to 5 'not eager at all to be spectacle independent', and represented a high internal consistency (Cronbach's $\alpha=0.77)$. The personality trait neuroticism was expressed by the Neuroticism (N) scale of the Eysenck Personality Questionnaire-Revised Short Scale (EPQ-RSS) ${ }^{13}$, and ranged from 0 'not at all neurotic' to 12 'highly neurotic'.

\subsubsection{Study protocol}

Phacoemulsification under subtenon retrobulbar anaesthesia with a no-stitch $3.2 \mathrm{~mm}$ posterior limbal incision was performed, and either a monofocal foldable IOL (AMOPhacoFlexII $^{\circledR}$ SI40 NB, Allergan, Irvine, CA, USA) or a multifocal foldable IOL (AMOArray ${ }_{\circledast}$ SA40 N, Allergan, Irvine, CA, USA) was implanted. Both IOLs are structurally identical differing only in front surface optics. Postoperative refraction was aimed at emmetropia for monofocal and multifocal implants. Second eye surgery was planned sixteen weeks after the first lens extraction. Block randomisation by means of a computerised random number generator was used to keep the number of subjects in the different groups balanced. A technical ophthalmic assistant, allocated the treatment condition via sealed envelopes that contained a card identifying the lens type. Assessments took place 1 to 2 weeks before cataract surgery (t1), 3 months after first eye surgery (t2), and 3 months after second eye surgery (t3) by face-to-face structured interviews and ophthalmic tests. Measurements took place at the department of ophthalmology at the UHM by trained interviewers $(n=2)$ and ophthalmologists $(n=3)$. Patients were masked with respect to the type of lens until the first postoperative visit. Interviewers and ophthalmologists were unaware of the treatment group of the patient at baseline. However, because there were obvious differences between the treatment conditions, masking of interviewers and ophthalmologists postoperatively was not feasible. In order to control the assessments with respect to the amount of attention given to a patient, a time-analysis was conducted on both interviews and ophthalmic tests at $\mathrm{t} 1$, $\mathrm{t} 2$, and $\mathrm{t} 3$. 


\subsubsection{Primary outcome measures}

Postoperative refraction (i.e., best correction) was determined by the ophthalmologist 4 weeks postoperatively. Patients were instructed to present their prescription to their optician, and glasses were actually obtained upon the preference of the individual patient. Patients with a postoperative refractive error in spherical equivalent (SE) of more than 1.5 D from emmetropia were excluded from further analyses (Figure 5.1, monofocal $n=8$, multifocal $n=3$ ).

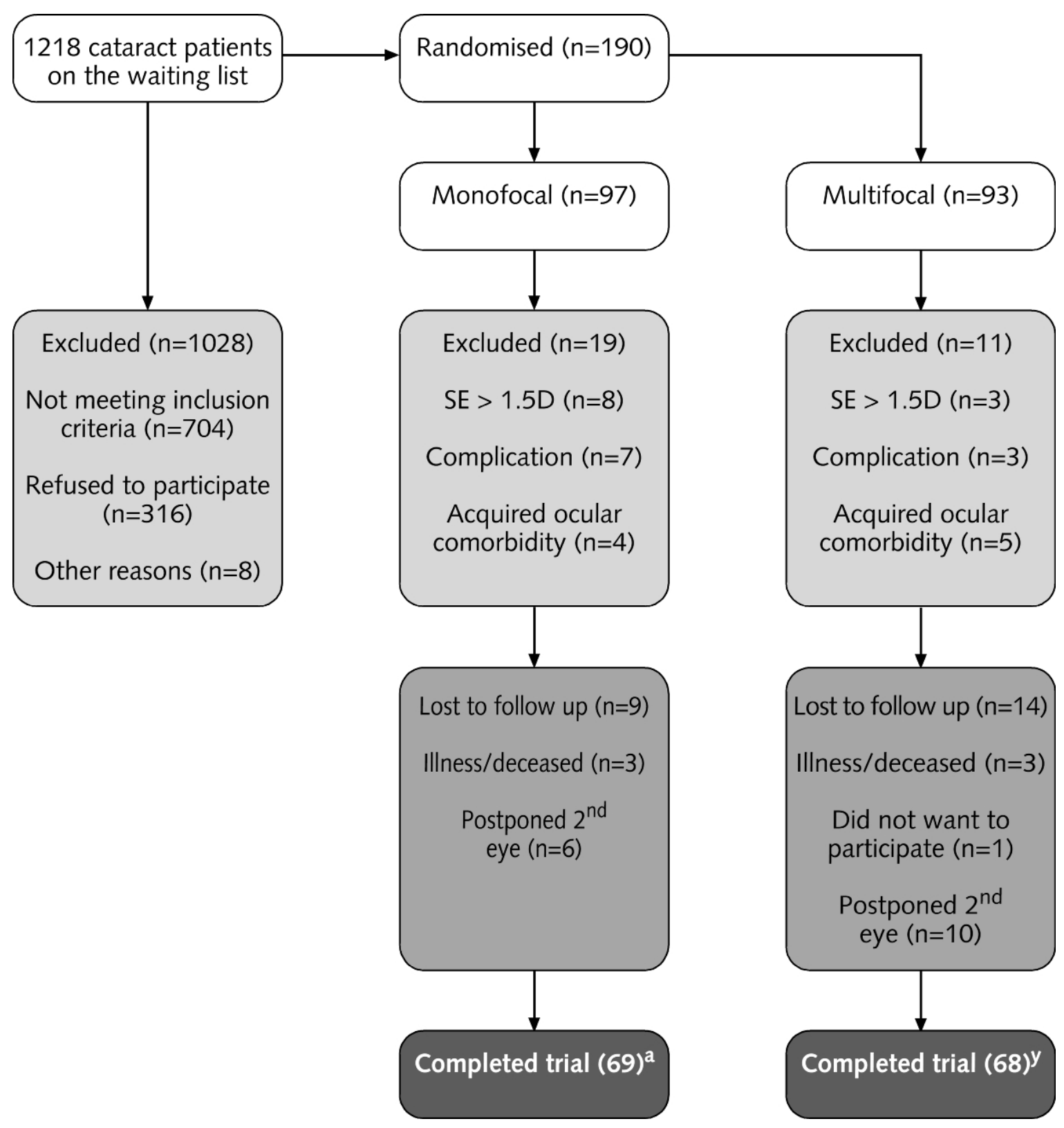

Figure 5.1: Trial profile

- $\quad a=$ One patient missed assessment at $t 2$ and four patients missed assessment at $t 3$

$y=$ Four patients missed assessment at $t 2$ 
To fit the ophthalmic tests to the reported functioning in everyday life, distance visual acuity (PCDVA) and near visual acuity (PCNVA) were measured as the patient presented with or without the prescribed spectacles (defined as present correction, PC). Additionally, uncorrected distance (UCDVA) and near (UCNVA) visual acuity were assessed to evaluate the effectiveness of the treatment. Best corrected distance (BCDVA) and near visual acuity (BCNVA) were registered to verify if patients had optimal clinical outcomes or not. Early Treatment Diabetic Retinopathy Study (ETDRS) distance visual acuity charts (Precision Vision, La Salle, IL, USA) and the reading charts 'De Nederlanders' (Medical Workshop, Groningen, the Netherlands), and 'Parinaud' (van Hopplynus, Brussels, Belgium) were used monocularly. For statistical analysis of distance visual acuity the logarithm of the minimal angle of resolution scale (logMAR) was used. ${ }^{14}$ Near visual acuity was expressed by local units controlled for the reading distance, and subsequently transformed into Jaeger values $(J)$.

\subsubsection{Secondary outcome measures}

Spectacle dependence was expressed by a frequency score varying from 1 'always' to 5 'never' for distance and near vision separately. A Visual Functioning questionnaire (VF-14) represented the amount of trouble patients had regarding vision related daily activities (e.g. reading and driving), and ranged from $0-100$ (higher scores meaning better functioning). ${ }^{1,15}$ Vision related quality of life (VQOL) was expressed by a VCM1 (Core Module) score ranging from 0 'best possible VQOL' to 5 'worst possible VQOL'. ${ }^{16}$ Bother from double or distorted vision, glare, halos, changes in colour perception, and worsening of vision, was expressed by the Cataract Symptom Score (CSS) varying from 0 'not at all bothered by any of the symptoms' to 15 'very bothered by all symptoms'. ${ }^{1}$ The VF-14, VQOL, and CSS have proven validity, reliability, and responsiveness, ${ }^{1,15-18}$ which permitted accurate estimation of effect sizes. ${ }^{19}$ All vision related functioning outcomes were evaluated with present correction in place. To assess satisfaction, patients were asked to rate their quality of near and distance vision with and without glasses separately on a 5-point Likert scale ranging from 1 'poor' to 5 'excellent'. ${ }^{20,21}$ In addition, the expectancy disconfirmation model was applied to define overall patient satisfaction. ${ }^{22}$ Preoperative expectations with respect to vision improvement (range 4 'very much improvement' to 1 'no or little improvement') were subtracted from postoperative evaluations (range 4 'very much improvement' to 0 'decrease in vision'). If low expectations were held preoperatively (e.g. response 1), and high evaluations were given postoperatively (e.g. response 4), people were considered as (highly) satisfied (satisfaction score $=3$ ). If expectations met postoperative evaluations (satisfaction score $=0$, cut-off point), people were considered to be satisfied. By using this fulfilment theory, the lack of response variability in satisfaction scores was overcome. . $^{3,15,21,23}$ 


\subsubsection{Statistical analyses}

To control for selection bias, eligible patients who refused to participate in the study (nonrespondents) were compared to respondents with regard to neuroticism, age, and sex. Statistical significance of the differences between the treatment groups regarding patient characteristics, primary outcome measures, and patient satisfaction were tested using independent t-tests with SPSS (version 10.0). In case of non-normality, the Mann-Whitney U-test was used. Paired t-tests were used to compare outcomes within groups. We used analysis of variance for repeated measures (RM ANOVA) to account for multiple testing, and to ascertain differences between the groups with respect to the course of secondary outcome measures. The between subjects source of variation was the experimental condition, whereas the within-subject factor was the outcome at the different points in time (t1 to $\mathrm{t} 3$ ). Correlational and standard multiple regression analyses were used to determine the relationship between patient satisfaction and the experimental condition, patient characteristics, primary and secondary outcome measures. Difference scores (postoperative - preoperative score) of the primary and secondary outcomes were used in these analyses. ${ }^{24}$ Patients were analysed according to the treatment as administered. An alpha $(\alpha)$ of 0.05 was the criterion for significance. Power calculations were made to determine the sample size. Given a two-sided effect testing, a power of $80 \%$, and a significance level of $p=0.05$, numbers needed to satisfy valid conclusions were 33 patients per arm. This was based on the assumption that a $10 \%$ difference on a 5 -point satisfaction scale was plausible. ${ }^{25} \mathrm{We}$ included a larger group of patients to meet the required sample size for regression analysis based upon the cases-to-independent variables ratio. ${ }^{26}$

\subsection{Results}

\subsubsection{Representativeness of the study group}

Five hundred and fourteen (42.2\%) cataract patients on the waiting list were eligible based on the inclusion criteria (Figure 5.1). Pseudophakia (prior cataract surgery in one eye) was the main reason for ineligibility. One hundred and nineteen patients were randomised (monofocal $n=97$, multifocal $n=93$ ). Nineteen patients (monofocal $n=11$, multifocal $n=8$ ) were excluded because of complications (5.3\%) or acquired ocular co-morbidity (4.7\%). Sixteen patients (monofocal $n=6$, multifocal $n=10$ ) had unilateral surgery. Two of these 10 patients postponed second eye surgery because of unacceptable side-effects (halos) of the multifocal intraocular lens at night. Both patients scored quality of near and distance vision comparable to patients that completed the trial ('good' to 'excellent'). Other reasons for dropout were illness/deceased (total $n=6)$ and not willing to participate anymore $(n=1)$. Only age differed significantly between respondents and non-respondents; the older elderly were less likely to participate: mean age $76.7 \pm 8.3$ and $71.6 \pm 8.5(p<0.001)$. Twenty-six percent of the non-respondents declared they had no time or did not want to participate, $18 \%$ suffered from a disease, and $11 \%$ were afraid because of the experimental character of the study. Other less frequently reported reasons for non-response were non-accessibility of the hospital, personal circumstances, cancellation of the operation, and decease. 
Patient characteristics (Table 5.1) and baseline data of primary (Table 5.2) and secondary outcomes (Table 5.3 and Table 5.4) were similar for the multifocal and monofocal group, which indicated a good quality of the randomisation procedure. There were no differences in primary and secondary outcomes when the study group was stratified by whether they had secondary cataract (monofocal $n=5$, multifocal $n=9$ ). Furthermore, time analysis showed that interviewers and ophthalmologists shared an equal period of time with both patient groups at all time points ( $p>0.05)$.

\begin{tabular}{|c|c|c|c|}
\hline & UHM & UHG & $p$-value* \\
\hline Age & $72.0(8.5)$ & $72.0(7.7)$ & 0.99 \\
\hline Male/Female n (\%) & $27 / 48(36 / 64)$ & $26 / 52(33 / 67)$ & 0.74 \\
\hline Education $\mathrm{n}(\%)^{*}$ & & & 0.34 \\
\hline Low & $38(50.6)$ & $46(58.9)$ & \\
\hline Middle & $21(28.0)$ & $22(28.2)$ & \\
\hline High & $12(16.0)$ & $8(10.2)$ & \\
\hline ESI & $3.2(0.7)$ & $3.1(0.8)$ & 0.35 \\
\hline Neuroticism & $3.8(3.3)$ & $3.9(3.2)$ & 0.78 \\
\hline \multicolumn{4}{|l|}{ Legend } \\
\hline \multicolumn{4}{|c|}{$\begin{array}{l}\text { Data are mean (SD) unless otherwise indicated } \\
\text { ESI = eagerness for spectacle independence } \\
\text { *Differences in normally distributed variables were tested by independent t-test, } \\
\text { Chi-square tests were used for ordinal variables, and Mann-Whitney U-test for } \\
\text { ordinal/non-normally distributed variables }\end{array}$} \\
\hline
\end{tabular}




\subsubsection{Primary outcome measures}

The monofocal group showed a slightly myopic SE compared to multifocal IOLs $(p<0.05$, Table 5.2). Mean postoperative logMAR PCDVA was similar in both groups. First eye surgery resulted in $0.11 \pm 0.2$ (20/25 Snellen) and 0.12 \pm 0.2 (20/25 Snellen) for monofocal and multifocal IOLs, respectively. Second eye surgery showed similar outcomes: $0.07 \pm 0.1$ (20/25 Snellen) and 0.09 \pm 0.2 (20/25 Snellen) for monofocal and multifocal IOLs, respectively. Patients in both groups had optimal results with their best correction in place, followed by present correction as compared to the UCDVA $(p<0.05)$. While mean postoperative PCNVA did not differ between both groups, mean UCNVA showed better results in the multifocal group $(p<0.01)$. Furthermore, BCNVA surpassed PCNVA and UCNVA in both groups $(p<0.01)$. 


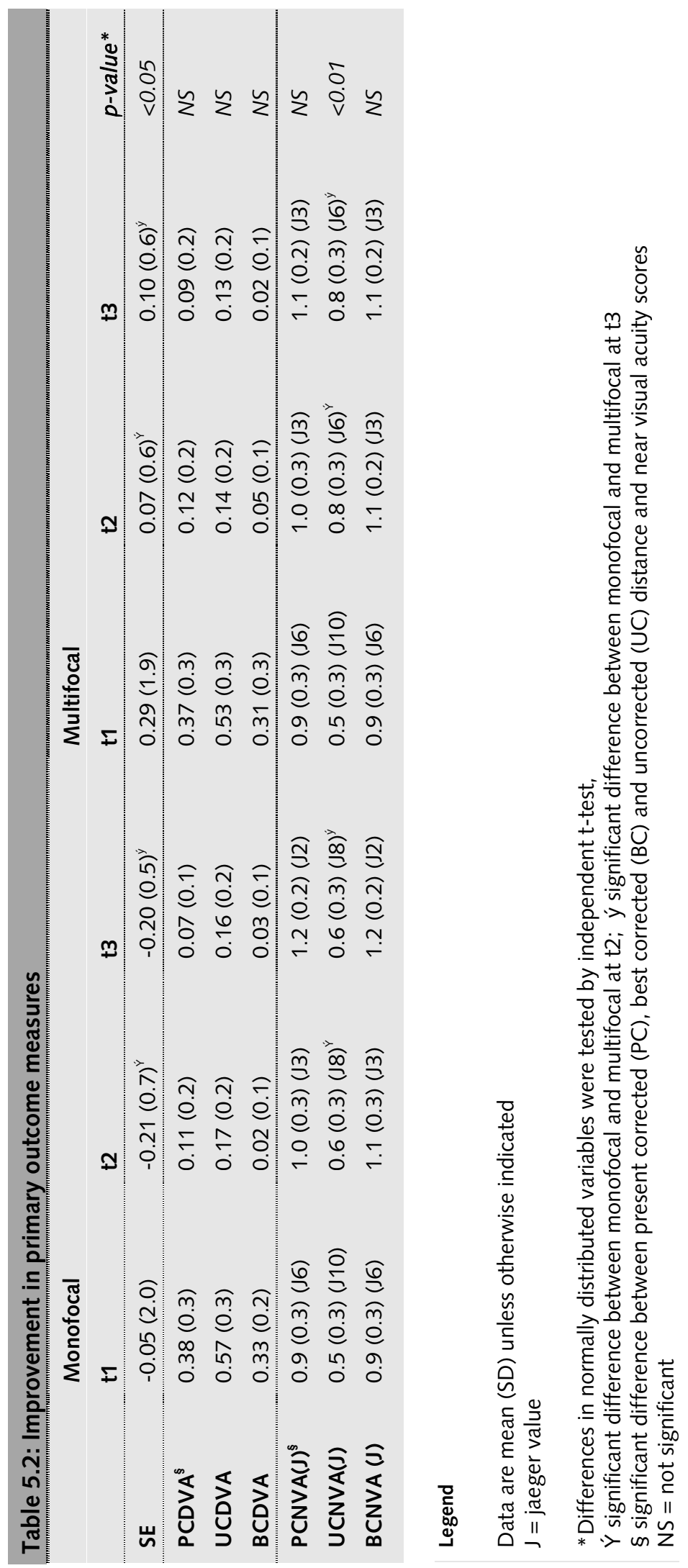




\subsubsection{Secondary outcome measures}

Patients with multifocal IOLs showed reduced spectacle dependence for near at $\mathrm{t} 2(\mathrm{p}=0.02)$ and $\mathrm{t} 3(\mathrm{p}=0.002)$, and for distance vision at $\mathrm{t} 3(\mathrm{p}=0.001)$ in comparison to the monofocal group (Table 5.3). In the monofocal group 14 out of 65 (21.6\%) patients were spectacle independent for near vision (no reading glasses or only wearing them 'now and then') at $\mathrm{t} 3$ as compared to 29 out of 68 (42.7\%) in the multifocal group. Nineteen (28\%) patients with multifocal IOLs always wore glasses for near vision at $\mathrm{t} 3$. Table 5.4 shows the vision related functioning in both groups over time. All vision related functioning measures showed significant improvements over time $(p<0.001)$. Except for CSS, which showed higher scores in the multifocal group $(p=0.002)$, no differences were found comparing both groups on these vision related functioning outcomes. At $\mathrm{t} 388.0 \%$ in the monofocal group and $89.7 \%$ in the multifocal group was satisfied (scores 3 'good' to 5 'excellent') about their quality of near vision with glasses compared to $49.2 \%$ and $61.8 \%$ without glasses. Quality of near vision without glasses differed over time across intervention groups (Table 5.4 and Figure 5.2, RM ANOVA within $\mathrm{p}<0.001$, interaction $\mathrm{p}=0.04)$. However, independent of time no significant difference was showed in quality of unaided near vision comparing the mono- and multifocal group (RM ANOVA between $\mathrm{p}=\mathrm{NS}$ ). Quality of distance vision with glasses was scored as 3 'good' to 5 'excellent' at t3 by $92.3 \%$ of the patients in the monofocal and $88.2 \%$ in the multifocal group compared to $89.2 \%$ and $94.1 \%$ without glasses.

Preoperative expectations regarding vision improvement were high in both groups: $90.6 \%$ from the monofocal and $96.0 \%$ from the multifocal group expected 'much' to 'very much' improvement in visual acuity $(\mathrm{p}=0.12)$. Paired t-tests showed that preoperative expectations were significantly higher than evaluations after $2^{\text {nd }}$ eye surgery: $3.5 \pm 0.67$ and $3.1 \pm 0.99$, respectively $(p<0.001)$. After bilateral surgery the expectations of $62.5 \%$ of the monofocal and $61.5 \%$ of the multifocal group were fulfilled. No difference was found between monofocal and multifocal lenses at both postoperative points in time. Differences regarding visual acuity with present or best correction in place indicated that not all patients bought the spectacles as prescribed by their ophthalmologist. However, satisfaction scores did not change when patients who did not buy the prescribed glasses were excluded from the analysis: $61.8 \%$ in the monofocal and $62.3 \%$ in the multifocal group were satisfied after bilateral surgery. 


\begin{tabular}{|c|c|c|c|}
\hline & Monofocal n (\%) & Multifocal n (\%) & $p$-value* \\
\hline \multicolumn{4}{|l|}{ Distance (t1) } \\
\hline Always & $45(60.0)$ & $49(62.8)$ & \\
\hline Most of the time & $6(8.0)$ & $5(6.4)$ & \\
\hline Quite often & $4(5.3)$ & $2(2.6)$ & NS \\
\hline Now and then & $8(10.7)$ & $6(7.7)$ & \\
\hline Never & $7(9.3)$ & $10(12.8)$ & \\
\hline Not applicable & $5(6.7)$ & $6(7.7)$ & \\
\hline \multicolumn{4}{|l|}{ Near (t1) } \\
\hline Always & $46(61.3)$ & $59(75.6)$ & \\
\hline Most of the time & $11(14.7)$ & $4(5.1)$ & \\
\hline Quite often & $3(4.0)$ & $2(2.6)$ & NS \\
\hline Now and then & $10(13.3)$ & $6(7.7)$ & \\
\hline Never & $3(4.0)$ & $4(5.1)$ & \\
\hline Not applicable & $2(2.7)$ & $3(3.8)$ & \\
\hline \multicolumn{4}{|l|}{ Distance (t2) } \\
\hline Always & $33(44.6)$ & $26(35.1)$ & \\
\hline Most of the time & $5(6.8)$ & $11(14.9)$ & \\
\hline Quite often & $3(4.1)$ & $2(2.7)$ & NS \\
\hline Now and then & $7(9.5)$ & $4(5.4)$ & \\
\hline Never & $11(14.9)$ & $20(27.0)$ & \\
\hline Not applicable & $15(20.3)$ & $11(14.9)$ & \\
\hline \multicolumn{4}{|l|}{ Near (t2) } \\
\hline Always & $43(58.1)$ & $28(37.8)$ & \\
\hline Most of the time & $9(12.2)$ & $14(18.9)$ & \\
\hline Quite often & $4(5.4)$ & $7(9.5)$ & 0.02 \\
\hline Now and then & $10(13.5)$ & $12(16.2)$ & \\
\hline Never & $5(6.8)$ & $5(6.8)$ & \\
\hline Not applicable & $3(4.1)$ & $8(10.8)$ & \\
\hline
\end{tabular}

\section{Legend}

*Differences were tested with Mann-Whitney U-tests

NS = not significant

Not applicable $=$ patients who did not have distance or reading glasses 


\section{Table 5.3 (continued): Spectacle dependence}

Monofocal n (\%) Multifocal n (\%) $\quad$-value*

Distance (t3)

$\begin{array}{lcc}\text { Always } & 27(41.5) & 12(17.6) \\ \text { Most of the time } & 3(4.6) & 3(4.4) \\ \text { Quite often } & 5(7.7) & 2(2.9) \\ \text { Now and then } & 1(1.5) & 1(1.5) \\ \text { Never } & 12(18.5) & 19(27.9) \\ \text { Not applicable } & 17(26.2) & 31(45.6)\end{array}$

Near (t3)

$\begin{array}{lccc}\text { Always } & 27(41.5) & 12(17.6) & \\ \text { Most of the time } & 3(4.6) & 3(4.4) & 0.002 \\ \text { Quite often } & 5(7.7) & 2(2.9) & \\ \text { Now and then } & 1(1.5) & 1(1.5) & \\ \text { Never } & 12(18.5) & 31(45.6) & \end{array}$

\section{Legend}

${ }^{*}$ Differences were tested with Mann-Whitney U-tests

NS = not significant

Not applicable $=$ patients who did not have distance or reading glasses 


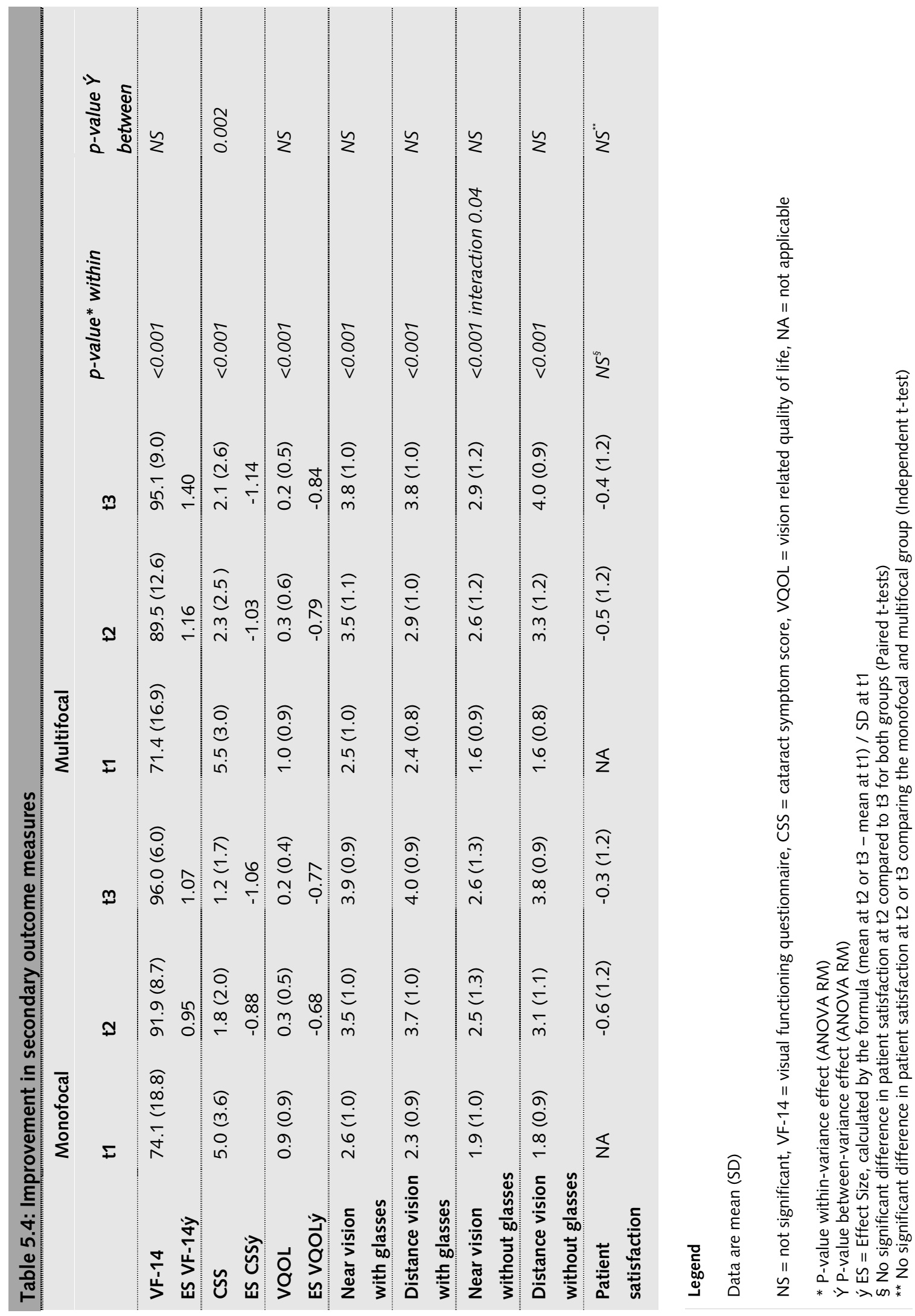




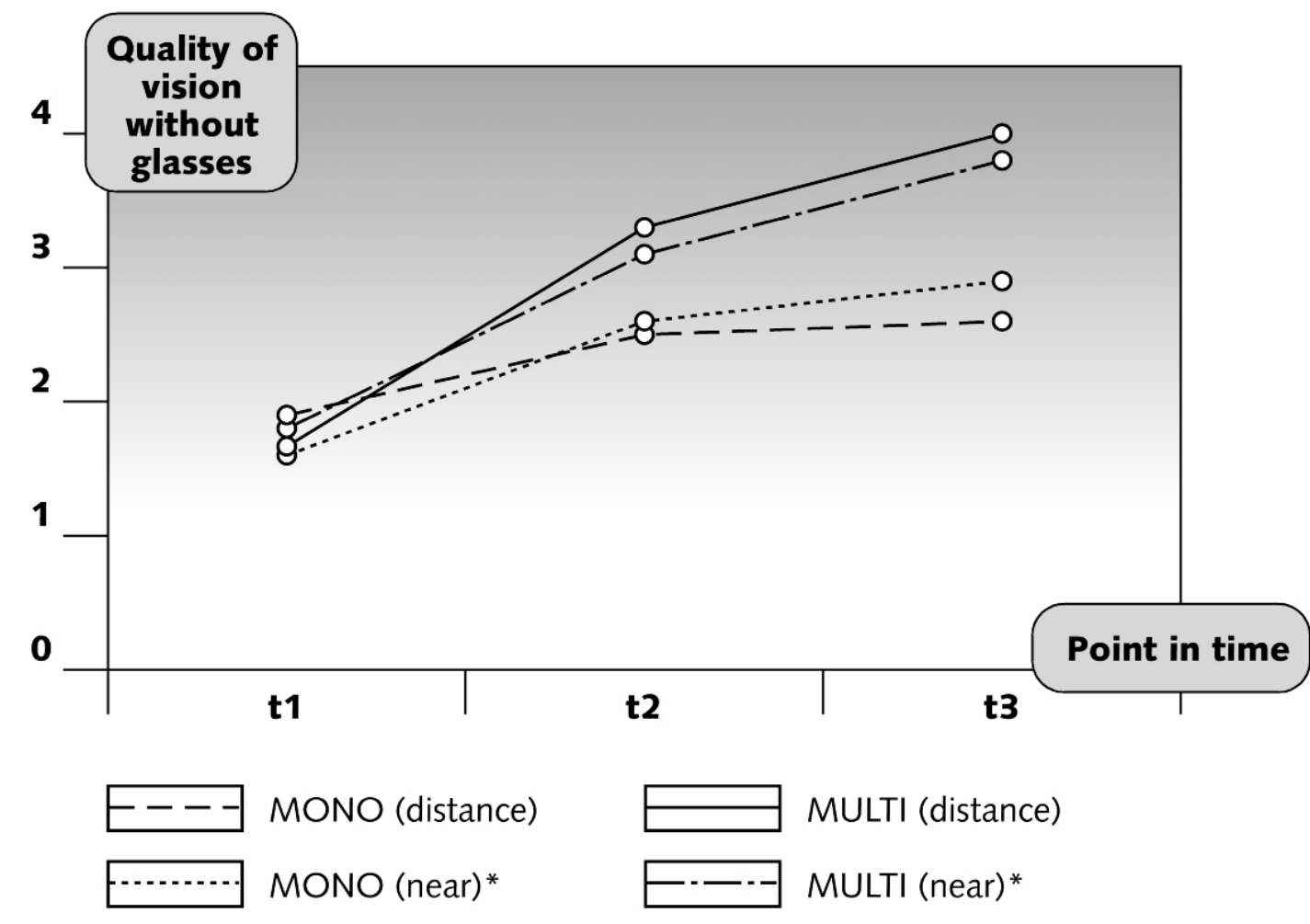

Figure 5.2: Quality of vision without glasses

- repeated measures plot of the patient satisfaction measured as quality of vision without glasses at distance and near. $M O N O=$ monofocal intraocular lens, MULTI = multifocal intraocular lens.

* significant within-subjects interaction effect (RM ANOVA), indicating a difference in the course of quality of vision at near without glasses over time comparing both treatment conditions. 


\subsubsection{Predictors of patient satisfaction}

Standard multiple regression analysis was performed to identify predictors of patient satisfaction as defined by fulfilment of expectations. Table 5.5 displays the correlations ( $\mathrm{r}$ ) between the variables, the standardized regression coefficients ( $(3)$, and explained variance $\left(\mathrm{R}^{2}\right)$. Quality of near vision with glasses contributed significantly to the prediction of patient satisfaction ( $(=0.22,95 \% \mathrm{CI} 0.060-0.523)$. Altogether, 26.8\% (16.3\% adjusted) of the variability in patient satisfaction scores was predicted by the independent variables. Treatment condition did not predict the fulfilment of preoperative expectations $(\mathrm{r}=-0.06)$. Unlike hypothesized, socio-demographics, ESI, and neuroticism score were not associated with satisfaction scores. Although the correlations between patient satisfaction and PCNVA or vision related functioning were significant, these outcome measures did not contribute significantly to regression. 


\section{Table 5.5: Standard multiple regression of patient personality} characteristics and primary and secondary outcomes on patient satisfaction

\begin{tabular}{|c|c|c|}
\hline Variables & $r$ & $\beta$ \\
\hline Treatment condition & -0.05 & -0.12 \\
\hline Age & 0.002 & 0.04 \\
\hline Gender & 0.00 & -0.06 \\
\hline Dummy lower education & 0.05 & -0.10 \\
\hline Dummy middle education & 0.04 & -0.15 \\
\hline Dummy higher education & -0.04 & -0.06 \\
\hline ESI & 0.06 & 0.15 \\
\hline Neuroticism & -0.02 & 0.01 \\
\hline PCDVA & 0.10 & -0.05 \\
\hline PCNVA & $-0.24 * *$ & -0.17 \\
\hline Spectacle dependence (distance) & 0.07 & 0.11 \\
\hline Spectacle dependence (near) & 0.15 & 0.02 \\
\hline VF-14 & $0.24 * *$ & 0.13 \\
\hline VQOL & $-0.28 * *$ & -0.21 \\
\hline CSS & - $0.19 *$ & 0.02 \\
\hline Quality of near vision with glasses & $0.26^{* *}$ & $0.22 \dot{Y}$ \\
\hline Quality of distance vision with glasses & 0.02 & -0.07 \\
\hline Quality of near vision without glasses & $0.19 *$ & 0.12 \\
\hline Quality of distance vision without glasses & $0.23 * *$ & 0.17 \\
\hline$R^{2} \dot{y}$ & 0.27 & \\
\hline Adjusted $\mathrm{R}^{2}$ & 0.16 & \\
\hline
\end{tabular}

\section{Legend}

Standard multiple regression of patient characteristics and primary and secondary outcomes on patient satisfaction

$\mathrm{ESI}=$ eagerness for spectacle independence, $\mathrm{PCDVA}=$ present corrected distance visual acuity, PCNVA = present corrected near visual acuity, VF-14 = visual functioning questionnaire, $\mathrm{VQOL}=$ vision related quality of life, $\mathrm{CSS}=$ cataract symptom score

* Significant correlation at the 0.05 level

* * Significant correlation at the 0.01 level

$\dot{y}$ Significant regression coefficient at the 0.05 level $(95 \% \mathrm{Cl} 0.06-0.52)$

ý Unique variability $=.03$; shared variability $=.24$ 


\subsection{Discussion}

The present study shows that multifocal IOLs are more effective at improving UCNVA, and have a reduced spectacle dependence for near and distance as compared to monofocal IOLs. The heterogeneousness in mean postoperative UCNVA as reported in multifocal vs. monofocal IOL studies might be explained by differences in postoperative SE (a myopic outcome provides some near vision without glasses) and the incomparability of the different reading charts..$^{3-6,27-32}$ The SE of the present monofocal group was slightly myopic but UCNVA and spectacle independence were not as good as in the multifocal group. Although multifocal IOLs showed reduced spectacle dependence, 39 out of 68 (57.3\%) multifocal participants still used glasses for near vision, which was reported before. , $^{5,33}$

Non-response analysis indicated that participants were younger than non-respondents. However, our age distribution agrees with former studies. 6,15,18,34 Time-analysis suggested that the multifocal group was not biased as a result of excessive attention. Remarkably, the PCDVA and PCNVA differed from BCDVA and BCNVA. When patients who did not buy the prescribed glasses were excluded from analysis, satisfaction rates stayed the same in both treatment groups. These findings represent the contrast between the instantaneous observations at the medical setting (best corrected) and the daily situation (present corrected) of the patients. Accordingly, regression analysis showed a small association between primary outcome measures and patient satisfaction. This might suggest that patients have their own standards regarding quality of vision, which differ from ophthalmologists' standards.

Despite the superiority of the multifocal IOL in primary outcome measures and spectacle dependence, overall patient satisfaction using the fulfilment theory (subtraction of preoperative expectations from postoperative evaluations) was similar between multifocal and monofocal IOL groups. Because preoperative expectations were negatively skewed (>90\% expecting 'much' to 'very much') as reported before, ${ }^{35,36}$ and differed significantly from postoperative evaluations, satisfaction scores were relatively low. On the contrary, perceived quality of vision showed high ratings (about 90\% satisfied about aided near and distance vision in both groups). Therefore, consistency in the application of instruments to assess visual satisfaction is necessary to avoid incomparable findings. Correlational and regression analysis demonstrated that patient satisfaction is predicted by aided quality of near vision. This indicates that patients do not mind wearing reading glasses as long as the quality of near vision is good according to their own standards. Older patients might be less eager to be spectacle independent since about 80\% from our study group (mean age 72 years) were used to wearing glasses for distance and reading before surgery. Subgroup analysis should clarify whether ESI might have another influence on satisfaction in younger cataract patients. Furthermore, both patient groups scored quality of uncorrected near vision lower in comparison to quality of uncorrected distance vision. This agrees with the technical characteristics of both IOLs: monofocal IOLs have only one focus at distance, while multifocal IOLs have various foci but are distant-dominant. ${ }^{9}$ 
Whether these evaluations of patients should recommend the producers of the multifocal IOL to improve the light distribution for near focus, depends on patient's expectations and requirements about their near vision in comparison to their distance vision. Future investigations should clarify if personal occupation and lifestyle might be important predictors with respect to these personal standards.

In view of our results, we have reason to believe that the quality of aided near vision should be optimal to assure patient satisfaction after cataract surgery. This desirable outcome can be achieved by monofocal and multifocal IOLs. Multifocal IOLs might offer an additional advantage regarding reduced spectacle dependence, although patients seem to find it more important to have a good quality of vision irrespective of spectacle dependence. The relatively small explained variance in satisfaction scores may indicate that a successful outcome on both primary and secondary measures is no guarantee for a satisfied patient. Personality trait neuroticism and a measure of eagerness for spectacle independence are not suitable for the selection of patients for multifocal IOLs in cataract surgery. Therefore other factors should be found to formulate patient selection criteria that should improve the prediction of postoperative patient satisfaction. ${ }^{23,35}$ Our most important recommendations are to help patients to set realistic expectations and to use patient-based assessments (patient's judgements about their own functional state) for evaluation and prediction of the effectiveness of surgery. ${ }^{37}$ 


\section{References}

1. Steinberg EP, Tielsch JM, Schein OD, et al. The VF-14. An index of functional impairment in patients with cataract. Arch Ophthalmol 1994; 112: 630-638.

2. Snellingen T, Evans JR, Ravilla T, Foster A. Surgical interventions for age-related cataract (Cochrane Review).The Cochrane Library, Issue 2, 2002. Oxford: Update Software

3. Leyland $M$, Zinicola $E$. Multifocal versus monofocal intraocular lenses after cataract extraction (Cochrane Review). The Cochrane Library, Issue 1, 2002. Oxford: Update Software

4. Avitabile T, Marano F. Multifocal intraocular lenses. Curr Opin Ophthalmol 2001; 12: 12-16

5. Brydon KW, Tokarewicz AC, Nichols BD. AMO array multifocal lens versus monofocal correction in cataract surgery. J Cataract Refract Surg 2000; 26: 96-100

6. Javitt J, Brauweiler HP, Jacobi KW, et al. Cataract extraction with multifocal intraocular lens implantation: clinical, functional, and quality-of-life outcomes. Multicenter clinical trial in Germany and Austria. J Cataract Refract Surg 2000; 26: 1356-1366

7. Weghaupt $\mathrm{H}$, Pieh $\mathrm{S}$, Skorpik $\mathrm{C}$. Visual properties of the foldable Array Multifocal intraocular lens. J Cataract Refract Surg 1996; 22(Supplement 2): 1313-1317

8. Pieh $S$, Lackner $B$, Hanselmayer $G$, et al. Halo size under distance and near conditions in refractive multifocal intraocular lenses. Br J Ophthalmol 2001; 85: 816-821

9. Pieh $S$, Hanselmayer $G$, Lackner $B$, et al. Tritan colour contrast sensitivity function in refractive multifocal intraocular lenses. Br J Ophthalmol 2001; 85: 811-815

10. Häring $G$, Dick $H B$, Krummenauer $F$, et al. Subjective photic phenomena with refractive multifocal and monofocal intraocular lenses. results of a multicenter questionnaire. J Cataract Refract Surg 2001; 27: 245-249

11. Schmitz $S$, Dick HB, Krummenauer $F$, et al. Contrast sensitivity and glare disability by halogen light after monofocal and multifocal lens implantation. Br J Ophthalmol 2000; 84: 1109-1112

12. Dick $H B$, Krummenauer $F$, Schwenn $O$, et al. Objective and subjective evaluation of photic phenomena after monofocal and multifocal intraocular lens implantation. Ophthalmology 1999; 106: $1878-1886$

13. Sanderman $R$, Arrindell WA, Ranchor AV, et al. Het meten van persoonlijkheidskenmerken met de Eysenck Personality Questionnaire (EPQ) - een handleiding. Groningen (NL): Noordelijk Centrum voor Gezondheidsvraagstukken, Rijksuniversiteit Groningen, 1995; 1-34

14. Westheimer G. Scaling of visual acuity measurements. Arch Ophthalmol 1979; 97: 327-330

15. Nijkamp MD, Nuijts RMMA, van den Borne HW, et al. Determinants of patient satisfaction after cataract surgery in 3 settings. J Cataract Refract Surg 2000; 26: 1379-1388

16. Frost NA, Sparrow JM, Durant JS, et al. Development of a questionnaire for measurement of vision-related quality of life. Ophthalmic Epidemiology 1998; 5: 185-210

17. Cassard SD, Patrick DL, Damiano AM, et al. Reproducibility and responsiveness of the VF-14. An index of functional impairment in patients with cataracts. Arch Ophthalmol 1995; 113: 1508-1513

18. Alonso J, Espallargues $M$, Andersen TF, et al. International applicability of the VF-14: An index of visual function in patients with cataracts. Ophthalmology 1997; 104: 799-807

19. Deyo RA, Diehr P, Patrick DL. Reproducibility and responsiveness of health status measures Statistics and strategies for evaluation. Control Clin Trials 1991; 12: 142s-158s 
20. Hall J, Dornan M. Meta-analysis of satisfaction with medical care: description of research domain and analysis of overall satisfaction levels. Soc Sci Med 1988; 27: 637-644

21. Ware JE, Hays RD. Methods for measuring patient satisfaction with specific medical encounters. Med Care 1988; 26: 393-402

22. Cadotte ER, Woodruff RB, Jenkins RL. Expectations and norms in models of consumer satisfaction. J Marketing Res 1987; 24: 305-314

23. Linder-Pelz SU. Toward a theory of patient satisfaction. Soc Sci Med 1982; 16: 577-582

24. Donabedian A. The definition of quality and approaches to its assessment. Ann Arbor (MI): Health Administration Press, 1980; 82-83

25. Javitt JC, Wang F, Trentacost DJ, et al. Outcomes of cataract Extraction with Multifocal Intraocular Lens Implantation - Functional Status and Quality of Life. Ophthalmology 1997; 104: 589-599

26. Tabachnick B, Fidell L. Using multivariate statistics. 3rd ed. New York (NY): HarperCollins College Publishers, 1996; 132-133

27. Wallace III RB. Multifocal vision after cataract surgery. Curr Opinion in Ophthalmology 1998; 9 : 66-70

28. Javitt JC, Steinert RF. Cataract extraction with multifocal intraocular lens implantation: a multinational clinical trial evaluating clinical, functional, and quality-of-life outcomes. Ophthalmology 2000; 107: 2040-2048

29. Dick $H B$, Krist $R$, Schwenn $O$, Pfeiffer $N$. Nahvisus nach Implantation monofokaler versus multifokaler Intraokularlinsen. Klin Monatsbl Augenheilkd 2001; 218: 406-411

30. Verrezen CA, Hardus P, Treffers WF. Hoe valide is het invaliditeitspercentage? Dialoog 1997; Feb: $13-16$

31. Datiles $M B$, Gancayco $T$. Low myopia with low astigmatic correction gives cataract surgery patients good depth of focus. Ophthalmology 1990; 97: 922-926

32. Percival SP, Setty SS. Prospectively randomized trial comparing the pseudoaccommodation of the AMO ARRAY multifocal lens and a monofocal lens. J Cataract Refract Surg 1993; 19: 26-31

33. Orme ME, Paine AC, Teale CW, Kennedy LM. Cost-effectiveness of the AMOArray multifocal intraocular lens in cataract surgery. J Refract Surg 2002; 18: 162-168

34. Laidlaw DHA, Harrad RA, Hopper CD, et al. Randomised trial of effectiveness of second eye cataract surgery. Lancet 1998; 352: 925-929

35. Baron-Epel $O$, Dushenat $M$, Friedman $N$. Evaluation of the consumer model: relationship between patients' expectations, perception and satisfaction with care. Int J Qual Health Care 2001; 13: 317-323

36. Tielsch JM, Steinberg EP, Cassard SD, et al. Preoperative functional expectations and postoperative outcomes among patients undergoing first eye cataract surgery. Arch Ophthalmol 1995; 113: 1312-1318

37. Massof RW, Rubin GS. Visual Function Assessment Questionnaires. Surv Ophthalmol 2001; 45:531-548 



\section{Epilogue}

Determinants of patient satisfaction after cataract surgery: Most important findings, practical implications, and recommendations for future research 


\section{Most important findings, practical implications and recommendations for future research}

\section{The importance of outcome, process, and structure related quality of care}

This thesis started by proposing the following two main questions:

- "What are the most important determinants of patient satisfaction?"

- "Which factors may improve the quality of care related to cataract surgery?"

A 3-dimensional model was developed to find an answer to these questions. As explained by the model, an objective successful surgical outcome (e.g. improved visual acuity) is not necessarily the most important factor in patient satisfaction after cataract surgery. Ophthalmologists have recognised the importance of subjective outcome measures (e.g. visual functioning) besides objective assessments in explaining the variation in patient satisfaction after surgery. Scientific publications require not only a description of objective but also subjective measures of visual functioning at this point in time, and some clinics even integrated this additional subjective assessment into daily clinical practice. For example, in order to respond to this new recognized need for subjective criteria two ophthalmic clinics in Arizona opened a special phone line (free of charge) that registered patient's self reported VF-14 scores. However, these outcome related quality of care aspects do not explain patient satisfaction fully. The high rate of success achieved by modern cataract surgery has created a situation in which patient expectations are high too. For the most part, patient's high expectations with respect to postoperative vision are fulfilled, which limit the power to detect reasons for dissatisfaction in patients. In addition, patient satisfaction seems to be influenced by process and structure related quality of care. A 3-dimensional model concerning the assessment of quality of care was emphasized before in marketing approaches, but has not been used in evaluating patient satisfaction after ophthalmic surgery up to now. With the introduction of 'consumerism' within the health care setting, only parts of the theoretical background of patient satisfaction originally developed by marketing scientists were adapted to health sciences.

\section{Surgery related fear in cataract patients}

With respect to surgery related fear, the historical paternalistic model may have a negative effect on patient's experience. By an increased distance between the doctor and the patient, the patient may feel helpless. Dentists and physicians who conduct painful procedures have already learned this lesson well. The phrase "Tell me if I am hurting you" gives patients an opportunity to express worries, to react on their own behalf, and to regain a feeling of control over the stressful event. This might increase the likelihood of positive evaluations and ultimately patient satisfaction. Furthermore, fear may narrow patient's attention to specific aspects of the doctor's information. This selective attention may in it's turn increase fear, which leads to a vicious circle process. 
Although in general cataract patients report low levels of anxiety, preparatory communications to patients about to undergo cataract surgery may be important in the process of emotional inoculation against surgery related stress.

From personality theories we know that effects of stressors depend on cognitive factors associated with unpredictability and perceived lack of control. A belief in actual or potential control may prevent feelings of helplessness and thereby the magnitude of the stress response (fear). The belief that one is able to control a stressful event may facilitate adjustment. Furthermore, bringing a companion (e.g. partner, son or daughter) during the hospital visits may also reduce problems related to selective attention.

\section{Patient satisfaction after cataract surgery using multifocal intraocular lenses}

The personality disposition of neuroticism has been found to be related to stress vulnerability, and may lead to maladaptive styles of appraisal and coping. Therefore, ophthalmologists may expect lower satisfaction rates in patients with higher neuroticism scores. However, in the present study (Chapter 5) the hypothesis posing a relationship between patient satisfaction and neuroticism was rejected. This may indicate that the effect of neuroticism on patient satisfaction is mediated by good doctor-patient communication. The relevance of information and support that helps patients to set realistic expectations is emphasized once again. Especially successful use of multifocal intraocular lenses demands a good doctor-patient communication because both the ophthalmologist and the patient do not know exactly what to expect with respect to the postoperative quality of vision. Specifically, former studies that evaluated the effectiveness of multifocal intraocular lenses reported different success rates with respect to objective as well as subjective criteria of quality of vision. These ambiguous results make it hard for ophthalmologists to inform patients in an unambiguous way. This difficulty was recognized in clinical practice, citing an ophthalmologist: "You can get patients 20/20 and J2, but if they see halos at night and they don't expect this, they may not be satisfied". However, the practice-based recommendation to exclude patients who are 'too demanding' (categorised as highly neurotic) for the implantation of multifocal intraocular lenses was scientifically refuted.

In addition, in several publications the influence of eagerness of spectacle independence was seemingly overrated by reporting ophthalmologists. Our analyses did not show a significant negative influence of patients' wish to not having to wear glasses anymore on their postoperative satisfaction score. On the one hand patients were used to wear glasses, and on the other hand spectacles have certain advantages, which should not be overlooked. Unlike hearing-aids that are usually associated with being handicapped and old, spectacles may also appeal wisdom and may be seen as an ornament. These two examples indicate differences in interpretation of success according to the doctor's and the patient's perspective. Therefore, we recommend to use the patient's perspective in defining quality of vision and patient satisfaction, because doctors unfortunately still cannot see through the patient's eyes. 


\section{The use of the patient's perspective in defining quality of vision and patient satisfaction}

Communication between doctor and patient is frequently complicated by technical jargon, time pressure, and a low level of empathy with the patient. Understanding patient's needs is the first step in helping them to achieve the best outcomes. Health care professionals should analyse the patient's expectations with respect to the surgery: night drivers, frequent readers, and internet addicts all have different needs. Therefore, a doctor's diagnosis and treatment protocol should not be limited to tests of visual functioning but should also include background information about the patient's life style and profession. Setting realistic treatment goals is the responsibility of both doctor and patient. A doctor should try to translate medical outcomes into standards a patient can refer to, while the patient should make clear explicitly what he or she experiences as problems due to the cataract and what he or she expects from surgery. This shared responsibility may lead to an increased feeling of mastery on the individual level, which may consequently reduce stress. Moreover, the involvement of patients in decisions with respect to surgery may also decrease the vulnerability of ophthalmologists.

An ideal health care system is hard to accomplish due to limits of medical properties, changing norms and values, and a limited supply of resources. However, an optimal quality of care is a realistic goal, which can be achieved by a relatively simple change of view within the health care setting. Up to now ophthalmologists merely focussed on outcome management stimulated by health insurance companies demanding proof for their medical success. A far better method would be not only to judge the product quality (i.e. surgical outcome), but also to evaluate the service quality (i.e. process and structure related quality of care). By defining success of medical treatments from a patient's perspective, a robust delusion in clinical practice may thus be overcome. As a consequence, outcome, process, and structure related quality of care are truly patient directed, ultimately leading to higher levels of patient satisfaction. 
Summary/Samenvatting 


\section{Summary}

Patient satisfaction depends on the one hand on the effectiveness of the operation. On the other hand, patient education and counselling determine the evaluation of the health care intervention. From a scientific and a practical point of view, the important questions to ask are: what are the determinants of patient satisfaction, and what can we do to improve the quality of care related to cataract surgery? The aim of this thesis is to analyse which factors are related to patient satisfaction after cataract surgery. Apart from relating satisfaction scores to objective and subjective outcome measures, a new questionnaire was developed and validated to assess the process and structure related quality of care.

This thesis starts with a theoretical and methodological overview of satisfaction studies in Chapter 1. The original motivation of studying satisfaction within the health care setting was to introduce the concept of consumerism in health care settings and to introduce an indicator of the quality of care. Because different satisfaction studies are conducted in very specific contexts any standard classification of patient satisfaction never seems entirely appropriate. Because of the lack of consistency in defining the concept of satisfaction, reliability and validity of the measurement instruments is ambivalent. Up to now satisfaction studies among cataract patients were limited to objective and subjective outcome measures. A 3-dimensional model is suggested that includes outcome, process, and structure related quality of care aspects, which influence each other and ultimately patient satisfaction.

In Chapter 2 the determinants of satisfaction and postoperative visual functioning after cataract surgery are analysed in three different settings in the Netherlands. In general, patients were very satisfied. Patient satisfaction with regard to hospital care had a stronger correlation with overall satisfaction than patient satisfaction with regard to the medical outcome. This emphasizes the relevance of patient education and counselling by hospital staff in cataract surgery.

Valid assessments of quality of care should not only focus on objective and subjective outcome parameters, but should also measure the process and structure of care. Chapter 3a describes the potential of a newly developed QUOTE-cataract questionnaire that measures the quality of care from the perspective of cataract patients. Aspects concerning patient education were scored as the most important quality aspects by the patients. The QUOTE-cataract is a useful instrument to measure quality of care in cataract surgery at different hospital settings and provides practical information for quality assurance programs.

Chapter $\mathbf{3 b}$ assesses the reliability and validity of the QUOTE-cataract. The QUOTEcataract was tested in a multicentre study. A strong internal consistency coefficient and high repeatability demonstrated good reliability of the questionnaire. Content validity was assured by involvement of patients in the development of the questionnaire. Factor analysis confirmed an underlying taxonomy of generic and disease-specific items. 
Since surgery-related fear may have a negative influence on the patient evaluations with respect to quality of care Chapter $4 \mathbf{a}$ identifies factors that are related to fear among patients who need to undergo cataract surgery. Fear was experienced during pre- and postoperative stages. A model that represents the factors related to fear in patients awaiting cataract surgery was developed, which emphasizes the importance of a good doctor-patient relationship and the need for patient education that is tailored to the individual patients.

Chapter $4 \mathbf{b}$ was initiated to analyse the determinants of anxiety and reassurance in patients who need to undergo cataract surgery in a quantitative way. In general, patients reported little anxiety. The level of anxiety was the highest before surgery, decreased immediately after surgery, and finally increased again after the postoperative visit. Women and patients with higher trait anxiety were more likely to experience higher levels of state anxiety. Patient education and a good doctor-patient relationship may decrease anxiety.

Since multifocal intraocular lenses (IOLs) used in cataract surgery may treat both cataract and presbyopia, the clinical outcome and patient satisfaction after implantation of monofocal and multifocal IOLs were analysed in Chapter 5. Seventy-five patients with monofocal and seventy-eight patients with multifocal IOLs were followed in a randomised trial. Multifocal IOLs showed better uncorrected near visual acuity, higher quality ratings of unaided near vision over time, and reduced spectacle dependence. Monofocal IOLs showed less bother from cataract symptom scores. Overall patient satisfaction did not differ between the two groups of mono-and multifocal IOLs. Independent of eagerness for spectacle independence or neuroticism scores, success of both IOLs depends on preoperative expectations and postoperative quality of aided near vision. 


\section{Samenvatting}

Patiëntensatisfactie hangt aan de ene kant af van de effectiviteit van de operatie, aan de andere kant bepalen patiëntenvoorlichting en begeleiding de evaluatie van de medische interventie. Vanuit een wetenschappelijk en praktisch oogpunt zijn de belangrijke te stellen vragen: Wat zijn de determinanten van patiëntentevredenheid en hoe kan de kwaliteit van zorg verbeterd worden? De doelstelling van dit proefschrift is om te analyseren welke factoren gerelateerd zijn aan patiëntentevredenheid na een staaroperatie. Naast tevredenheid te relateren aan objectieve en subjectieve uitkomstmaten, is een nieuwe vragenlijst ontwikkeld en gevalideerd die de aan proces en structuur gerelateerde zorg in kaart brengt.

Dit proefschrift begint met een theoretisch en methodologisch overzicht van satisfactiestudies in Hoofdstuk 1. De aanvankelijke motivatie voor tevredenheidsonderzoek in de gezondheidszorg was het concept 'consumentisme' in te voeren in gezondheidszorginstellingen en een indicator voor kwaliteit van zorg te introduceren. Omdat verschillende tevredenheidstudies in verschillende contexten worden uitgevoerd, lijkt een standaard classificatie van patiëntensatisfactie nooit geheel adequaat. Door het gebrek aan consistentie in de definitie van tevredenheid is de betrouwbaarheid en validiteit van de bestaande meetinstrumenten discutabel. Tot nu toe beperkten satisfactiestudies bij staarpatiënten zich tot objectieve en subjectieve uitkomstmaten. Een driedimensionaal model is voorgesteld dat uitkomst, proces en structuur gerelateerde kwaliteit van zorg aspecten bevat. Deze beïnvloeden elkaar en uiteindelijk de patiëntentevredenheid.

In Hoofdstuk 2 zijn de determinanten van tevredenheid en postoperatief visueel functioneren na een staaroperatie geanalyseerd in drie verschillende zorginstellingen in Nederland. Over het algemeen zijn patiënten heel tevreden. Patiëntentevredenheid met betrekking tot de zorg in het ziekenhuis toonde een sterker verband met tevredenheid dan de medische uitkomst. Dit benadrukt de relevantie van patiëntenvoorlichting en -begeleiding door ziekenhuispersoneel bij staaroperaties.

Valide metingen van kwaliteit van zorg zouden zich niet alleen moeten richten op objectieve en subjectieve uitkomstparameters, maar ook op proces en structuur gerelateerde zorg. Hoofdstuk 3a beschrijft het potentieel van een nieuw ontwikkelde QUOTE-staar vragenlijst die de kwaliteit van zorg meet vanuit het patiëntenperspectief. Aspecten betreffende patiëntenvoorlichting zijn als meest belangrijke aspecten van zorg naar voren gebracht door de patiënten. De QUOTE-staar is een effectief instrument om de kwaliteit van zorg te meten rondom cataract chirurgie in verschillende ziekenhuisinstellingen en geeft praktische informatie voor kwaliteitsbewakingprogramma's. 
Hoofdstuk $\mathbf{3 b}$ analyseert de betrouwbaarheid en validiteit van de QUOTE-staar. De QUOTE-staar is getest in een multicenter studie. Een hoge interne consistentie en een grote samenhang tussen herhaalde metingen demonstreerden een goede betrouwbaarheid van de vragenlijst. De inhoudsvaliditeit werd verzekerd door patiënten te betrekken bij de ontwikkeling van de vragenlijst. Factoranalyse bevestigde een onderliggende taxonomie van generieke en ziektespecifieke items.

Omdat operatie gerelateerde angst een negatieve invloed kan hebben op de patiëntenevaluaties met betrekking tot kwaliteit van zorg, identificeert Hoofdstuk 4a factoren die gerelateerd zijn aan angst bij staarpatiënten die een operatie dienen te ondergaan. Angst werd ervaren in pre- en postoperatieve fasen. Een model, dat factoren die gerelateerd zijn aan angst bij patiënten die op een staaroperatie wachtten in kaart brengt, is voorgesteld. Deze benadrukt het belang van een goede arts-patiënt relatie en de noodzaak patiëntenvoorlichting op maat te maken voor individuele patiënten.

Hoofdstuk $4 \mathbf{b}$ werd geïnitieerd om de determinanten van angst en geruststelling op een kwantitatieve manier te analyseren in patiënten die een staaroperatie moeten ondergaan. Over het algemeen rapporteerden de staarpatiënten weinig angst. Het angstniveau was het hoogste voor de operatie, verminderde meteen na de operatie en verhoogde uiteindelijk weer na het postoperatieve consult. Vrouwen en patiënten met hogere angst- predispositie vertoonden meer angst. Patiëntenvoorlichting en een goede arts-patiënt relatie kunnen de angst verminderen.

Omdat multifocale intraoculaire lenzen (IOLs) een mogelijke oplossing bieden voor grijze staar en ouderdomsverziendheid, zijn medische uitkomst en patiëntensatisfactie na implantatie van monofocale en multifocale IOLs in Hoofdstuk $\mathbf{5}$ vergeleken. Vijfenzeventig patiënten met monofocale en achtenzeventig patiënten met multifocale IOLs zijn gevolgd in een gerandomiseerd experiment. Multifocale IOLs vertoonden een beter ongecorrigeerd gezichtsvermogen voor dichtbij, hogere kwaliteit van ongecorrigeerd zien van dichtbij en een gereduceerde bril afhankelijkheid. Monofocale IOLs vertoonden minder last van cataract symptoom scores. Patiëntsatisfactie verschilde in het algemeen niet tussen de twee groepen van mono- en multifocale IOLs. Onafhankelijk van preoperatieve wens voor brilonafhankelijkheid en neuroticisme score hangt het succes van beide IOLs af van preoperatieve verwachtingen en postoperatieve kwaliteit van dichtbij zien met leesbril. 

Dankwoord en Curriculum Vitae 


\section{Dankwoord}

Graag wil ik een dankwoord richten aan allen die voor mij veel betekent hebben bij het schrijven van dit proefschrift. Op de eerste plaats mijn promotores Dr. Rudy Nuijts, Prof. Dr. F. Hendrikse en Prof. Dr. H.W. van den Borne. Rudy, mede dankzij jouw ambitie en altijd kritische blik heb ik mij kunnen vormen tot een zelfstandig wetenschappelijk onderzoeker. Prof. Hendrikse wil ik bedanken voor de mogelijkheden het beschreven onderzoek uit te voeren, mede dankzij Mw. Ing Astrid Hacking. Bart, bedankt voor jouw fijne begeleiding en onze inspirerende brainstormsessies, mijn hart voor patiëntenvoorlichting is alleen maar gegroeid in de afgelopen jaren.

Maria Dolders en John de Brabander ben ik veel dank verschuldigd voor hun praktische inzet en theoretische adviezen bij het onderzoeken van de staarpatiënten. Maria en John, met veel plezier heb ik met jullie samengewerkt gedurende de afgelopen vier jaar. Samen hebben we de MERIM-studie tot een succes weten te maken. John, jouw enthousiasme voor onderzoek, jouw doceervaardigheden en grote behulpzaamheid zijn een voorbeeld voor mij. Maria, met veel plezier kijk ik terug op onze interviews met de patiënten, het was soms vermoeiend maar we bleven altijd de aardige M\&Ms. Tijdens jouw zwangerschapsverlof nam Emily de interviewersrol over. Emily, ook jou wil ik bedanken voor jouw betrokkenheid en meedenken.

Marjolein en Vaishali jullie wil ik bedanken voor jullie onmisbare oogmeetkundige hulp bij de MERIM-studie. Bedankt dat jullie niet gewoon 'deden', maar geïnteresseerd en betrokken de oogmetingen voor het onderzoek hebben gerealiseerd. Kiran, jij pakt de draad nu verder op, veel succes en plezier toegewenst bij je nieuwe 'onderzoekersrol'.

Herman, jouw deskundigheid op het gebied van de kwaliteit van zorg vanuit het perspectief van de patiënt heeft mij enorm geholpen bij het schrijven van hoofdstuk 3. Hopelijk zullen wij ook in de toekomst nog eens brainstormen over 'hoe het allemaal wel niet beter kan'.

Ik heb geluk gehad met de drie stagiaires die ik heb mogen begeleiden bij hun afstudeeronderzoek. Marijke, met veel plezier kijk ik terug op onze focusgroepen onder het genot van jouw eigen gebakken cake. Hennie, nog steeds ben ik je dankbaar dat jij koos voor de 'droge' validering van een meetinstrument in plaats van af te reizen naar exotisch Afrika. Chantal, jouw betrokkenheid bij de patiënten was zo hoog dat je, net als ik, al droomde dat jij zelf een staaroperatie moest ondergaan.

In het Dr Tansgebouw heb ik mijn kamer en 'onderzoekerspieken \& -dalen' gedeeld met Harriët, Frans \& John. Bedankt dat jullie een luisterend oor boden en mij adviseerden bij de vele zaken die ik nog moest leren. Harriët, jij bent een goede vriendin geworden en ik hoop dat we elkaar blijven opzoeken.

Met veel plezier heb ik verder samengewerkt met vele anderen op de Afdeling Oogheelkunde van het academisch ziekenhuis Maastricht, Medisch Centrum Maastricht Annadal en Atrium Heerlen en ik wil eenieder daarvoor ook bedanken. 
De patiënten hebben geweldig meegewerkt aan de intensieve onderzoeken en dat was niet mogelijk geweest zonder een goede ontvangst aan de balie, een accurate aslengtemeting, een goede OK-planning, een geslaagde operatie en een goede nazorg. In het bijzonder wil ik hiervoor bedanken Sasscha, Thea, Lilian, Wilma, Karina, Carroll, Hans, Servie en Daniëlle. Voor de samenwerking in het kader van de multicenter studies wil ik graag Frans Hiddema, Anne Lems van het oogziekenhuis Rotterdam en Steven Koopmans van het academisch ziekenhuis Groningen bedanken.

Het MEMIC was onmisbaar voor de data-invoer van het onderzoek. Inie, met veel vetrouwen kon ik mijn dozen vol vragenlijsten bij jou achterlaten. Fred Nieman, Rudolf Ponds en Uwe Pongs wil ik bedanken voor hun deskundige advies bij die zaken die buiten het vakgebied van de oogheelkunde en gezondheidsvoorlichting lagen. Jan Jagerman en collega's bij de firma Allergan/AMO, jullie interesse en vertrouwen in het onderzoek maakten het een plezier om de randomised controlled trial naar de effectiviteit van de multifocale implantlens op te zetten, uit te voeren, te analyseren en te presenteren. Ron Slagter bedankt voor jouw prachtige illustraties en snelle reactie.

Christine, I've found in you a very special friend. I am very grateful you were always willing to correct my English writing. I hope to see you soon!

De leden van de beoordelingscommissie bedank ik voor het beoordelen van het manuscript. Pat, thank you for the time and effort you took reading my thesis. Mijn 'nieuwe' collega's bij GVO bedank ik voor de goede werksfeer en adviezen bij de voorbereidingen van de promotie.

Gaston, ik heb je wat aangedaan...ik was veeleisend, onduidelijk in mijn deadlines, af en toe wat vergeetachtig met betrekking tot het opsturen van materialen, kortom een lastige klant' zeker voor jou als persoon die graag controle heeft over de gang van zaken. Toch wist je een geweldig mooie omslag te maken en de lay-out is om te zoenen, dankjewel!

Anniek, Saskia \& Marloes wil ik bedanken voor jullie bereidwilligheid mij te steunen bij de verdediging van mijn proefschrift. Anniek, ik ben ontzettend blij dat we niet alleen zusjes maar ook dikke vriendinnen zijn. Sas, nooit zal ik jouw 'Nice bag' vergeten, je bent een geweldige vriendin! Marloes, je bent een droom van een paranimf, als ik een man was zou ik met je trouwen! Heitie en memmie, jullie zijn mijn onuitputbare bron van energie, liefde en vertrouwen. Bedankt dat jullie zo'n lieve ouders zijn!

Dave, bedankt voor jouw onvoorwaardelijk vertrouwen in mijn kunnen. Jouw relativeringsvermogen, optimisme en gevoel voor humor hebben mij enorm geholpen bij het opzetten en vasthouden van de onderzoeksstructuur, het volhouden van het proces van begin tot einde en het komen tot de uitkomst die nu voor je ligt. Jij weet wat nodig is voor mijn tevredenheid! 


\section{Curriculum Vitae}

De auteur werd geboren op 27-05-1975 te Heerenveen. Na het eindexamen VWO aan het Bornego College te Heerenveen studeerde zij Gezondheidswetenschappen aan de Universiteit Maastricht (1993-1998). Vanaf mei 1997 was zij verbonden aan de afdeling Oogheelkunde van het academisch ziekenhuis Maastricht (azM) voor haar afstudeeronderzoek. In mei 1998 studeerde zij af met als afstudeerrichting Gezondheidsvoorlichting (GVO). Aansluitend begon zij haar promotieonderzoek aan het Eye Research Institute Maastricht (ERIM) en het onderzoeksinstituut HEALTH/ExTra. Vanaf augustus 2002 is zij verbonden als toegevoegd docent en onderzoeker aan de Capaciteitsgroep GVO van de Faculteit der Gezondheidswetenschappen aan de Universiteit Maastricht. 